\title{
Recent Progress in Emerging Two-Dimensional Transition Metal Carbides
}

Cite as

Nano-Micro Lett.

(2021) 13:183

Received: 12 April 2021

Accepted: 25 July 2021

Published online: 20 August 2021

(C) The Author(s) 2021

Tianchen Qin ${ }^{1}$, Zegao Wang ${ }^{1}$, Yuqing Wang ${ }^{2}$, Flemming Besenbacher ${ }^{2}$, Michal Otyepka ${ }^{3}$, Mingdong Dong ${ }^{2} \bowtie$

\section{HIGHLIGHTS}

- The phase diagram of transition metal carbides (TMCs) is discussed.

- The physical and chemical property of TMCs is systematically summarized.

- The potential application and controllable synthesis of TMCs is discussed.

- A summary is provided to afford the principle to further investigation.

\begin{abstract}
As a new member in two-dimensional materials family, transition metal carbides (TMCs) have many excellent properties, such as chemical stability, in-plane anisotropy, high conductivity and flexibility, and remarkable energy conversation efficiency, which predispose them for promising applications as transparent electrode, flexible electronics, broadband photodetectors and battery electrodes. However, up to now, their device applications are in the early stage, especially because their controllable synthesis is still a great challenge. This review systematically summarized the state-of-the-art research in this rapidly developing field with particular focus on structure, property, synthesis and applicability of TMCs. Finally, the current challenges and future perspectives are outlined for the application of 2D TMCs.

KEYWORDS Two-dimensional transition metal carbides; Phase diagram; Superconductivity; Energy conversation and storage; Largescale synthesis
\end{abstract}

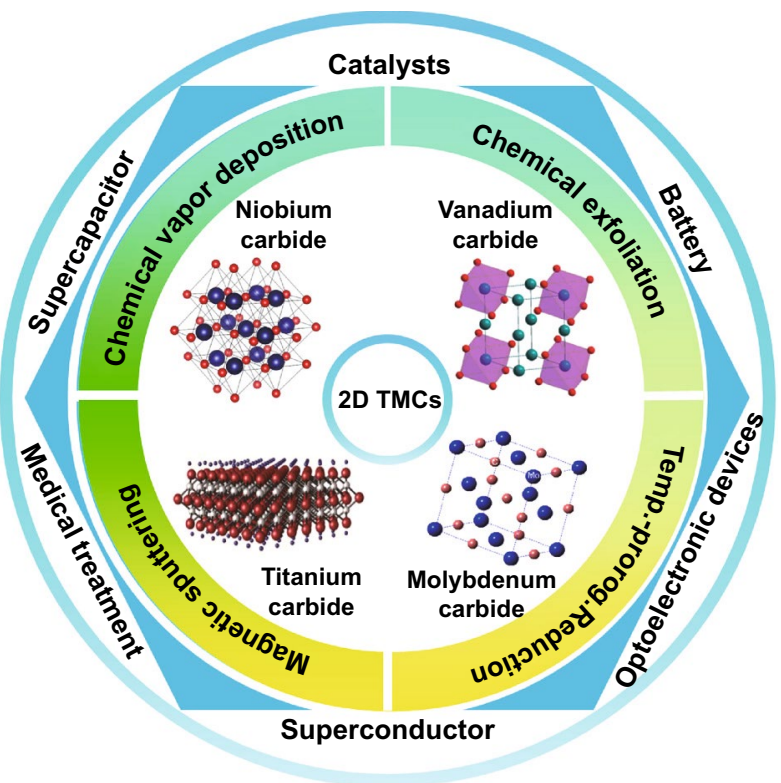

Zegao Wang, zegao@scu.edu.cn; Mingdong Dong, dong@inano.au.dk

College of Materials Science and Engineering, Sichuan University, Chengdu 610065, People's Republic of China

2 Interdisciplinary Nanoscience Center, Aarhus University, 8000 Aarhus, Denmark

3 Regional Centre of Advanced Technologies and Materials, Department of Physical Chemistry, Faculty of Science, Palacký University, 77146 Olomouc, Czech Republic 


\section{Introduction}

Ultra-thin two-dimensional (2D) nanomaterials, as a new kind of nanomaterials, have been widely concerned for a long time. This is because they have a special planar structure, where the horizontal size is beyond sub-micrometer; however, the vertical size limits in nanometer or even atomic level. As early as 200 years ago, it was found that there were some special layered minerals in nature, which can be peeled off to obtain a new lamellar structure [1]. In 2004, K. S. Novoselov, A. K. Geim and other collaborators reported the fabrication of graphite single layer named graphene by using a special scotch micromechanical stripping [2]. The graphene shows many unique properties, namely extraordinary carrier mobility of up to $200,000 \mathrm{~cm}^{2}(\mathrm{~V} \mathrm{~s})^{-1}$, the large specific surface area of $2630 \mathrm{~m}^{2} \mathrm{~g}^{-1}$, the transmittance of $97.7 \%$, the Young's modulus of $1 \mathrm{TPa}$ and the thermal conductivity of $3000 \mathrm{~W}(\mathrm{~m} \mathrm{~K})^{-1}[3,4]$. Ultra-thin 2D nanomaterials, as a representative of graphene, exhibit unique physical and chemical properties because the electrons are confined in 2D space. These excellent properties make ultrathin 2D nanomaterials enter the field of vision of researchers, ushering in the golden age of rapid development [5-11]. Since the discovery of graphene, more and more ultra-thin 2D materials have been found and synthesized, including hexagonal boron nitride (h-BN), carbon nitride $\left(\mathrm{g}-\mathrm{C}_{3} \mathrm{~N}_{4}\right.$ ), transition metal chalcogenides (TMDs), transition metal oxides (TMOs), transition metal carbides (TMCs), layered double hydroxides (LDHs), metal - organic frameworks (MOFs), phosphorene and other elemental 2D materials [12-15]. These materials not only enrich the types of ultrathin 2D nanomaterials, but also show a variety of properties due to the differences in composition and structure, which provide sufficient impetus for the follow-up research of ultrathin 2D nanomaterials.

In 2011, Gogotsi and Barsoum reported the synthesis of MXene, as a new member of 2D transition metal carbides (TMCs) [16]. The general chemical formula of MXene is $\mathrm{M}_{\mathrm{n}+1} \mathrm{X}_{\mathrm{n}} \mathrm{T}_{\mathrm{z}}(n=1,2,3)$, where $\mathrm{M}$ is transition metal element, such as Ti, Sr, V and Ta, $\mathrm{X}$ is $\mathrm{C}$ or $\mathrm{N}$, and $\mathrm{T}$ stands for $\mathrm{F}-$, $\mathrm{OH}-$ and other functional groups. So far, there are more than 70 members of the MXenes family reported. The MXene materials are typically prepared by selective etching the A layer (also named Al layer) with a high concentration of hydrofluoric acid using the MAX with layered hexagonal

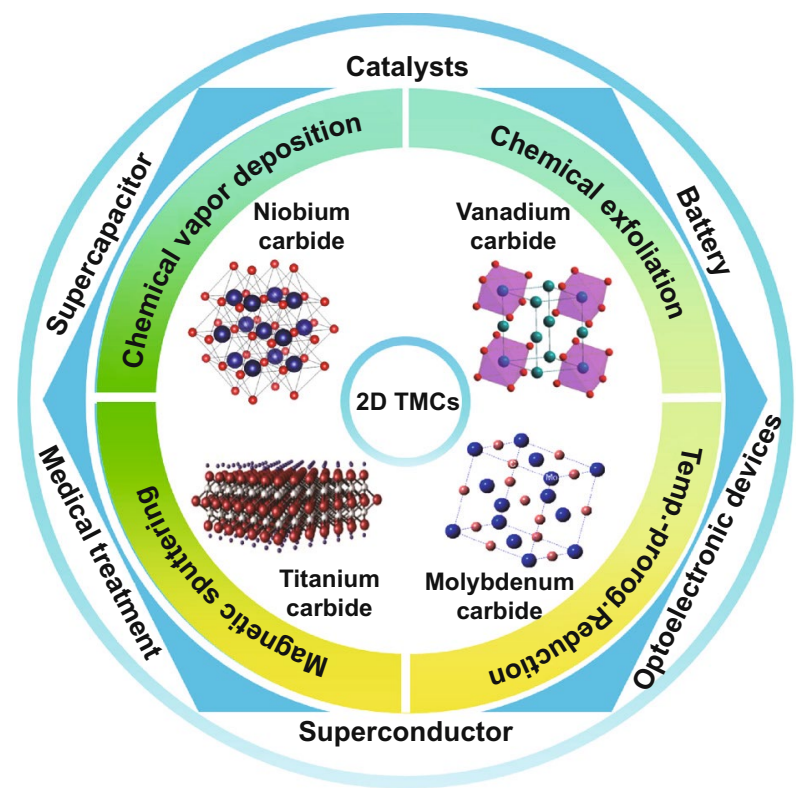

Fig. 1 The scope of this review

Due to their 2D layered structure, good conductivity, stability, hydrophilicity and unique in-plane anisotropic structure, MXene materials have attracted many attentions in recent years. However, the fundamental properties, potential applications and even the controllably synthesis of TMCs are still in their early stage. Previous review progresses are mainly focused on the energy storage, especially on Ti-based TMCs (also called MXenes). The phase diagram, property and synthesis strategy of TMCs including Ti-based and other transition metal-based TMCs have rarely been overviewed. The scope of this review is shown in Fig. 1. We will introduce the structure, physical and chemical properties, the potential applications and finally, the preparation methods of typical TMCs including niobium carbide, vanadium carbide, molybdenum carbide and titanium carbide.

\section{Structure and Property of Transition Metal Carbides}

In 1973, Levy and Boudart found that the carbon atoms in tungsten carbide would change the electron distribution of tungsten atoms resulting in the catalytic property similar with that of platinum and other precious metals [17]. This discovery led to extensive research on other early transition metal carbides, nitrides and carbonitrides. With the 
development of layered materials since 2004, the transition metal carbides (TMCs) recall its hot spot due to their many excellent dimensionality and structure-dependent properties. TMCs are mostly interstitial alloys formed by transition metal atoms and carbon atoms. Taking Mo-based TMCs as the example, the $\beta-\mathrm{Mo}_{2} \mathrm{C}$ and $\eta-\mathrm{Mo}_{3} \mathrm{C}_{2}$ of molybdenum carbide are orthogonal and the arrangement of Mo atoms in units is slightly different from that of hexagonal closepacked (hcp). The crystal structure can be described as that Mo atoms occupy the lattice site with the formation of hcp, while carbon atoms occupy half of the octahedral interstitial positions. However, the $\alpha-\mathrm{MoC}_{1-\mathrm{x}}$ has a face-centered cubic close-packed $(f c c)$ crystal structure. In addition, $\mathrm{Ti}, \mathrm{Nb}, \mathrm{V}$ and Ta atoms in their TMCs all form $f c c$ crystal structure [18]. These carbides are composed of two nested $f c c$ lattices, one contains metal atoms and the other contains carbon atoms, which is similar to the $\mathrm{NaCl}$ crystal structure. The bonding configuration is usually formed through the hybridization between the $2 \mathrm{~s}$ and $2 \mathrm{p}$ orbitals of carbon atoms with the d orbitals of transition metals. With the increase in $s p$ electrons, the parent metal structure gradually transfers from $b c c$ crystal structure to hcp crystal structure, and then to $f c c$ crystal structure. The lattice constant and bulk modulus of carbides have been calculated theoretically by Murnaghan

Table 118 kinds of MXenes with high synthesis possibility [20]

\begin{tabular}{lll}
\hline MXene predicted to be stable & & \\
\hline $\mathrm{Hf}_{4} \mathrm{C}_{3}$ & $\mathrm{Ta}_{4} \mathrm{~N}_{3}$ & $\mathrm{Sc}_{3} \mathrm{C}_{2}$ \\
\hline $\mathrm{Nb}_{3} \mathrm{C}_{2}$ & $\mathrm{Ta}_{2} \mathrm{C}$ & $\mathrm{Ti}_{2} \mathrm{~N}$ \\
$\mathrm{Zr}_{2} \mathrm{C}$ & $\mathrm{Hf}_{4} \mathrm{~N}_{3}$ & $\mathrm{Sc}_{2} \mathrm{C}$ \\
$\mathrm{Ta}_{3} \mathrm{C}_{2}$ & $\mathrm{Ti}_{4} \mathrm{C}_{3}$ & $\mathrm{~W}_{3} \mathrm{C}_{2}$ \\
$\mathrm{~W}_{4} \mathrm{C}_{3}$ & $\mathrm{Hf}_{2} \mathrm{C}$ & $\mathrm{Nb}_{2} \mathrm{~N}$ \\
$\mathrm{Zr}_{4} \mathrm{C}_{3}$ & $\mathrm{Sc}_{4} \mathrm{C}_{3}$ & $\mathrm{Mo}_{4} \mathrm{C}_{3}$ \\
\hline
\end{tabular}

equation, showing that the theoretical calculated values are in good agreement with the experimental values [19]. Recently, Frey et al. adopted a new model based on density functional theory-PU learning model, and studied 66 kinds 2D single transition metal atoms-based TMCs and there are more than 800 kinds of MAX with different phases through high-throughput calculation. The results predicted that about 111 kinds of MAX and 18 kinds of TMCs could be synthesized with the high possibility (Table 1) [20]. Specially, 14 of the 18 TMCs have the formation energies lower than $200 \mathrm{meV}$ atom $^{-1}$, which is below the threshold value, and the stability of 4 unstable TMCs $\left(\mathrm{W}_{4} \mathrm{C}_{3}, \mathrm{Ta}_{2} \mathrm{C}, \mathrm{W}_{3} \mathrm{C}_{2}\right.$ and $\mathrm{Mo}_{4} \mathrm{C}_{3}$ ) can also be improved by surface functionalization [21]. However, due to the low chemical activity and complex synthesis condition of these TMCs, until now, only the niobium carbide, vanadium carbide, molybdenum carbide and titanium carbide have get a reasonable investigated. Besides the existence of the TMCs, Table 2 exhibits the property of the typical layered materials, including the TMCs. One can see that the new layered TMCs have many excellent property, which would facilitate the development of the materials science. In the following, we introduce mainly the structure, synthesis, properties and applications of these four TMCs, which would inspire future studies.

\subsection{Niobium Carbide}

Among TMCs, niobium carbide has attracted much attention due to its excellent properties, such as high melting point $\left(3610{ }^{\circ} \mathrm{C}\right)$, excellent chemical stability, high toughness, high Young's modulus and higher hardness than other TMCs [22, 23]. Niobium carbide also exhibits better electrical properties, where its resistivity is as low as $4.6 \mu \Omega \mathrm{cm}$ at room temperature and will show superconductivity at $12 \mathrm{~K}$

Table 2 Basic parameters of the typical layered materials

\begin{tabular}{|c|c|c|c|c|c|}
\hline Materials & TMCs & Graphene & TMDs & BP & h-BN \\
\hline Band gap $(\mathrm{eV})$ & 0 (Metallic) & 0 (Metallic) & $1.2 \sim 1.8\left(\mathrm{MoS}_{2}\right)$ & $0.3 \sim 1.5$ & 6.07 \\
\hline Conductance (S/m) & $\sim 10^{6}$ (MXene fiber) & $\sim 10^{6}$ & I & 300 & / \\
\hline Critical temperature of Superconductor (K) & $2 \sim 10$ (Nb or Mo-based TMCs) & $\begin{array}{l}1.7 \text { (Twist } \\
\text { bilayer gra- } \\
\text { phene) }\end{array}$ & $12\left(\mathrm{MoS}_{2} @ 130 \mathrm{GPa}\right)$ & 7.5 (@5 GPa) & / \\
\hline Thermal conductance $\left(\mathrm{Wm}^{-1} \mathrm{~K}^{-1}\right)$ & $48.4\left(\mathrm{Mo}_{2} \mathrm{C}\right)$ & 3000 & 52 & $4.3-5.5$ & 300 \\
\hline Young's modules (GPa) & 14.0 (MXene) & 1000 & $230\left(\mathrm{MoS}_{2}\right)$ & $20 \sim 100$ & 1160 \\
\hline Stability in ambient & No & Yes & Yes & No & Yes \\
\hline
\end{tabular}


[24]. Niobium carbide has a B1 type crystal structure (as shown in Fig. 2), and the vacancies only appear in the carbon sublattice. The composition of the ordered atom-vacancy crystal structure is close to $\mathrm{NbC}_{0.38}$ [25]. There are different solid single-phase zones in the $\mathrm{NbC}$ system: solid solution of carbon in niobium(bcc), $\gamma-\mathrm{Nb}_{2} \mathrm{C}, \beta-\mathrm{Nb}_{2} \mathrm{C}, \mathrm{NbC}_{1-\mathrm{x}}, \mathrm{Nb}_{6} \mathrm{C}_{5}$, $\mathrm{NbC}$ and $\mathrm{Nb}_{4} \mathrm{C}_{3-\mathrm{x}}[26,27] \cdot \gamma-\mathrm{Nb}_{2} \mathrm{C}$ has a hexagonal structure and can be transformed into ordered hexagonal $\beta-\mathrm{Nb}_{2} \mathrm{C}$ at a lower temperature. $\mathrm{NbC}_{1-\mathrm{x}}$ has a $\mathrm{NaCl}$-type crystal structure and can be transformed into $\mathrm{Nb}_{6} \mathrm{C}_{5}$ with an ordered crystal structure at $1050{ }^{\circ} \mathrm{C}$. $\mathrm{NbC}$ also has a NaCl-type crystal structure, which can be regarded as two $f c c$ lattice structures interspersed with each other. The atoms in NbC have octahedral coordination, and carbon atoms occupy half of the octahedral gap. $\mathrm{Nb}_{4} \mathrm{C}_{3-\mathrm{x}}$ is very similar to the ordered $\mathrm{V}_{6} \mathrm{C}_{5}$ crystal structure, but whether there is a stable $\mathrm{Nb}_{4} \mathrm{C}_{3-\mathrm{x}}$ is still controversial. This phase may be produced by the peritectic reaction between $\mathrm{NbC}$ and $\mathrm{Nb}_{2} \mathrm{C}$ [27].

\subsection{Vanadium Carbide}

The vanadium carbide with stoichiometric composition (VC) cannot be obtained under equilibrium conditions. It usually has extensive homology disordered $\delta-\mathrm{VC}_{1-\mathrm{x}}\left(\mathrm{VC}_{0.65}-\mathrm{VC}_{0.90}\right)$ crystallizes with a $\mathrm{NaCl}$ cubic structure. Carbon atoms in $\mathrm{NaCl}$-type vanadium carbides can only fill the octahedral vacancies of the metal $f c c$ sublattice partially, that is, there are structural defects. Under certain conditions, their presence may lead to atomic ordering, which is caused by the redistribution of nonmetallic atoms and structural vacancies at interstitial lattice positions. Due to its high concentration of structural vacancies, this non-stoichiometric interstitial compound can be used in the field of electronic materials. It is found that the ordering of carbon atoms and the formation of structural vacancies in vanadium carbide are accompanied by the increase in micro-hardness and electrical conductivity [28]. Shacklete et al. studied the effect of ordered-disordered phase transition on the resistivity of vanadium carbide single crystal. The results show that the resistivity of vanadium carbide in disordered phase is significantly higher than that in ordered phase. There are 6 solid single-phase zones in the VC system: $\mathrm{VC}, \alpha-\mathrm{V}_{2} \mathrm{C}, \beta-\mathrm{V}_{2} \mathrm{C}, \mathrm{V}_{4} \mathrm{C}_{3}, \mathrm{~V}_{6} \mathrm{C}_{5}$ and $\mathrm{V}_{8} \mathrm{C}_{7}$, as shown in Fig. 3 [29]. Chong et al. systematically studied the stability, electronic structure and anisotropic mechanical properties of VC binary compounds by first-principles calculation, demonstrating their potential applications [30].

In the crystal structure of $\mathrm{VC}$, each unit cell contains 8 atoms ( $4 \mathrm{~V}$ atoms and $4 \mathrm{C}$ atoms). $\mathrm{V}_{4} \mathrm{C}_{3}$ is similar to $\mathrm{VC}$, but each cell has one $\mathrm{C}$ atom vacancy and 7 atoms, including $4 \mathrm{~V}$ atoms and $3 \mathrm{C}$ atoms. The appearance of natural carbon vacancy in $\mathrm{V}_{8} \mathrm{C}_{7}$ makes the space group become $\mathrm{P}_{4} 3_{3} 2$, and the maximum number of atoms in a unit cell is 60 ( $32 \mathrm{~V}$ atoms and $28 \mathrm{C}$ atoms). But the structure of
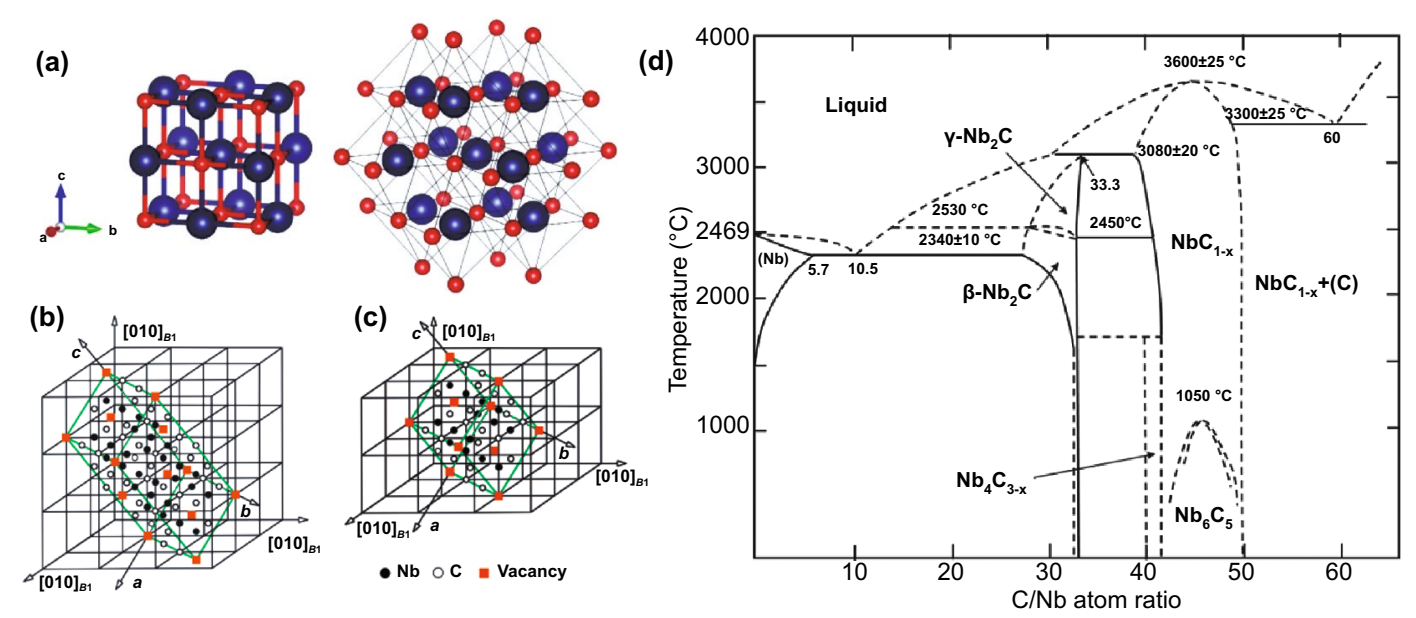

Fig. 2 Structure of Nb-based TMCs. a Schematic diagram of the B1 type crystal structure of NbC. Reproduced with permission from Ref. [27]. Copyright 2016, MDPI. b NbC ${ }_{0.38}$ unit cell structure with $\mathrm{C} 2$ space group. $\mathbf{c} \mathrm{NbC}_{0.38}$ unit cell structure with $\mathrm{C} 2 / \mathrm{m}$ space group. Reproduced with permission from Ref. [25]. Copyright 2021, Springer Nature. d Phase diagram of C-Nb system. Reproduced with permission from Ref. [27]. Copyright 2016, MDPI 
(a)

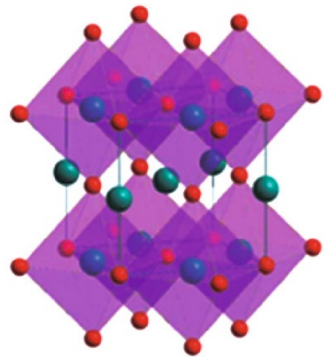

(b)

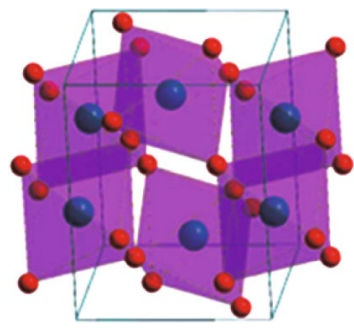

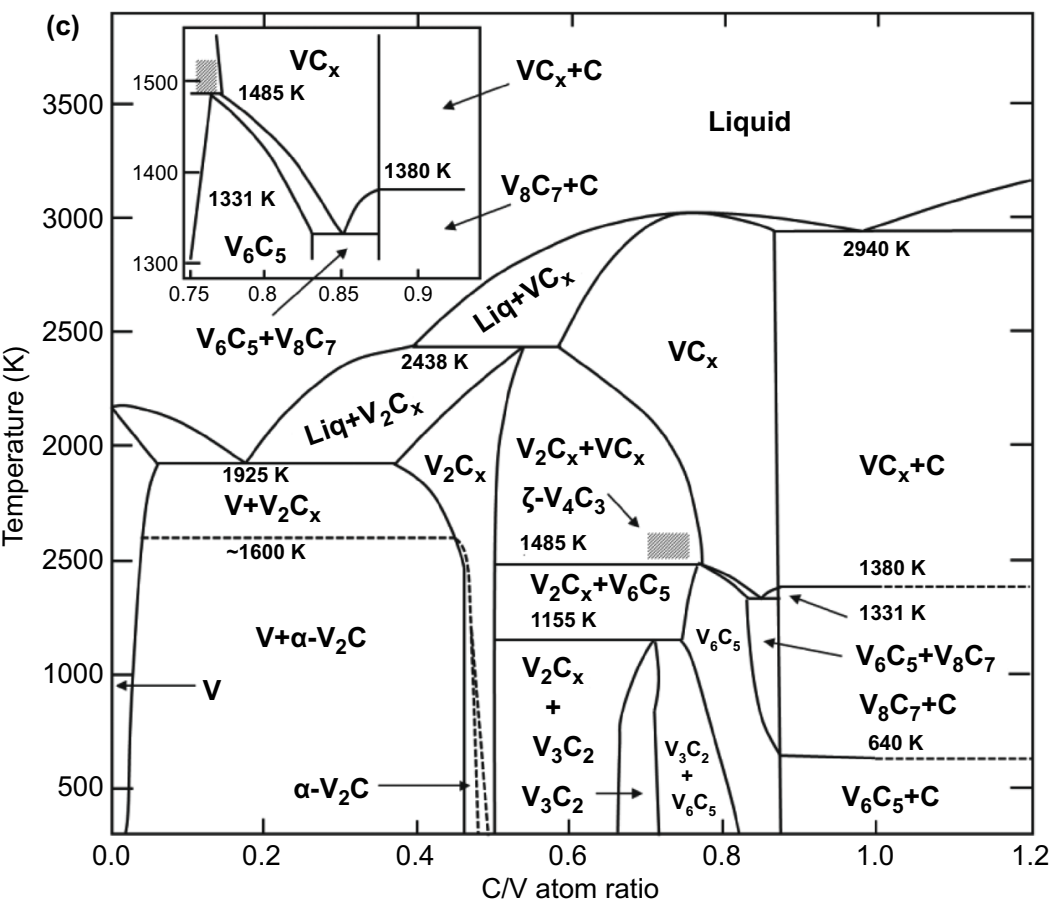

Fig. 3 Crystal structure of V-based TMCs. a VC, b $\alpha-V_{2}$ C. Reproduced with permission from Ref. [30]. Copyright 2011, The Royal Society of Chemistry. c Phase diagram of C-V system. Reproduced with permission from Ref. [31]. Copyright 1989, IOP Publishing

$\mathrm{V}_{8} \mathrm{C}_{7}$ is still cubic. The lattice parameters of $\mathrm{V}_{4} \mathrm{C}_{3}, \mathrm{~V}_{8} \mathrm{C}_{7}$ and $\mathrm{VC}$ are $8.219,8.315$ and $8.305 \AA$, respectively. The lattice constant of $\mathrm{V}_{4} \mathrm{C}_{3}$ is less than $\mathrm{VC}$, which should be due to the doping of carbon vacancies. On the other hand, the formation of natural carbon vacancies will change the space group in the actual $\mathrm{V}_{8} \mathrm{C}_{7}$ lattice, resulting in a slightly larger lattice constant [30]. The cohesive energy of $\mathrm{VC}$ binary phase increases in the following order: $\mathrm{V}_{6} \mathrm{C}_{5}<\mathrm{V}_{8} \mathrm{C}_{7}<\mathrm{VC}<\alpha-\mathrm{V}_{2} \mathrm{C}<\mathrm{V}_{4} \mathrm{C}_{3}<\beta-\mathrm{V}_{2} \mathrm{C}$ [30]. All vanadium carbides exhibit metallic property because of their narrow band gap at Fermi level. Near the Fermi level, the shape of the energy density curve of all $\mathrm{VC}$ compounds is similar to that of the V-d state, indicating that the $\mathrm{d}$ band of $\mathrm{V}$ atom dominates the Fermi level. The chemical bond of VC binary compound is mainly $\mathrm{VC}$ covalent bond, but it also has ionic and metallic properties, which makes vanadium carbide have a high melting point, high mechanical modulus, high hardness and good electrical conductivity [30]. Due to its high hardness, high melting point, excellent wear resistance, low friction coefficient and good corrosion resistance, vanadium carbide is often used to improve the life of mechanical components in tribological applications [32].

\subsection{Molybdenum Carbide}

Molybdenum carbide has five different crystal structures: $\alpha-\mathrm{MoC}_{1-\mathrm{x}}, \alpha-\mathrm{Mo}_{2} \mathrm{C}, \beta-\mathrm{Mo}_{2} \mathrm{C}, \gamma-\mathrm{MoC}$ and $\eta-\mathrm{MoC}$ [33]. For $\alpha-\mathrm{Mo}_{2} \mathrm{C}$, as shown in Fig. 4, two layers of Mo atoms are arranged in an $\mathrm{AB}$ structure, and a layer of carbon atoms is sandwiched in the middle, occupying octahedral center [34]. It is equivalent to that the Mo atoms are closely arranged in the hexagonal form and the carbon atoms are distributed in the octahedral gap with a Z-shaped structure. The lattice of Mo atoms is deformed because the carbon atoms deviate from the center of the gap, thus forming an orthogonal crystal structure. For $\beta-\mathrm{Mo}_{2} \mathrm{C}$, the Mo atoms are arranged in a strict close-packed hexagonal form, and the carbon atoms still occupy $50 \%$ of the octahedral gap. Thus, the distribution of carbon atoms has a certain randomness [35]. The $\alpha$ phase is stable at room temperature, while the $\beta$ phase is stable at high temperature and metastable at room temperature and can only exist stably above $1960{ }^{\circ} \mathrm{C}$. Recently, Liu et al. reported that under the irradiation of electron beams, the carbon atoms in $\mathrm{Mo}_{2} \mathrm{C}$ would migrate resulting in that $\mathrm{Mo}_{2} \mathrm{C}$ change from $\alpha$ phase to $\beta$ phase [35]. As regarding to the 
(a)

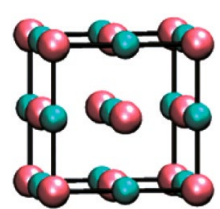

(c)

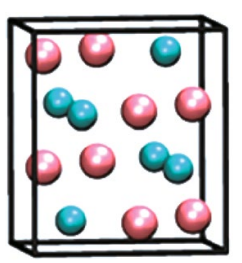

(b)

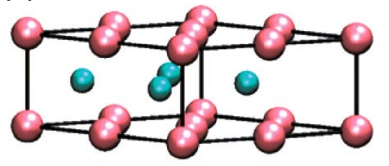

(d)

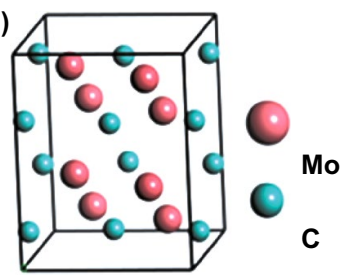

(e)

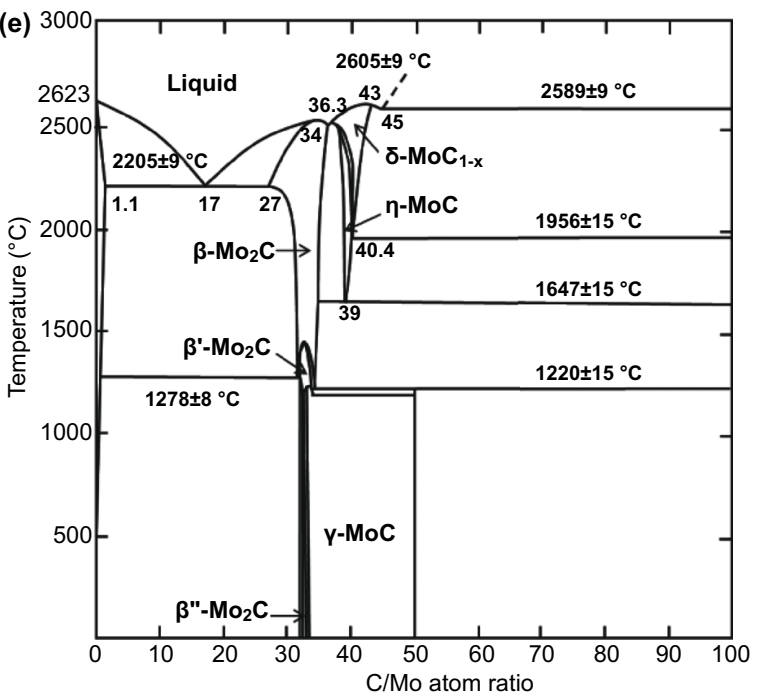

Fig. 4 Bulk crystallographic structures of Mo-based TMCs. a fcc $\alpha-M_{1-x}$, b hexagonal $\gamma-M o C$ and $\eta-M o C, \mathbf{c}$ orthorhombic $\beta-M o o_{2}$, d orthorhombic $\alpha-\mathrm{Mo}_{2} \mathrm{C}$. Reproduced with permission from Ref. [36]. Copyright 2018, Elsevier. e Phase diagram of C-Mo system. Reproduced with permission from Ref. [39]. Copyright 2001, American Physical Society

density of states of $\beta-\mathrm{Mo}_{2} \mathrm{C}$ and $\alpha-\mathrm{Mo}_{2} \mathrm{C}$ [36], the total density of states is mainly composed of $s, p$ orbitals of $\mathrm{C}$ and $\mathrm{d}$ orbital of Mo. Furthermore, there is no band gap near Fermi level indicating the metallicity of molybdenum carbide [36]. Molybdenum carbide has strong absorption for a large range of light, where the molybdenum carbide thin films have a uniform absorption in the range of 500-2000 $\mathrm{nm}$ [37]. Molybdenum carbide is a kind of saturated absorber. The absorptivity of molybdenum carbide to a certain wavelength decreases with the increase in light intensity. When the light intensity increases to a certain value, it is transparent to that wavelength. In this case, when molybdenum carbide is made into a grid with various periodic widths, and the grid is made into a transistor with $\mathrm{MoS}_{2}$ channels and electrodes, the device has a good response rate and a high light-dark current ratio in the range of 400-1400 nm [38].

\subsection{Titanium Carbide}

Titanium carbide is a carbide with a wide homogeneity (from $\mathrm{TiC}_{0.48}$ to $\mathrm{TiC}_{1.00}$ ). The synthesis conditions will affect the ordered arrangement of vacancies in the carbon sublattice, leading to the appearance of non-stoichiometric $\mathrm{TiC}_{\mathrm{x}}$, thereby resulting in the redistribution of carbon atoms and structural vacancies, and forming various ordered structures [40]. When the carbon vacancies are randomly distributed, the disordered $\mathrm{TiC}$ compound forms a cubic $\mathrm{NaCl}$ crystal structure. When the carbon vacancies are distributed in an orderly manner, there are two stable ordered titanium carbide phases, one is the cubic phase and the other is the triangular phase [41]. TiC with $\mathrm{NaCl}$ cubic crystal structure (as shown in Fig. 5) is the most common phase of titanium carbide and has been widely studied. The results show that the lattice spacing of ordered cubic phase $\mathrm{Ti}_{2} \mathrm{C}$ (space group $\mathrm{Fd} 3 \mathrm{~m}$ ) is twice as large as that of disordered titanium carbide $[42,43]$. The $\mathrm{Ti}_{6} \mathrm{C}_{5}$ phase is a stable ordered phase, and also a non-stoichiometric ordered phase of all IV and V group transition metal carbides [40]. Khaenko et al. demonstrated the existence of rhombohedral $\mathrm{Ti}_{8} \mathrm{C}_{5}$ [44]. Through grinding and polishing of titanium carbide, Dzhalabadze et al. found that $6 \mathrm{H}$-type ordered titanium carbide with $f c c$ lattice was formed on the surface [45]. In the process of the deposition of diamond films on titanium alloy substrate, Li et al. also found $6 \mathrm{H}$-type titanium carbide at the interface [41].

In 2011, MXene, represented by $\mathrm{Ti}_{3} \mathrm{C}_{2} \mathrm{~T}_{\mathrm{x}}$, entered the field of vision of researchers, and the research on titanium carbide rose again and expanded to various fields. The structural study of titanium carbide based on $\mathrm{Ti}_{3} \mathrm{C}_{2} \mathrm{~T}_{\mathrm{x}}$ and $\mathrm{Ti}_{2} \mathrm{CT}_{\mathrm{x}}$ MXene is also carried out gradually (as shown in Fig. 5). Through the heating treatment of $\mathrm{Ti}_{3} \mathrm{C}_{2} \mathrm{~T}_{\mathrm{x}}$ MXene, it was found that $\mathrm{Ti}_{3} \mathrm{C}_{2} \mathrm{~T}_{\mathrm{x}}$ has been significantly transformed into cubic $\mathrm{TiC}$ at $1100{ }^{\circ} \mathrm{C}$. As the temperature increases, free $\mathrm{C}$ 
(a)

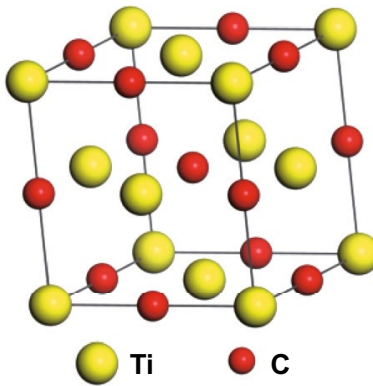

(b)

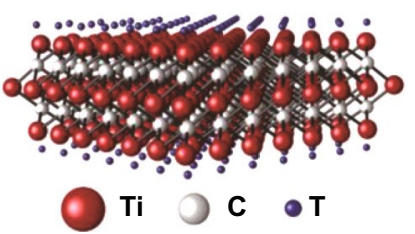

(c)
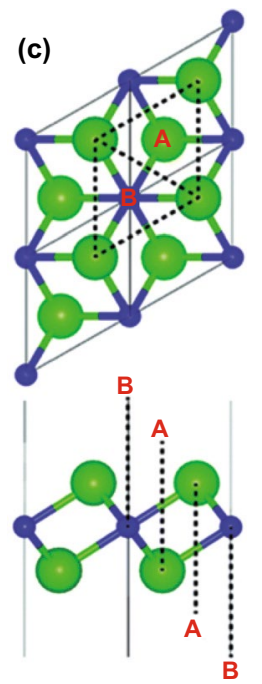

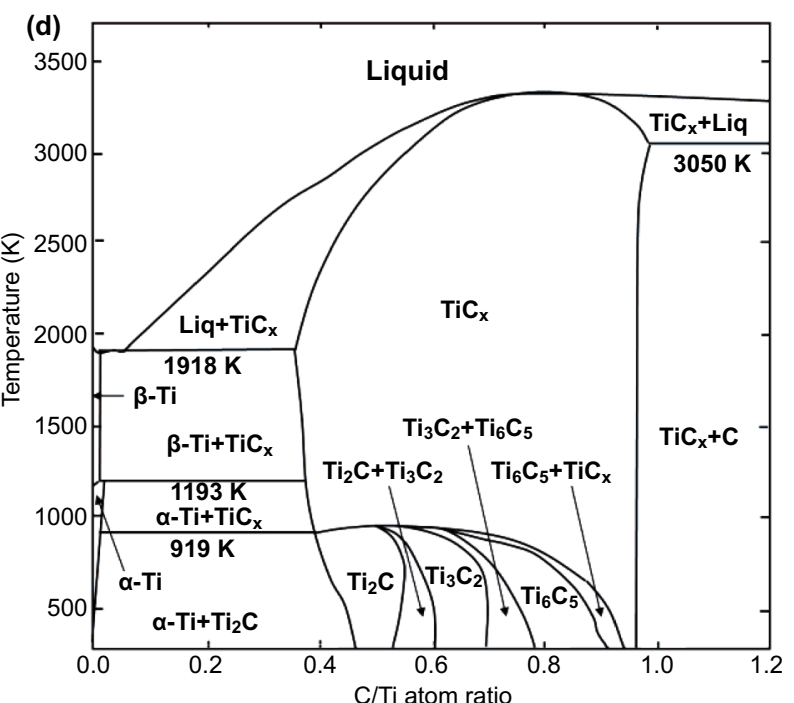

Fig. 5 Structure of titanium carbide. a Ordered structures of cubic TiC. b Molecular structure model of single layer Ti ${ }_{3} \mathrm{C}_{2} \mathrm{~T}_{\mathrm{x}}$. Reproduced with permission from Ref. [46]. Copyright 2016, WILEY-VCH. c Molecular structure model of single layer $\mathrm{Ti}_{2} \mathrm{CT}_{\mathrm{x}}$. Reproduced with permission from Ref. [47]. Copyright 2013, The Royal Society of Chemistry. d Phase diagram of C-Ti system. Reproduced with permission from Ref. [40]. Copyright 1997, Elsevier

is lost due to the conversion of $\mathrm{CO}_{2} / \mathrm{CO}$, and holes appear in the accordion layered structure. When the heat treatment temperature reaches $1250{ }^{\circ} \mathrm{C}, \mathrm{Ti}_{3} \mathrm{C}_{2} \mathrm{~T}_{\mathrm{x}}$ MXene completely transforms into cubic TiC [44].

\section{Synthesis of Transition Metal Carbides}

Although TMCs exhibit many excellent properties, the controlling synthesis is still in its infant. There are a few issues that need further investigation. During the synthesis of TMCs, the production of surface pollutants will block the active sites and cavities, resulting in a suppressed electrocatalytic activity. Normally, the traditional preparation methods of TMCs are usually based on solid-solid reaction or gas-solid reaction, that is, the directly pyrolysis of metal carbonyl compounds or the reaction of metal/metal oxides with $\mathrm{C}$ source. However, at relatively high temperature, the aggregation or overgrowth of TMCs during pyrolysis leads to the decrease in electrochemical reaction active sites and electrocatalytic activity. So far, researchers have been committed to enhance the electrocatalytic activity through the engineering of structures and interfaces, including nanostructures, doping, morphology controlling and the introduction of various carbon-based materials. To sum up, the reasonable design of the preparation process is essential to maximize the exposure of the active sites of TMCs in the process of efficient electrochemical reaction [48].

Besides the particle-like TMCs utilizing in catalytic and energy storage fields, film is another fashion of TMCs, where the solid materials have tiny dimensions in one dimension. Because the thickness is small, the proportion of surface particles is large, and the continuity of the structure is restricted by the surface interface, the properties of the thin films are quite different from those of the bulk materials including [49]: the decreases of melting point [32]; the selective projection and reflection of light [50]; the generation of surface energy level and surface magnetic anisotropy [51]; the varied critical temperature of superconductivity [52]; and the generated tunnel current in the direction of the thickness [53]. With the dimensionality decrease from three-dimensional to two-dimensional, the few-layered graphene and $\mathrm{MoS}_{2}$ display many unique properties, which are quite different with their bulk states, such as higher carrier mobility and field modulated effect $[53,54]$. Due to the high melting point of most carbides, the TMCs materials can be hardly prepared by directly thermal evaporation, while 
electron beam evaporation has been used in the preparation of $\mathrm{TiC} / \mathrm{TiB}_{2}$ films [49]. Up to now, some typical methods have been used to prepare the TMCs.

\subsection{Chemical Exfoliation}

Chemical exfoliation is that it uses HF and LiF to selectively etch the A layer of the parent phase MAX with threedimensional layered structure to realize the preparation of carbides, nitrides and carbonitrides, where $\mathrm{M}$ is transition metal $(\mathrm{Cr}, \mathrm{Ti}, \mathrm{V}, \mathrm{Cr}, \mathrm{Zr}, \mathrm{Nb}$, Mo, Hf or Ta), A is mostly IIIA or IVA group elements ( $\mathrm{Al}, \mathrm{Si}$, etc.), and $\mathrm{X}$ is $\mathrm{C}$ or $\mathrm{N}$ [55]. In order to highlight the similarity between the product and graphene, Naguib et al. named it with MXene. At present, the general process of synthesizing MXene by chemical exfoliation mainly includes: Max precursor synthesis, etching and exfoliation. The schematic diagram of the process of preparing MXene by chemical exfoliation is shown in Fig. 6 [16]. Taking $\mathrm{Ti}_{3} \mathrm{AlC}_{2}$ as an example, Naguib et al. reported a method to remove $\mathrm{Al}$ layer from $\mathrm{Ti}_{3} \mathrm{AlC}_{2}$ without destroying the layered morphology. It was found that the exfoliated $\mathrm{Ti}_{3} \mathrm{C}_{2}$ with large interlayer distance can be obtained by treating $\mathrm{Ti}_{3} \mathrm{AlC}_{2}$ powder with $50 \% \mathrm{HF}$ aqueous, and then, few-layered $\mathrm{Ti}_{3} \mathrm{C}_{2}$ flakes can be prepared through ultrasonic treatment in methanol [16] (Fig. 7).

Many aluminum-based MAX phases are synthesized at a temperature above $1300{ }^{\circ} \mathrm{C}$ [60]. Most of the M-A bonds in the layered MAX precursor phase are metal bonds or covalent bonds, which rules out the possibility of producing MXenes by mechanically shearing their parent phase MAX. Element A can be selectively etched using electrochemical reactions which take place in an acidic solution or an alkaline solution [61]. Recently, another type of layered solids has also been used as precursors, which is $(\mathrm{MC})_{\mathrm{n}} \mathrm{Al}_{3} \mathrm{C}_{2}$ and $(\mathrm{MC})_{\mathrm{n}}(\mathrm{Al}, \mathrm{Si})_{4} \mathrm{C}_{3}$; for example, $\mathrm{Al}_{3} \mathrm{C}_{3}$ and $(\mathrm{Al}, \mathrm{Si})_{4} \mathrm{C}_{4}$ were etched to obtain $\mathrm{Zr}_{3} \mathrm{C}_{2} \mathrm{~T}_{\mathrm{x}}$ and $\mathrm{Hf}_{3} \mathrm{C}_{2} \mathrm{~T}_{\mathrm{x}}$ [62]. However, except for $\mathrm{Ti}_{3} \mathrm{SiC}_{2}$, only the Al-containing MAX phase was successfully etched to synthesize MXene. The experiments also show that the MAX phase with larger $\mathrm{n}$ atom and larger $\mathrm{M}$ atom mass often requires longer etching time and more corrosive solution, which

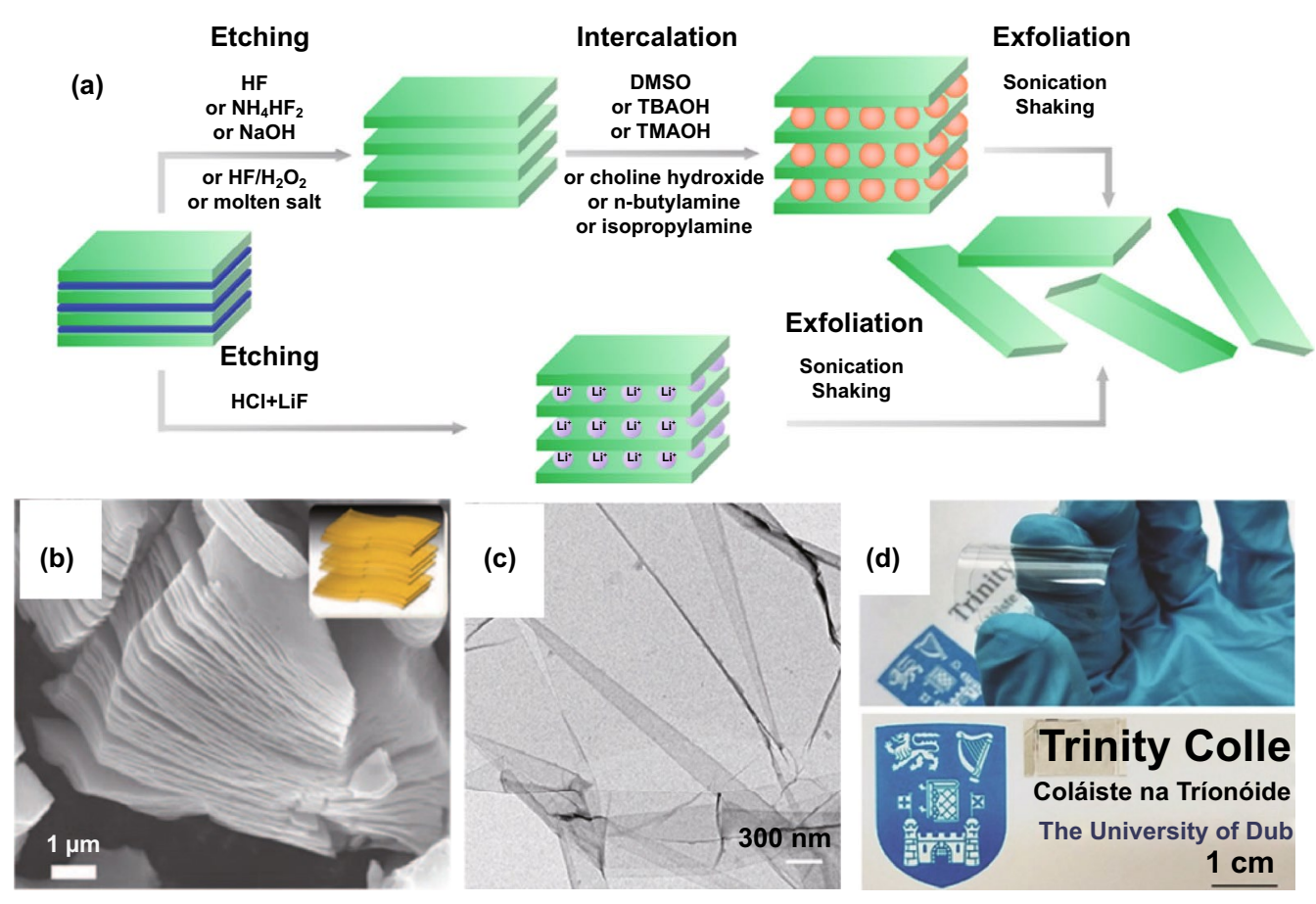

Fig. 6 MXene preparation by chemical exfoliation. a Mechanism of chemical exfoliation. Reproduced with permission from Ref. [56]. Copyright 2019, Elsevier. b SEM image of intercalated procure. Reproduced with permission from Ref. [57]. Copyright 2013, The American Association for the Advancement of Science. c TEM image of few-layer MXene. Reproduced with permission from Ref. [58]. Copyright 2014, Royal Society of Chemistry. d Digital image of MXene-based transparent electrode. Reproduced with permission from Ref. [59]. Copyright 2017, WILEY-VCH 
(a)

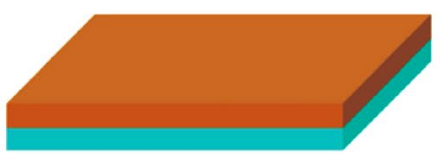

Solid Cu/Mo

(b)

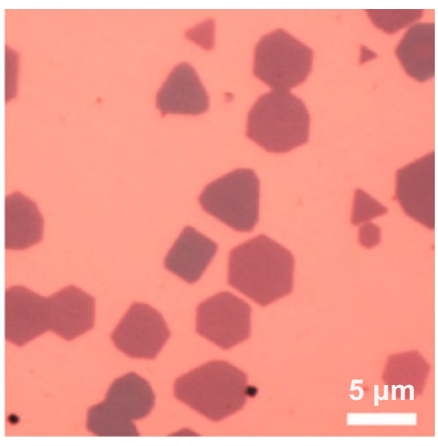

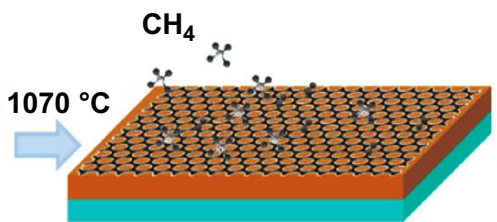

Graphene/Solid Cu/Mo

(c)

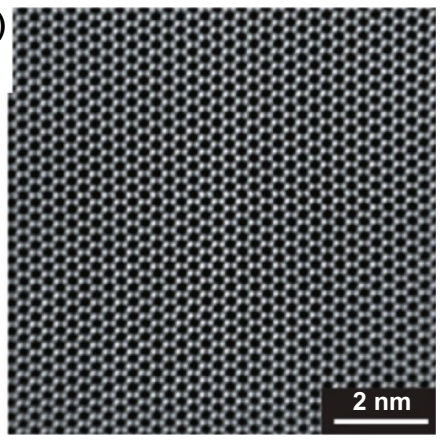

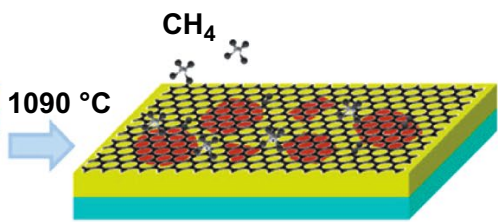

Graphene/2D Mo $2 \mathrm{C} /$ Liquid Cu/Mo

(d)

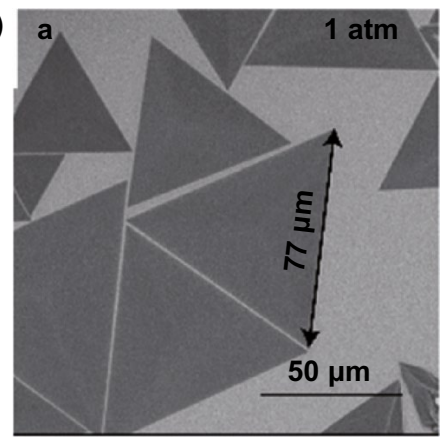

Fig. 7 Preparation of TMCs by chemical vapor deposition. a Mechanism of $\mathrm{Mo}_{2} \mathrm{C}$ growth, where the $\mathrm{Cu}$ foil is located on the surface of Mo foil. Reproduced with permission from Ref. [95]. Copyright 2017, American Chemical Society. b Formation of $\mathrm{Mo}_{2} \mathrm{C}$ flakes under graphene under high temperature. Reproduced with permission from Ref. [95]. Copyright 2017, American Chemical Society. c Atomic pattern of Mo $\mathrm{C}_{2}$ by high resolution TEM. Reproduced with permission from Ref. [90]. Copyright 2015, Springer Nature. d SEM image of VC flakes. Reproduced with permission from Ref. [96]. Copyright 2020, Elsevier

may be due to the large number of $\mathrm{M}$ valence electrons [63]. Etching conditions usually depend on the chemical structure of the parent phase. For example, if $50 \mathrm{wt} \% \mathrm{HF}$ is used for etching $\mathrm{Ti}_{2} \mathrm{AlC}$ and $\mathrm{Cr}_{2} \mathrm{AlC}$, the sample will complete dissolute. Although $\mathrm{Ti}_{2} \mathrm{CT}_{\mathrm{x}}$ can be obtained by reducing the concentration of $\mathrm{HF}$ to $10 \mathrm{wt} \%$, it still not works on $\mathrm{Cr}_{2} \mathrm{AlC}$ [64].

In order to avoid or minimize the use of concentrated HF due to its very strong corrosive, a few other synthetic pathways have been proposed. One of the most widely methods uses a mixture of hydrochloric acid $(\mathrm{HCl})$ and fluoride salts. Using fluorides ( $\mathrm{LiF}, \mathrm{NaF}, \mathrm{KF}$ and $\mathrm{NH}_{4} \mathrm{~F}$ ) and $\mathrm{HCl}$ solution, it was found that the $\mathrm{Ti}_{3} \mathrm{AlC}_{2}$ can be effectively etched and exfoliated to produce layered $\mathrm{Ti}_{3} \mathrm{C}_{2}$ MXene [64-67]. Alhabeb studied the etching effect under different molar ratio of $\mathrm{HCl}$ to $\mathrm{LiF} / \mathrm{HCl}$, and found that the MXene obtained by chemical exfoliation includes $\mathrm{Ti}_{2} \mathrm{CT}_{\mathrm{x}}, \mathrm{Ti}_{3} \mathrm{C}_{2} \mathrm{~T}_{\mathrm{x}}, \mathrm{V}_{2} \mathrm{CT}_{\mathrm{x}}$, etc., where $\mathrm{T}_{\mathrm{x}}$ is a surface atom or atomic group, such as $\mathrm{O}$, $\mathrm{OH}$ and $\mathrm{F}$ [68]. The surface hydrophilicity, conductivity and other physical and chemical properties of MXene prepared by etching method have a great relationship with the choice of etchant and the process. For example, etching with HF will make the surface of MXene mainly contain fluoride functional groups, but LiF-HCl etching will make MXene surface with oxygen-containing functional groups [69].

Similar to titanium-based TMCs, vanadium-based TMCs can also been prepared through this chemical exfoliation [70,71]. He et al. used the mixture of $\mathrm{NaF}$ and $\mathrm{HCl}$ as an etchant to chemically strip $\mathrm{V}_{2} \mathrm{AlC}$. The obtained layered $\mathrm{V}_{2} \mathrm{C}$ MXene has a high specific surface area of $19.3 \mathrm{~m}^{2} \mathrm{~g}^{-1}$ [72]. Zada et al. proposed a new chemical stripping method for large-scale preparation of MXene, which proves that the algae extract can effectively intercalate and strip $\mathrm{V}_{2} \mathrm{AlC}$, avoiding the use of traditional $\mathrm{HF}$ and other dangerous etchants, and has the advantages of environment friendly and low cost [50]. Up to now, the main method to prepare $\mathrm{V}_{2} \mathrm{C}$ MXene is chemically etching. However, the formation energy of $\mathrm{V}_{2} \mathrm{C}$ from $\mathrm{V}_{2} \mathrm{AlC}$ is relatively high, the complete removal of $\mathrm{Al}$ layer in $\mathrm{V}_{2} \mathrm{AlC}$ is difficult, and thus, the final $\mathrm{V}_{2} \mathrm{C}$ MXene usually contains a certain amount of unreacted $\mathrm{V}_{2} \mathrm{AlC}$. Therefore, the conversion efficiency of $\mathrm{V}_{2} \mathrm{AlC}$ to $\mathrm{V}_{2} \mathrm{C}$ needs to be improved, which is of great significance for the further application of $\mathrm{V}_{2} \mathrm{C}$ MXene [73]. Guan reported that the purity of $\mathrm{V}_{2} \mathrm{C}$ MXene can be up to $90 \%$ when using the mixed solution of $\mathrm{LiF}$ and $\mathrm{HCl}$ to treat $\mathrm{V}_{2} \mathrm{AlC}$ [74]. The $\mathrm{Zr}$ - and Nb-based 
TMCs have also been synthesized. Zhou synthesized twodimensional $\mathrm{Zr}_{3} \mathrm{C}_{2}$ MXene by the similar chemical exfoliation using layered $\mathrm{Zr}_{3} \mathrm{Al}_{3} \mathrm{C}_{5}$ as parent phase MAX. It was found that $\mathrm{Zr}_{3} \mathrm{C}_{2}$ MXene has better structural stability at high temperature, compared with that of $\mathrm{Ti}_{3} \mathrm{C}_{2}$ MXene, suggesting its potential advanced application [62]. Xin studied the effect of surface functional groups on the work function of $\mathrm{Nb}_{\mathrm{n}+1} \mathrm{C}_{\mathrm{n}}$ MXene through density functional theory. The results show that the terminated $\mathrm{F}$ and $\mathrm{O}$ atoms will increase the work function of $\mathrm{Nb}_{n+1} \mathrm{C}_{\mathrm{n}}$ MXene, while the $\mathrm{OH}$ and $\mathrm{OCH}_{3}$ groups will decrease its work function, indicating its widely potential application in electronics $[75,76]$. Pang used a new, fluorine-free, concise and rapid synthesis method to prepare one-dimensional $\mathrm{Nb}_{2} \mathrm{CT}_{\mathrm{x}}$ nanowires. The synthesis process includes a twostep etching process: the first is hydrolysis, and the second is 3D electrode thermally assisted electrical etching. With strong stirring, the parent phase MAX creates gaps on the TiC surface and splits into small pieces, the lateral size of which is reduced from $10 \sim 30$ to $1 \sim 5 \mu \mathrm{m}$. Under ultrasonic treatment, a shorter etching time can make the MAX-MXene composite produce nanowire "shred effect" [77].

The chemically exfoliation has also been used to synthesize the multi transition metal-based TMCs. Pinto et al. prepared the two-dimensional bimetallic TMCs $\left(\mathrm{Mo}_{\mathrm{x}} \mathrm{V}_{4-\mathrm{x}} \mathrm{C}_{3}\right.$ MXene) by selectively etching $\mathrm{Al}$ from the $\mathrm{Mo}_{\mathrm{x}} \mathrm{V}_{4-\mathrm{x}} \mathrm{AlC}_{3}$ precursor. Unlike the reported ordered bimetallic carbides $\mathrm{Mo}_{2} \mathrm{TiC}_{2}$ MXene and $\mathrm{Mo}_{2} \mathrm{Ti}_{2} \mathrm{C}_{3}$ MXene, the Mo and V layers in this $\mathrm{Mo}_{\mathrm{x}} \mathrm{V}_{4-\mathrm{x}} \mathrm{C}_{3}$ MXene exist in the form of solid solution. By changing the precursor composition, four different types of $\mathrm{Mo}_{\mathrm{x}} \mathrm{V}_{4-\mathrm{x}} \mathrm{C}_{3}$ MXene with $\mathrm{x}=1,1.5,2$ and 2.7 have been obtained [78]. However, due to the difficult synthesis of stable MAX precursors, many predicted TMCs MXenes have not been successfully synthesized. For example, MAX precursors for $\mathrm{Cr}_{3} \mathrm{~N}_{2}, \mathrm{Mo}_{3} \mathrm{~N}_{2}, \mathrm{Hf}_{3} \mathrm{~N}_{2}$ and $\mathrm{Cr}_{3} \mathrm{C}_{2}$ have not been reported. On the other hand, even some MAX phase can be synthesized; the chemically exfoliation also faces challenge because the as-prepared TMCs MXenes also can be destroyed and solved in the hydrofluoric acid aqueous. For example, although the MAX phase of $\mathrm{Cr}_{2} \mathrm{AlC}$ was synthesized long time before, the $\mathrm{Cr}_{2} \mathrm{C}$ MXenes was yet well prepared [79]. It was found that the samples can be dissolved after a few hours even the etchant concentration has been greatly diluted [80].
Except the etchant, the used dispersion solution is also important, which can affect the size and the stability of the exfoliation flakes. It was found that the yield is quite low when directly stripped by ultrasound in etchant $[81,82]$. Recently, it was reported that $\mathrm{Ti}_{3} \mathrm{C}_{2}$ MXene and $\left(\mathrm{Mo}_{2 / 3} \mathrm{Ti}_{1 / 3}\right)_{3} \mathrm{C}_{2}$ MXenes can be stripped by polar organic molecule dimethyl sulfoxide (DMSO) [83, 84], but it has no obvious effect on other TMCs-based MXene. Tetrabutylammonium hydroxide (TBAOH), which is commonly used for stripping other two-dimensional materials [85], has also been successful in stripping $\mathrm{V}_{2} \mathrm{C}$ MXene and $\mathrm{Ti}_{3} \mathrm{CN}$ MXene with good exfoliation and stability [86]. $\mathrm{Nb}_{2} \mathrm{C}$ MXene can also be stripped in isopropylamine [87].

In summary, the etchant solution and the dispersion solution play the key role in the chemical exfoliation. Although using the fluoride salts can somehow decrease the dangerous of the protocol, the yield and the size of the MXene flakes are still need further improve. The dispersion solution is another important factor, which not only affects the exfoliation rate, but also affects the stability of the as-prepared MXene, indicating that more efforts are still needed.

\subsection{Chemical Vapor Deposition}

Chemical vapor deposition (CVD) is another method which can grow film with large scale and high quality, thus has been widely used in industry. To grow film by CVD, the sources are usually supplied with the formation of gas, which can be easily controlled. However, recently, considering the rare and expensive gas source of transition metal, the traditional CVD has been modified; for example, the gas source of transitional metal was supplied by pre-heating its corresponding transition metal oxide. By this modified CVD method, the high crystallinity $\mathrm{MoS}_{2}$ films have been grown $[88,89]$. The products obtained by this method are very different from those obtained by chemical exfoliation, where the source molecular would react and deposited on the growth substrate. Under high temperature, the molecular or cluster of the samples would migrate and re-organized to form film with high quality, such as singe-crystal-like film or flakes. Therefore, its fashion is quite different from the sample prepared by chemical exfoliation and has yet named with MXene. 
In 2015, Xu et al. reported for the first time the growth of high-quality ultra-thin TMCs crystals $\left(\mathrm{Mo}_{2} \mathrm{C}\right.$ superconducting crystals) by CVD method using double-layer metal foils (copper, copper/transition metal) as substrates; By these methods, $\mathrm{Xu}$ et al. also grown TaC and WC thin films [90]. Firstly, the $\mathrm{Cu} / \mathrm{Mo}$ foil laminate was heated to above $1085{ }^{\circ} \mathrm{C}(\mathrm{Cu}$ melting point) in hydrogen, and then, the $\mathrm{Cu}$ metal would melt and form a uniform liquid $\mathrm{Cu}$ film on the Mo substrate. Methane was introduced at a low flow rate to form $\mathrm{Mo}_{2} \mathrm{C}$ crystals on the surface of the liquid $\mathrm{Cu}$. The top liquid copper layer plays an important role in the growth process. On the one hand, it acts as a catalyst to decompose methane into carbon atoms. On the other hand, it acts as a channel to control the diffusion of Mo atoms from the Mo foil to the surface of the liquid $\mathrm{Cu}$. The results show that ultra-thin $\mathrm{Mo}_{2} \mathrm{C}$ crystals are formed on the surface of $\mathrm{Cu}$ by the reaction of $\mathrm{C}$ atoms and $\mathrm{Mo}$ atoms. Once the growth is finished, $\mathrm{Mo}_{2} \mathrm{C}$ can be further transferred to any target substrate by etching $\mathrm{Cu}$, which is similar with the transferring of graphene [91]. However, it should be noted that the thinnest $\mathrm{Mo}_{2} \mathrm{C}$ film is composed of at least six layers of $\mathrm{Mo}_{2} \mathrm{C}$ rather than a monolayer film, suggesting that the growth of monolayer film needs further optimization [90].

Geng et al. reported an one-step directly growth of $\mathrm{Mo}_{2} \mathrm{C}$ where its size can be grown as large as centimeter [92]. Through controlling investigation, it was found that there is no graphene layer formed with low methane flax. However, at higher methane flax, the graphene would firstly form on the surface of liquid $\mathrm{Cu}$, and the migrated Mo atoms would go through the graphene layer and form the $\mathrm{Mo}_{2} \mathrm{C}$ cluster on the surface of graphene. Thus, the underlayer graphene would work as a buffer layer during the growth and guild the further growth of $\mathrm{Mo}_{2} \mathrm{C}$ crystal with its preferable morphology. Furthermore, the graphene layer would also block the migration of Mo atoms, resulting in the thin of $\mathrm{Mo}_{2} \mathrm{C}$ crystal (about $8.32 \mathrm{~nm}$ ). If there is no graphene layer, the as-grown $\mathrm{Mo}_{2} \mathrm{C}$ crystal can be as thick as $237 \mathrm{~nm}$. In addition, the thickness of $\mathrm{Mo}_{2} \mathrm{C}$ crystal can be tuned by varying the thickness of cooper layer, where the kinetics of Mo diffusion across the $\mathrm{Cu}$ layer can be modulated. The thinnest $\mathrm{Mo}_{2} \mathrm{C}$ crystals with thickness of $9.5 \mathrm{~nm}$ corresponding to 20 layers were obtained [93]. With the similar method, Zhang et al. placed the $\mathrm{V}$ foil, $\mathrm{Cu}$ foil and $\mathrm{W}$ foil in order. At higher temperature, the $\mathrm{Cu}$ foil would be melted on the surface of $\mathrm{W}$ foil; however, the $\mathrm{V}$ foil is still solid state. By controlling the temperature and methane flax, the VC flakes can be obtained on the surface of $\mathrm{Cu}$ foil and its thickness is about $12 \mathrm{~nm}$ [94]. By increasing the flux of hydrogen flax, it was found that the morphology of VC crystal would evaluate from continue film to branch shape, suggesting the etching role of hydrogen. Interestingly, although the $\mathrm{W}$ foil was employed as the substrate, there was no WC crystal formed. As a comparison, the researchers also found that there are no crystal-like VC flaks but only dense VC polycrystalline film formed when using $\mathrm{Cu}$ foil/ $\mathrm{V}$ foil as the source, due to the large amount of migrated $\mathrm{V}$ ions on the $\mathrm{Cu}$ surface.

Ikenoue et al. prepared the uniform $\mathrm{WC}_{1-\mathrm{x}}$ film on the substrate surface by mist CVD method, where the $\mathrm{WCl}_{6}$ acetonitrile solution was carried into the furnace by $\mathrm{Ar} / \mathrm{H}_{2}$ mixture gas. When the temperature is higher than $650{ }^{\circ} \mathrm{C}$, $\mathrm{WC}_{1-\mathrm{x}}$ begins to form, and with the increase in preparation temperature, the element ratio of $\mathrm{C} / \mathrm{W}$ is gradually close to 1. Mechanical characterization shows that the hardness and Young's modulus of $\mathrm{WC}_{1-\mathrm{x}}$ films grown at $750{ }^{\circ} \mathrm{C}$ are 25 and $409 \mathrm{GPa}$, respectively [97]. Atomic layer deposition has also been used to prepare $\mathrm{NbC}$ thin films by employing $\mathrm{NbF}_{5}$ and $\mathrm{NbCl}_{5}$ as the raw materials, TMA as a carbon source and reducing agent. The $\mathrm{NbC}$ film is amorphous with a thickness of about $60 \sim 70 \mathrm{~nm}$. If the film is thicker, NbC nanocrystals with a diameter of $15 \mathrm{~nm}$ will be formed. SQUID magnetometer measurements show that the 75-nm-thickness $\mathrm{NbC}$ film displays superconducting behavior where its transition temperature is about $1.8 \mathrm{~K}$ [52].

Carbide films with different compositions which synthesized by CVD, such as $\mathrm{Ti}\left(\mathrm{C}_{\mathrm{x}} \mathrm{N}_{\mathrm{y}}\right), \mathrm{TiC} / \mathrm{TiN}, \mathrm{TiC} / \mathrm{Al}_{2} \mathrm{O}_{3}, \mathrm{TiC} /$ $\mathrm{TiB}_{2}$ and $\mathrm{TiC} / \mathrm{Al}_{2} \mathrm{O}_{3} / \mathrm{TiN}$ multilayer films, have been developed and applied [98]. However, some problems have been found in the process of gas-phase synthesis: the synthesized carbides are usually polluted by the pollutant produced by the pyrolysis of carbonaceous gases. The pollutants block the pores, wrap the active sites on the surface of the carbides, which are difficult to be eliminated. In addition, most gasphase synthesis processes are not only tedious and complex, but also involve the use of expensive and toxic reagents, such as gaseous molybdenum precursors, which are harmful to organisms and the environment. Thirdly, the current reaction toward single-crystal TMCs film is usually carried out under the assistant of $\mathrm{Cu}$ and high temperature. Considering the plasma or laser treatments may help to improve the activity of transition metal or the carbon source, the growth temperature may decrease such as growing by plasma-assisted 
chemical deposition or laser-assisted chemical deposition. In addition, the development of the transition metal-based organic gaseous precursor may help to grow the TMCs film by metal-organic chemical vapor deposition, which can further optimize the growth condition.

\subsection{Temperature-programmed Reduction}

To improve the catalytic property of TMCs, one of the strategies is that synthesize TMCs with high surface area. With the developing, some methods have gradually developed, including gas-phase reactions that occur using gaseous precursors of metal compounds, reactions between gaseous reactants and solid metal compounds, and thermal decomposition of metal precursors. Among them, the temperatureprogrammed reduction (TPR) developed by Boudart et al. has a broad prospect [99]. So far, almost all the work has been focused on the synthesis of molybdenum and tungsten based carbides, and few other transition metal carbides have been studied. However, TPR has broad research space in the synthesis of binary and ternary early transition metal carbides used in the field of catalysis, due to its easily synthesis condition [100]. It was found that below $1500 \mathrm{~K}$, the mixture of Mo and $\mathrm{C}$ has the four phases: $\mathrm{Mo}, \beta-\mathrm{Mo}_{2} \mathrm{C}$, $\alpha-\mathrm{MoC}_{1-\mathrm{X}}$ and $\mathrm{C}$, which depends on the relative content of the two components [101]. Through the study of Teixeira, the synthesis temperatures are $1170 \mathrm{~K}$ for both $\mathrm{NbC}$ and vanadium carbide [102-104]. However, to synthesize the $\mathrm{TaC}$, the temperature should increase to $1220 \mathrm{~K}$ [105]. Directly carbonizing metal has also been studied, where a $\mathrm{W} / \mathrm{C}(10 \mathrm{~nm} / 20 \mathrm{~nm})$ planar heterostructure was pre-prepared by magnetron sputtering. Then, the original crystallization of $\mathrm{W} / \mathrm{C}$ heterostructure was studied in the temperature range of 300 to $1200{ }^{\circ} \mathrm{C}$. It is found that the nucleation process of reactive synthesis of metal carbides is realized by twostep mechanism. Firstly, the amorphous intermediate with spinodal structure is formed by an amorphous precursor, and then, nucleation of amorphous intermediate occurs [106].

Besides the transition metal was used as the source, John et al. demonstrated that the TMCs can also be synthesized by employing vanadium, niobium, tantalum, molybdenum, tungsten and other binary or ternary oxides as transition metal raw materials. During the TPR process, it seems that it is easier to synthesize carbides for the ternary oxides of $\mathrm{V}$ group and VI group, because either the reaction rate is faster or the synthesis temperature is lower [100]. Post-annealing treatment has also been carried out. After post-annealing at $1500,1600,1700$ and $1800{ }^{\circ} \mathrm{C}$ for $2 \mathrm{~h}$, it was found that the lattice constant and average grain size of $\mathrm{ZrC}$ increased. The crystal grain orientation changed and the crystallinity of $\mathrm{ZrC}$ increased with the annealing temperature; at the same time, the structural defects decreased and the hardness decreased slightly [107]. Sun et al. have synthesized high-quality and high-density $\mathrm{TaC}$ through the high-pressure high-temperature (HPHT) sintering method. Under a pressure of 5.5 GPa, the pre-compressed $\mathrm{TaC}$ powder is heated to $1400{ }^{\circ} \mathrm{C}$ with a temperature increase rate of $150{ }^{\circ} \mathrm{C} \mathrm{min}^{-1}$. After holding for $20 \mathrm{~min}$, the sample was quenched to room temperature at a cooling rate of $150^{\circ} \mathrm{C} \mathrm{min}{ }^{-1}$. The Vickers indentation test shows that the $\mathrm{TaC}$ sample has a mechanical strength of $20.9 \pm 0.5 \mathrm{GPa}$, which is about $35 \%$ higher than the reported data [108].

To prepare the TMCs film by the TRP, polymer-assisted deposition (PAD) has been employed where the transition metal ion would first bind with polymer. Zou et al. prepared the Ti, V or Ta precursor by binding these ions with EDTA and PEI polymer, as shown in Fig. 8 [109]. Through annealing the spin-coated precursor, the $\mathrm{TiC}, \mathrm{VC}$ and $\mathrm{TaC}$ films have been prepared. Especially, it was found that the asprepared TMCs film has high quality and epitaxial on the sapphire substrate, where its grain size and roughness are 50 and $3.5 \mathrm{~nm}$, respectively. Further studying shows that the hardness and Young's modulus of TiC films are 21.27 and $413 \mathrm{GPa}$. The TiC film shows a semiconducting behavior, where its resistivity at room temperature is about 372 $\mu \Omega \mathrm{cm}$. By the similar method, the uranium dicarbide films have also been epitaxially grown on yttria-stabilized zirconia substrate [110]. The investigation exhibits that by controlling the precursor and the annealing progress, it was able to prepare TMCs film with high quality. Considering the low cost and high yield of spin-coating technology, this method can grow TMCs with large scale. However, controlling binding the transition metal ions with polymer is still a challenge, the binding rate needs further optimization.

\subsection{Magnetic Sputtering}

Magnetic sputtering is another kind method to grow film with large scale, which has also been utilized to grow TMCs films. Due to the high wear resistance, 


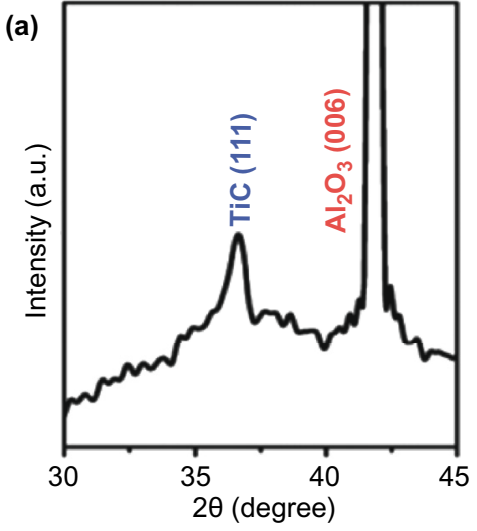

(d)

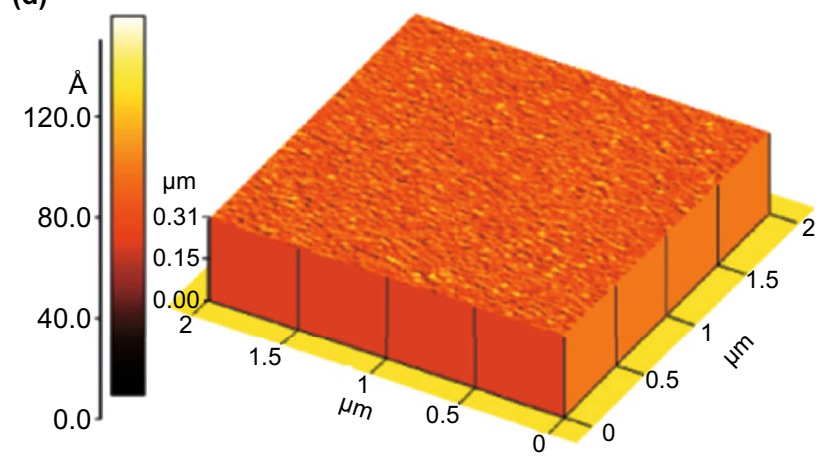

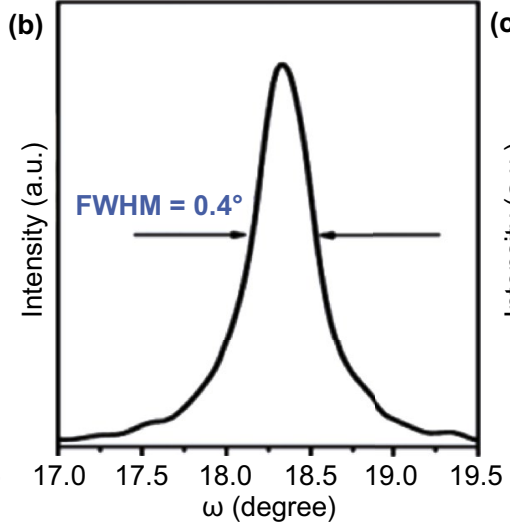
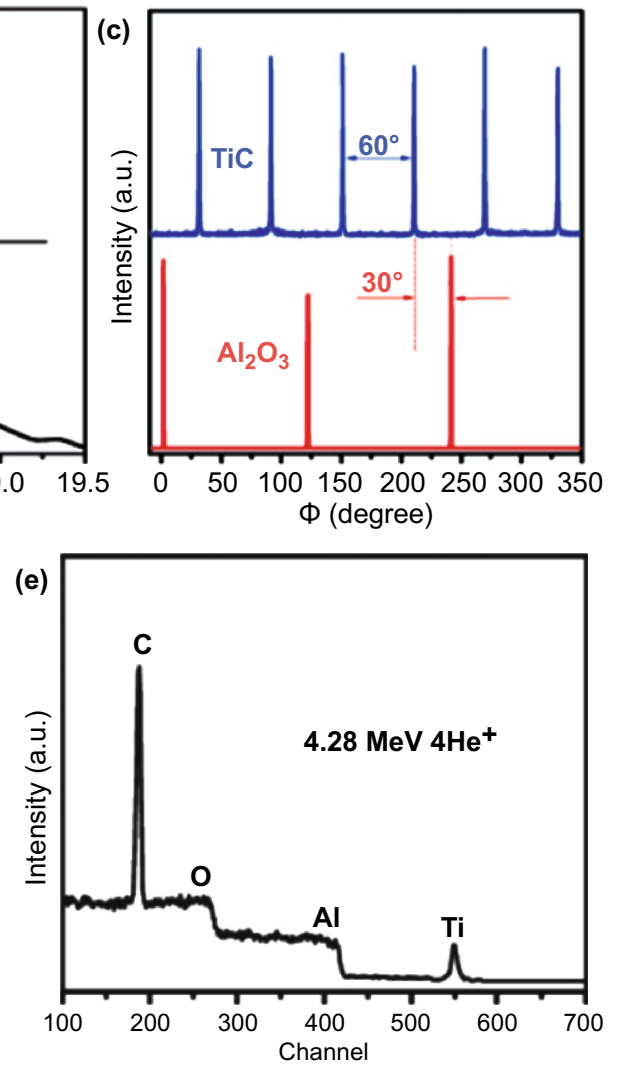

Fig. 8 Preparation of TiC by temperature-programmed reduction. a-c XRD analysis of TiC film. d AFM morphology of TiC film. e Element analysis of TiC film. Reproduced with permission from Ref. [109]. Copyright 2010, American Chemical Society

conductivity, hardness and oxidation resistance, niobium carbide has been well studied than other TMC materials [23, 111-113]. By DC reactive magnetron sputtering using pure $\mathrm{Nb}$ target, the effects of deposition rate, chemical bonding, phase composition, microstructure and internal stress on the properties of the $\mathrm{NbC}_{\mathrm{x}}$ films have been studied $[23,114]$. The results show that the hexagonal $\mathrm{Nb}_{2} \mathrm{C}$ phase would form when the carbon content is 32.7 at $\%$. However, cubic NbC phase with a mixed orientation of (111) and (200) would form when the carbon content is higher than 32.7 at $\%$. Thus, by tuning the carbon content, the phase can be varied between hexagonal $\mathrm{Nb}_{2} \mathrm{C}$ and cubic $\mathrm{NbC}$. Considering the hexagonal $\mathrm{Nb}_{2} \mathrm{C}$ phase has higher hardness than that of cubic NbC phase [115, 116], the Nb-based TMCs film with tunable hardness can be prepared by tuning the carbon content. In addition, when the carbon content is varied from $41.8 \%$ to $68.7 \%$, the grain size would decrease monotonically from 40.6 to $3.9 \mathrm{~nm}$ [114]. Molybdenum carbide film has also been grown by radio frequency magnetron sputtering by using $\mathrm{Mo}_{2} \mathrm{C}$ target, and its application in the generation of solid-state passive Q-switched pulsed lasers has been studied [117]. At 1064 and $1342 \mathrm{~nm}$, the $\mathrm{Mo}_{2} \mathrm{C}$ films show a large nonlinear saturated absorption, and the modulation depth is $10.39 \%$ and $8.89 \%$, respectively, suggesting a well broadband nonlinear optical application.

By magnetic sputtering, the TMC film with large scale can be grown facilitating its potential application; however, the technology has not well investigated. More efforts may input to study its crystallization and texture; the additional carbon sources also need to be considered to improve the carbon vacancy. 


\section{Application of Transition Metal Carbides}

\subsection{Electrocatalysis and Photocatalysis}

At present, precious metals such as platinum $(\mathrm{Pt})$, palladium $(\mathrm{Pd})$ and rhodium $(\mathrm{Ru})$ have shown favorable activity toward hydrogen evolution reaction (HER). However, the application of these precious metals is greatly hindered because of their low abundance and high cost. TMCs with high abundance in the earth, such as $\mathrm{Ni}_{3} \mathrm{C}, \mathrm{Mo}_{2} \mathrm{C}$ and $\mathrm{VC}$, have been proved to be excellent catalysts for HER both theoretically and experimentally. Most of the previous studies on TMCs were conducted on low surface area materials. However, the key to the preparation of high efficiency catalyst lies in the synthesis of high surface area materials [118]. Theoretical calculation shows that TMCs meet the basic requirements of hydrogen evolution reaction (HER). In fact, TMCs (such as $\mathrm{Ti}_{2} \mathrm{C}, \mathrm{V}_{2} \mathrm{C}$ and $\mathrm{Ti}_{3} \mathrm{C}_{2}$ ) with $-\mathrm{OH}$ and $-\mathrm{O}$ on their surface are the basis of their metallicity, which causes charge transfer and transport. In addition, oxygen atoms which on the surface of TMCs provide active sites for HER, because the interaction between $\mathrm{O}$ atoms and $\mathrm{H}$ atoms on the surface of TMCs promotes the removal of hydrogen [119-121]. The volcano curve reflects the ability of various TMCs for HER in Fig. 9. TMCs at the top of the volcano have the highest catalytic activity, such as $\mathrm{Ti}_{2} \mathrm{CO}_{2}, \mathrm{~W}_{2} \mathrm{CO}_{2}, \mathrm{TiVCO}_{2}$ and $\mathrm{Nb}_{2} \mathrm{CO}_{2}$. In addition, bimetallic TMCs $\left(\mathrm{M}_{1} \mathrm{M}_{2} \mathrm{CO}_{2}\right)$ are also potential candidates because they have moderate $\mathrm{H}_{2}$ adsorption free energy catalysts for HER, thus showing higher activity. For these reasons, TMCs-based systems have become a hot spot in the design of electrocatalysts and solarpowered photocatalysts [122].

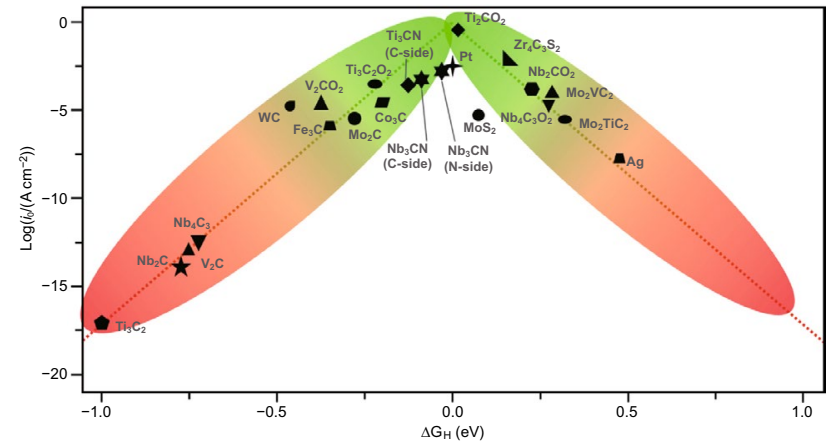

Fig. 9 Exchange current as the function of Gibbs free energy of hydrogen adsorption of TMCs
Using the adsorption of atomic hydrogen as a probe, the chemical properties of the surfaces of different carbide can be studied. Due to the tensile strain generated on the carbide surface when carbon is bonded to the crystal lattice, the adsorption of hydrogen to the carbides surface which at the end of metal is stronger than that to the tightly filled pure metal surface. John et al. found that the adsorption of hydrogen atoms on the Mo terminated surface of molybdenum carbide is much stronger than that on the surface of pure metal Mo (110) [19]. Compared to the ground-state pure metal surface, the metal terminated surface of the carbide has the lower hydrogen bonding energy (HBE) values. It can be seen that for other carbides except $\mathrm{VC}$, the adsorption of $\mathrm{H}$ on the terminated surface of TMCs is stronger than that on the surface of pure metal. One of the reasons for the strong adsorption energy of the TMCs surface may be that the carbide surface is in a state of tensile strain compared with the pure metal surface. The distance between metal atoms in TMCs is farther than the distance between metal atoms in pure metal [19].

Wan et al. have systematically analyzed the crystal structure, electronic properties, free energy, surface energy and crystal formation energy of $\mathrm{V}_{4} \mathrm{C}_{3}, \mathrm{~V}_{8} \mathrm{C}_{7}$ and $\mathrm{VC}_{3}$ during HER and OER processes by using the first-principles calculation method [123]. The results show that the vanadium carbide has excellent HER performance but poor OER activity. In particular, $\mathrm{V}_{8} \mathrm{C}_{7}$ has the best HER activity in these vanadium carbide phases. Compared with other phases, $\mathrm{V}_{8} \mathrm{C}_{7}$ has excellent catalytic activity, which can be attributed to the following factors: (i) larger surface energy is easier to capture ionized hydrogen/oxygen; (ii) more moderate hydrogen adsorption energy can accelerate HER rate; (iii) lower crystal formation energy and easier formation of $\mathrm{C}$ defects increase the specific surface area and active center of HER, and provide faster charge transport for HER; (iv) larger VC bond length and weaker bond strength contribute to the formation of suitable hydrogen absorption energy and smaller free energy $\Delta \mathrm{G}\left(\mathrm{H}^{*}\right)$. In addition, there is a significant similarity in the density of d-band states between $\mathrm{VC} / \mathrm{V}_{8} \mathrm{C}_{7}$ and Pt on the (110) and (111) crystal planes, indicating that the HER mechanism of $\mathrm{VC} / \mathrm{V}_{8} \mathrm{C}_{7}$ is similar to $\mathrm{Pt}$ [123].

Experimentally, Tian et al. found that the combination of vanadium carbide and $\mathrm{TiO}_{2}$ can be used as an effective and stable co-catalyst for photocatalytic hydrogen evolution [124]. As a co-catalyst, VC can not only effectively capture the photogenerated electrons from $\mathrm{TiO}_{2}$, greatly improve 
the separation efficiency of photogenerated charges, but also significantly reduce its overpotential, thus enhancing the catalytic activity of $\mathrm{TiO}_{2} / \mathrm{VC}$. Besides, the vanadium carbide has also be hybridized with active metal nanoparticle, where Pt nanoparticles with an average particle size of $3 \mathrm{~nm}$ are evenly distributed on the surface of carbon and cubic vanadium carbide (Pt/VC-C), which can be used as an electrocatalyst for oxygen reduction reaction (ORR) [125]. The combination of Pt nanoparticles and cubic vanadium carbide nanoparticles is beneficial to enhance the synergistic effect. Compared with the reversible hydrogen electrode (RHE), the mass activity of ORR on the surface of Pt/VC-C can reach $230 \mathrm{~mA} \mathrm{mg}_{\mathrm{Pt}}^{-1}$ at $0.9 \mathrm{~V}$, which is 2.4 times higher than that of Pt/C electrocatalyst $\left(97 \mathrm{~mA} \mathrm{mg}_{\mathrm{Pt}}^{-1}\right)$. Furthermore, the vanadium carbide has also been demonstrated to effectively encapsulate on carbon-based skeleton, delivering a great
HER activity such as a current density of $100 \mathrm{~mA} \mathrm{~cm}^{-2}$ and an overpotential of $238 \mathrm{mV}$ [126]. Yoon et al. successfully doped $\mathrm{V}_{2} \mathrm{CT}_{\mathrm{x}}$ with controllable concentration of phosphorus. The experimental results are in good agreement with the theoretical calculation that the $\mathrm{P}-\mathrm{C}$ bond in $\mathrm{P}-\mathrm{V}_{2} \mathrm{CT}_{\mathrm{x}}$ works as active sites promoting the weakening of the hydrogen bond strength and leads to the desorption of $\mathrm{H}_{\text {ads }}$ during the HER process. $\mathrm{V}_{2} \mathrm{CT}_{\mathrm{x}}$ with the highest $\mathrm{P}-\mathrm{C}$ bond concentration exhibits a Tafel slope of $74 \mathrm{mV} \mathrm{dec}^{-1}$ and an overpotential of $163 \mathrm{mV}$ at $10 \mathrm{~mA} \mathrm{~cm}^{-2}$ [127, 128].

Molybdenum carbide has been widely employed as electrocatalyst to split water, as shown in Table 3. Chen et al. studied the formation of molybdenum carbide from ammonium molybdate in inert environment. It was found that the coupling effect caused by the covalent bond between $\mathrm{Mo}_{2} \mathrm{C}$ and carbon carrier has a unique effect on the electrochemical

Table 3 Electrocatalytic performance of transition metal carbides

\begin{tabular}{|c|c|c|c|c|c|c|}
\hline Sample & Prepare method & Morphology & HER or OER & Tafel slope $\left(\mathrm{mV} \mathrm{dec}{ }^{-1}\right)$ & $\begin{array}{l}\text { Overpotential } \\
\text { at } 10 \mathrm{~mA} \mathrm{~cm}^{-2} \\
(\mathrm{mV})\end{array}$ & Refs \\
\hline $\mathrm{Ti}_{3} \mathrm{C}_{2}$ & Chemical exfoliation & Nanofibers & HER & $97\left(\mathrm{H}_{2} \mathrm{SO}_{4}\right)$ & 169 & [7] \\
\hline $\mathrm{Ti}_{2} \mathrm{CT}_{\mathrm{x}}$ & Chemical exfoliation & Nanosheets & HER & $100\left(\mathrm{H}_{2} \mathrm{SO}_{4}\right)$ & 75 & [138] \\
\hline $\mathrm{W}_{2} \mathrm{C}$ & Microwave combustion & Nanodots & HER & $45\left(\mathrm{H}_{2} \mathrm{SO}_{4}\right)$ & 71 & [139] \\
\hline $\mathrm{Mo}_{2} \mathrm{C}$ & Microwave combustion & Nanodots & HER & $46\left(\mathrm{H}_{2} \mathrm{SO}_{4}\right)$ & 77 & [139] \\
\hline $\mathrm{Mo}_{2} \mathrm{C}$ & Precipitation and calcine & Nanoporous & HER & $54\left(\mathrm{H}_{2} \mathrm{SO}_{4}\right)$ & 200 & [140] \\
\hline$\alpha-\mathrm{Mo}_{2} \mathrm{C}$ & Urea-glass route & Nanoparticles & HER & $57(\mathrm{KOH})$ & 176 & [141] \\
\hline $\mathrm{Mo}_{2} \mathrm{CT}_{\mathrm{x}}$ & Chemical exfoliation & Nanosheets & HER & $189\left(\mathrm{H}_{2} \mathrm{SO}_{4}\right)$ & 75 & [142] \\
\hline $\mathrm{Mo}_{2} \mathrm{TiC}_{2} \mathrm{~T}_{\mathrm{x}}$ & Chemical exfoliation & Nanosheets & HER & $248\left(\mathrm{H}_{2} \mathrm{SO}_{4}\right)$ & 74 & [142] \\
\hline $\mathrm{Mo}_{2} \mathrm{Ti}_{2} \mathrm{C}_{3} \mathrm{~T}_{\mathrm{x}}$ & Chemical exfoliation & Nanosheets & HER & $275\left(\mathrm{H}_{2} \mathrm{SO}_{4}\right)$ & 99 & [142] \\
\hline TaC NCs@C & $\begin{array}{l}\text { Micro-cutting-fragmen- } \\
\text { tation }\end{array}$ & Nanocrystals & HER & $143\left(\mathrm{H}_{2} \mathrm{SO}_{4}\right)$ & 146 & [143] \\
\hline Ta-Hf-C & Magnetron sputtering & Films & HER & $129\left(\mathrm{H}_{2} \mathrm{SO}_{4}\right)$ & 198 & [144] \\
\hline $\mathrm{Co}_{3} \mathrm{~W}_{3} \mathrm{C}$ & TPR & Nanoparticles & OER & $59(\mathrm{KOH})$ & 238 & [145] \\
\hline $\mathrm{Ni}_{0.7} \mathrm{Fe}_{0.3} \mathrm{PS}_{3} @ \mathrm{MXene}$ & Solid-state reaction & Nanohybrid & OER & $36.5(\mathrm{KOH})$ & 282 & [146] \\
\hline $\mathrm{Ni}-\mathrm{Mo}_{\mathrm{x}} \mathrm{C}$ & Thermal conversion & $\begin{array}{l}\text { Graphene/nanotube } \\
\text { hybrid }\end{array}$ & OER & $74(\mathrm{KOH})$ & 328 & [147] \\
\hline $\mathrm{Fe}-\mathrm{Ni}_{3} \mathrm{C}$ & Carburizing treatment & Nanosheets & OER & $62(\mathrm{KOH})$ & 275 & [148] \\
\hline $\mathrm{Ti}_{3} \mathrm{C}_{2} \mathrm{~T}_{\mathrm{x}}-\mathrm{CoBDC}$ & Interdiffusion reaction & Nanosheets & OER & $48.2(\mathrm{KOH})$ & 410 & [149] \\
\hline $\mathrm{Co}_{3} \mathrm{Mo}_{3} \mathrm{C}$ & TPR & Micrometers particles & HER & $93(\mathrm{KOH})$ & 169 & [150] \\
\hline $\mathrm{N}-\mathrm{Ti}_{2} \mathrm{CT}_{\mathrm{x}}$ & Chemical exfoliation & Nanosheets & HER & $67\left(\mathrm{H}_{2} \mathrm{SO}_{4}\right)$ & 215 & [151] \\
\hline $\mathrm{Co}-\mathrm{Mo}_{2} \mathrm{C}$ & Carbonization & Nanosheets & HER & $39\left(\mathrm{H}_{2} \mathrm{SO}_{4}\right)$ & 48 & [152] \\
\hline $\mathrm{Mo}_{2} \mathrm{C}-\mathrm{C}$ & $\begin{array}{l}\text { spray drying and calcina- } \\
\text { tion }\end{array}$ & Flake structure & HER & $69\left(\mathrm{H}_{2} \mathrm{SO}_{4}\right)$ & 110 & [153] \\
\hline $\mathrm{Ti}_{3} \mathrm{C}_{2} \mathrm{O}_{\mathrm{x}}$ & Chemical exfoliation & 2D flakes & HER & $60.7\left(\mathrm{H}_{2} \mathrm{SO}_{4}\right)$ & 190 & [154] \\
\hline $\mathrm{W}_{2} \mathrm{C} @ \mathrm{GL}$ & Heat treatment & Nanoparticles & HER & $68\left(\mathrm{H}_{2} \mathrm{SO}_{4}\right)$ & 135 & [155] \\
\hline Mo-WC@NCS & TPR & Nanosheet & HER & $81(\mathrm{KOH})$ & 179 & [156] \\
\hline VC@NC/C & TPR & 3D network & HER & $165(\mathrm{KOH})$ & 238 & [126] \\
\hline
\end{tabular}


performance. First of all, the conjugation with high bond strength can promote the close combination of $\mathrm{Mo}_{2} \mathrm{C}$ catalyst and carbon carrier, and provide a low resistance path suitable for rapid electron transfer. Secondly, this binding hinders the aggregation of $\mathrm{Mo}_{2} \mathrm{C}$ nanoparticles, thus promoting the production of highly active sites on the surface. Third, anchoring induces the transfer of charge from molybdenum to carbon, which further reduces the d-band center of molybdenum, thus reducing the hydrogen bonding energy of molybdenum. This, in turn, is beneficial to the electrochemical adsorption of $\mathrm{H}_{\mathrm{ads}}$, resulting in a relatively moderate Mo-H bond binding strength, which enhances the HER performance. Molybdenum itself is considered to be a strong hydrogen-bonded metal due to its unique d-band position $[129,130]$. To further improve the activity and the amount of active sites, doping heteroatoms has been considered. After boron doping [131], the HER activity of $\mathrm{Mo}_{2} \mathrm{C}$ catalyst is significantly improved, where the slope of Tafel downs to $78 \mathrm{mV} \mathrm{dec}{ }^{-1}$, which is much smaller than that of the blank control $\left(134 \mathrm{mV} \mathrm{dec}^{-1}\right)$. In addition, the nitrogendoped WC nano-arrays also show excellent HER activity, where overpotentials were 89 and $190 \mathrm{mV}$ corresponding to the current density of 10 and $200 \mathrm{~mA} \mathrm{~cm}^{-2}$, respectively. Furthermore, the initial potential of the water splitting is $1.4 \mathrm{~V}$ when employing N-WC nano-array as both the cathode and anode, suggesting its high activity [132]. This is mainly due to the increase in the number of active sites, the turnover frequency increases, and the resistance to electron transfer decreases.

Metallic alloy effect has also been studied such as MoW-C [133-135]. When the Mo/W ratio of this bimetal hollow sphere is adjusted to $1.26 / 0.74$, the overpotentials are 106,127 , and $152 \mathrm{mV}$ corresponding to use $1 \mathrm{M} \mathrm{KOH}$, $0.5 \mathrm{M} \mathrm{H}_{2} \mathrm{SO}_{4}$ and $1 \mathrm{M}$ phosphate buffer as the medium, respectively, indicating its board activity. Specially, the overpotential of the $\mathrm{Mo}_{1.26} \mathrm{~W}_{0.74} \mathrm{C} @ \mathrm{C}$ in alkaline and acid electrolytes is only 237 and $250 \mathrm{mV}$ at the current density of $300 \mathrm{~mA} \mathrm{~cm}^{-2}$, which is obviously better than most reported electrocatalysts. Chen et al. used a new metal-organic framework derivatization method to synthesize a vertically arranged pure phase porous bimetallic carbide with $\mathrm{N}$-doped carbon as a matrix on a flexible carbon cloth $\left(\mathrm{Co}_{6} \mathrm{~W}_{6} \mathrm{C} @ \mathrm{NC} /\right.$ $\mathrm{CC}$ ). It exhibits excellent OER activity with an overpotential of $286 \mathrm{mV}$ at $10 \mathrm{~mA} \mathrm{~cm}^{-2}$. At the same time, it exhibits an enhanced HER activity with an overpotential of $59 \mathrm{mV}$ at $10 \mathrm{~mA} \mathrm{~cm}^{-2}$. The unique HER activity of bimetallic alloy based TMCs can be mainly attributed to the synergistic effect which not only modulated the electronic structure, activity of the active site, but also tuned its conductivity [134]. Except the Mo- and W-based TMCs, other TMCs have not been well studied. Kou et al. prepared the tantalum carbide nanocrystals (TaC NCs@C) adhered to carbon, which have high refractive index (222) crystal planes. Due to the formation of a transition zone between the carbon layer and the (222) crystal planes of $\mathrm{TaC}$, its stability in the process of preparation and electrochemical reaction is enhanced. TaC nanocrystals have a low overpotential of $146 \mathrm{mV}$ at $10 \mathrm{~mA} \mathrm{~cm}^{-2}$, a large exchange current density of $9.69 \times 10^{-2} \mathrm{~mA} \mathrm{~cm}^{-2}$ and excellent cycle stability, which is far superior to other reported group- $\mathrm{V}$ metal carbide catalysts [136].

Besides employing as the electrocatalysts, the TMCs have also been used in photocatalysts; however, it is still in infant. Huang et al. used tungsten carbide to degrade organic pollutants by near-infrared photocatalysis. The experimental results are well consisted with the three-dimensional finite element simulation, which prove that plasmon resonance responding from WC nanoparticles can occur on the local surface of the near-infrared light, thereby showing high UV-Visible-NIR full-spectrum absorption and high nearinfrared triggered photocurrent response. It has near-infrared photocatalytic degradation performance and the catalytic degradation rate of methylene blue (MB) by WC nanoparticles under near-infrared radiation is up to 50\% [137].

\subsection{Gas Catalysis and Sensing}

The gas molecular conversation would greatly increase the utilization of production in petrochemical industry. The physical and chemical properties of molybdenum carbide with different phases have a significant difference, especially in the field of catalysis. It is known that the catalytic performance of fcc- $-\mathrm{MoC}_{1-\mathrm{x}}$ is different from that of hcp- $\mathrm{Mo}_{2} \mathrm{C}$ in ethane hydrogenation, methanol reforming to hydrogen production, toluene hydrogenation and $\mathrm{CO}$ hydrogenation [81]. For example, the $\mathrm{CO}$ hydrogenation activity of cubic phase fcc- $-\mathrm{MoC}_{1-\mathrm{x}}$ is twice as high as that of hcp- $\mathrm{Mo}_{2} \mathrm{C}$ hexagonal phase, while hcp- $\mathrm{Mo}_{2} \mathrm{C}$ is more active than fcc- $\mathrm{MoC}_{1-\mathrm{x}}$ in ethane hydrolysis. In addition, hcp- $\mathrm{Mo}_{2} \mathrm{C}$ nanoribbons with unsaturated Mo sites on surface have higher activity than fcc- $-\mathrm{Mo}_{2} \mathrm{C}$ nanoribbons in the dehydrogenation of benzyl 
alcohol. The different catalytic activities of different phases in molybdenum carbides may be attributed to the influence of surface structure [157]. Dudari et al. prepared molybdenum carbide by Pechini method and $\mathrm{CH}_{4} / \mathrm{H}_{2}$ carburizing gas temperature-programmed reduction method. It was found that the molybdenum carbide prepared by Pechini method mainly contains face-centered cubic $\mathrm{MoC}_{1-x}$ phase, while the $\mathrm{Mo}_{2} \mathrm{C}$ phase prepared by TPR method has hexagonal compact packing structure. And the defect phase can be produced by changing the flow rate of Carburizing gas [157]. In addition, the molybdenum carbide has also been demonstrated showing the well catalytic performance in butane dehydrogenation and $\mathrm{CO}_{2}$ hydrogenation [158]. Theoretical investigation proves that a rectifying contact is formed at the interface between $\mathrm{MoC}$ nanoparticles and nitrogen-doped carbon, which can promote the adsorption and activation of gas molecules, thereby selectively forming formic acid (FA). Molybdenum carbide with different phase structure show different activity and stability for WGS catalytic reaction. The layered $\mathrm{Mo}_{2} \mathrm{CT}_{\mathrm{x}}$ had better catalytic activity and stability than other molybdenum carbide structures (as shown in Fig. 7f), and had high selectivity for $\mathrm{CO}_{2}$ and $\mathrm{H}_{2}$ [159]. The doped molybdenum carbide samples $\left(\mathrm{MoC} / \mathrm{N}_{5.6} \mathrm{C}\right)$ with significant electron enrichment obtained in the experiment

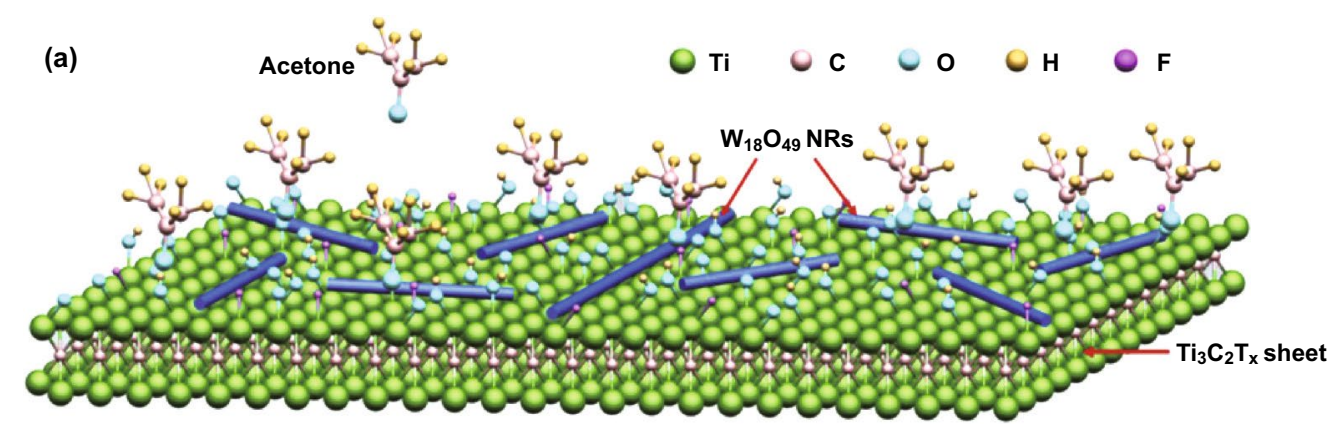

(b)

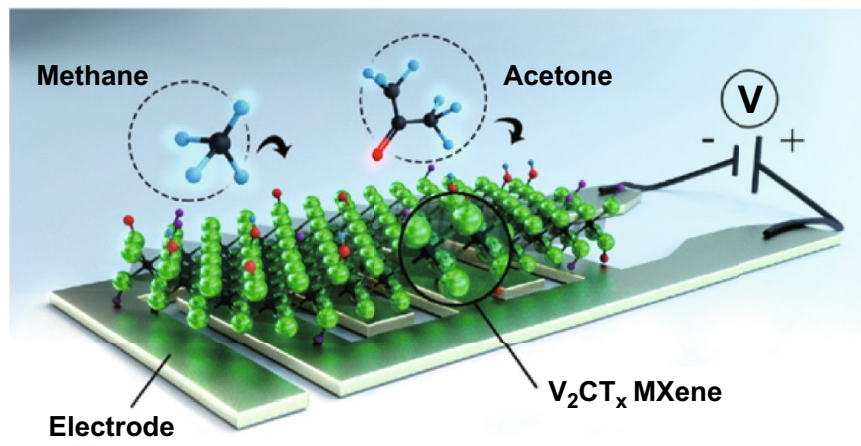

(c)

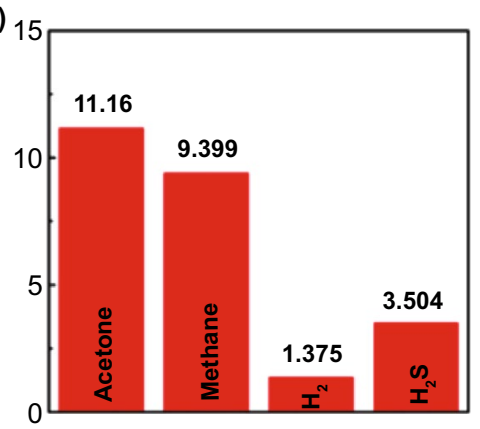

(d)

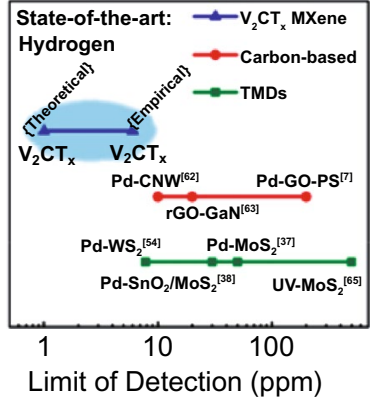

(e) State-of-the-art: $\longrightarrow \mathrm{V}_{2} \mathrm{CT}_{\mathbf{x}} \mathrm{MXene}$

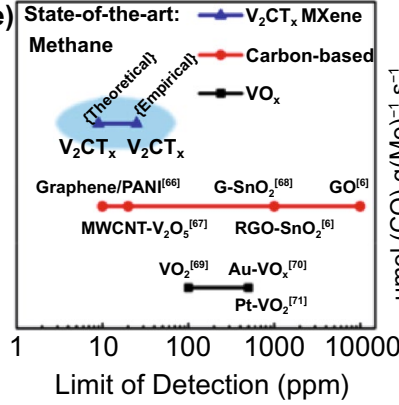

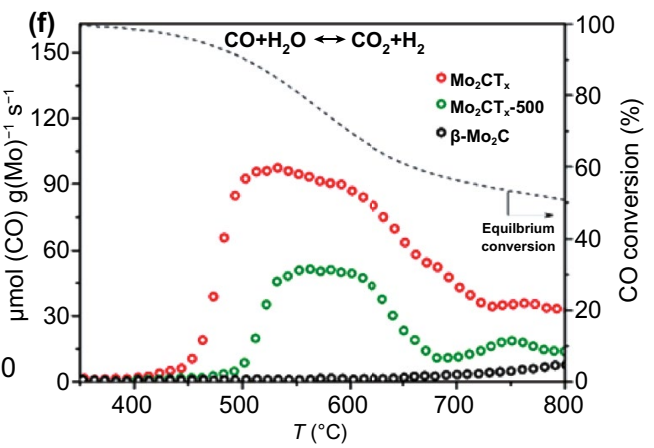

Fig. 10 Gas catalytic property of TMCs. a Schematic of the reaction between acetone and $\mathrm{W}_{18} \mathrm{O}_{49} / \mathrm{Ti}_{3} \mathrm{C}_{2} \mathrm{~T}_{\mathrm{x}}$ composite. Reproduced with permission from Ref. [163]. Copyright 2020, Elsevier. b Schematic diagram of the sensing mechanism of the $\mathrm{V}_{2} \mathrm{CT}_{\mathrm{x}}$ gas sensor. $\mathbf{c}$ Theoretical LoD of $\mathrm{V}_{2} \mathrm{CT}_{\mathrm{x}}$ film toward acetone, methane, hydrogen and hydrogen sulfide at room temperature. Comparison of LoD of $\mathbf{d}$ hydrogen and $\mathbf{e}$ methane for room temperature gas sensor. Reproduced with permission from Ref. [161]. Copyright 2019, American Chemical Society. f WGS catalytic activity of $\mathrm{Mo}_{2} \mathrm{CT}_{\mathrm{x}}, \mathrm{Mo}_{2} \mathrm{CT}_{\mathrm{x}}-500$, and $\beta-\mathrm{Mo}_{2} \mathrm{C}$. Reproduced with permission from Ref. [159]. Copyright 2019, American Chemical Society 
can be used as a stable catalyst to efficiently produce FA through $\mathrm{CO}_{2}$ hydrogenation, which is superior to the existing non-precious metals based catalysts. In this study, a durable Schottky heterojunction catalyst with low cost and high performance was designed, which opened up a new way for the application of doped molybdenum carbide in the field of hydrogenation reaction, and further promoted the research on carbon dioxide emission reduction. Except the Mo-based catalysts, Pajares et al. studied the property of $\mathrm{VC}_{\mathrm{x}}$ with different phases: stoichiometric $\mathrm{VC}$ phase and $\mathrm{C}$-deficient $\mathrm{V}_{8} \mathrm{C}_{7}$ phase. On the reverse water gas shift reaction, $\mathrm{V}_{8} \mathrm{C}_{7}$ showed higher $\mathrm{CO}_{2}$ conversion rate, $\mathrm{CO}$ selectivity, lower apparent activation energy and good chemical stability [160]. Besides as catalysts in gas molecular conversion, the TMCs can also be employed to sense dangerous gas. Sun et al. prepared a composite of one-dimensional $\mathrm{Ti}_{3} \mathrm{C}_{2} \mathrm{~T}_{\mathrm{x}}$ and one-dimensional $\mathrm{W}_{18} \mathrm{O}_{49}$ nanorods (as shown in Fig. 10a) [161]. Based on the special interface effect, the composite exhibits high responsiveness to acetone, and has ideal selectivity and long-term stability. Lee prepared layered $\mathrm{V}_{2} \mathrm{CT}_{\mathrm{x}}$ MXene on polyimide substrate by chemical exfoliation. The two-dimensional $\mathrm{V}_{2} \mathrm{CT}_{\mathrm{x}}$ MXene gas sensor shows ultra-low detection limit ( $2 \mathrm{ppm}$ ) for $\mathrm{H}_{2}$ at room temperature, which is better than other two-dimensional gas sensor materials reported at present (as shown in Fig. 10c-e) [161]. In a word, in both catalysis gas conversion and sensing gas, the interface of TMCs and gas molecular plays an important role [162], which could occupy the gas molecular and materials. More efforts should be focused on the interface and improve its occupied mechanism, thus enhancing the interaction.

\subsection{Energy Storage}

With the environmental crisis, developing energy storage such as battery and supercapacitor has been considered as an environment-friendly strategy. Different with black phosphorene, which has ultra-high diffusivity of $\mathrm{Li}$ along the zigzag direction and enhanced electrical conductivity after Li- intercalation [164, 165], TMCs with large specific surface area, good electrical conductivity and excellent cationic intercalation properties have been widely used as electrode materials in energy storage [166]. $\mathrm{Nb}_{2} \mathrm{C}$ and $\mathrm{V}_{2} \mathrm{C}$ show good reversible capacity, high cycle rate and stability, indicating that the rapid diffusion of $\mathrm{Li}$ between MXene layers has application prospects in the field of high power [167]. Pang et al. introduced a fluorine-free, simple and rapid method for synthesizing one-dimensional metal carbide nanowires based on three-dimensional $\mathrm{Nb}_{2} \mathrm{CT}$ MXene. The method can synthesize one-dimensional metal carbide nanowires in $\mathrm{HCl}$ electrolyte within $4 \mathrm{~h}$. It was found that MXene-based $\mathrm{Nb}_{2} \mathrm{CT}$ nanowires can maintain high stability at a fairly low overpotential $(236 \mathrm{mV})$, and as a water-based zinc-ion battery exhibiting the high power density $\left(420 \mathrm{~W} \mathrm{~kg}^{-1}\right)$ after 150 cycles [77]. V-based TMCs have better performance than many other TMCs and attracted much attention. $\mathrm{V}_{4} \mathrm{C}_{3}$ was used as the anode material of lithium-ion battery, demonstrating that $\mathrm{V}_{4} \mathrm{C}_{3}$ has high capacity, good rate performance and cycle performance. In the case of current density of $0.1 \mathrm{~A} \mathrm{~g}^{-1}, \mathrm{~V}_{4} \mathrm{C}_{3}$ can still provide a high specific capacity of $225 \mathrm{mAh} \mathrm{g}^{-1}$ after 300 charge-discharge cycles [168, 169]. Wang et al. prepared high purity $\mathrm{V}_{2} \mathrm{CT}_{\mathrm{x}}$ by a simple hydrothermal assistant method using the mixed solution of $\mathrm{NaF}$ and $\mathrm{HCl}$ as etchant, and studied the effects of reaction conditions, reaction time and reaction temperature on the reaction yield [137]. It was found that the reaction rate of this system is much faster than that of HF system, and the MAX phase can be etched in three days. At the same time, the electrochemical performance of lithium-ion battery as anode was studied, and it showed a high specific capacitance. When the current was $0.1 \mathrm{~A} \mathrm{~g}^{-1}$, the capacity of lithium-ion battery was $233 \mathrm{mAh} \mathrm{g}^{-1}$.

Through chemically etching and exfoliation, the asprepared $\mathrm{Nb}_{2} \mathrm{CT}_{\mathrm{x}}$ nanosheets can provide a high discharge capacity of $354 \mathrm{mAh} \mathrm{g}^{-1}$ at a current density of $0.05 \mathrm{~A} \mathrm{~g}^{-1}$. In addition, $\mathrm{Nb}_{2} \mathrm{CT}_{\mathrm{x}}$ has good cycle stability, where after 800 cycles at a high current density of $1.0 \mathrm{Ag}^{-1}$, the specific capacity is stable at $225 \mathrm{mAh} \mathrm{g}^{-1}$, indicating that $\mathrm{Nb}_{2} \mathrm{CT}_{\mathrm{x}}$ can be used as an anode material for LIBs [170]. Nano-NbC decorated N\&P-codoped trichoderma spore carbon was synthesized and exhibited an ultra-high rate performance (810 $\mathrm{mAhg}^{-1}$ at $5 \mathrm{C}$ ) and good cycle stability $\left(937.9 \mathrm{mAh} \mathrm{g}^{-1}\right.$ at $0.1 \mathrm{C}$ after 500 cycles) due to the high conductivity attributing to the synergistic effect [171]. Besides, nanocrystalline niobium carbide $(\mathrm{NbC})$ was used as an advanced intermediate layer material for $\mathrm{Li}-\mathrm{S}$ batteries. The $\mathrm{NbC}$ coating combines the anchoring effect of polysulfide (PS) with the advantages of high conductivity, which can effectively inhibit the electrochemical reaction of sulfur and the shuttle of PS. The NbC coating also has excellent cycling stability, the capacity decay rate after 1500 cycles is only $0.037 \%$ cycle $^{-1}$, and it has an ultra-high rate capability of up to $5 \mathrm{C}$, 
Table 4 Energy storage performance of transition metal carbides

\begin{tabular}{|c|c|c|c|c|c|c|c|}
\hline Sample & Prepare method & Structure & Application & Charge density & Performance & Retention rate & Refs \\
\hline $\mathrm{Ti}_{3} \mathrm{C}_{2} \mathrm{~T}_{\mathrm{x}}$ & Chemical exfoliation & Nanosheets & Na-ion battery & $0.5 \mathrm{C}$ & $103 \mathrm{mAh} \mathrm{g}^{-1}$ & $\begin{array}{l}85.8 \% \text { after } 500 \\
\text { cycles }\end{array}$ & [181] \\
\hline Titanium carbide & Chemical exfoliation & Nanorods & Li-ion battery & $1 \mathrm{C}$ & $843 \mathrm{mAh} \mathrm{g}^{-1}$ & $\begin{array}{l}98.78 \% \text { after } 250 \\
\text { cycles }\end{array}$ & [182] \\
\hline Porous- $\mathrm{Ti}_{3} \mathrm{C}_{2} \mathrm{~T}_{\mathrm{x}}$ & Chemical exfoliation & Nanosheets & Li-ion battery & $0.1 \mathrm{C}$ & $1250 \mathrm{mAh} \mathrm{g}^{-1}$ & N/A & [183] \\
\hline $\mathrm{V}_{2} \mathrm{CT}_{\mathrm{x}}$ & Chemical exfoliation & Few-layer nanosheets & Al-ion battery & $0.5 \mathrm{C}$ & $76 \mathrm{mAh} \mathrm{g}^{-1}$ & $\begin{array}{l}96.6 \% \text { after } 100 \\
\text { cycles }\end{array}$ & [173] \\
\hline $\mathrm{Nb}_{4} \mathrm{C}_{3} \mathrm{~T}_{\mathrm{x}}$ & Chemical exfoliation & Layered structure & Li-ion battery & $5 \mathrm{C}$ & $380 \mathrm{mAh} \mathrm{g}^{-1}$ & $\begin{array}{l}84.2 \% \text { after } 1000 \\
\text { cycles }\end{array}$ & [184] \\
\hline $\mathrm{Co}_{3} \mathrm{ZnC}$ & TPR & Microspheres & Li-ion battery & $0.5 \mathrm{C}$ & $908 \mathrm{mAh} \mathrm{g}^{-1}$ & $\begin{array}{l}67.0 \% \text { after } 300 \\
\text { cycles }\end{array}$ & [185] \\
\hline $\mathrm{TiO}_{2} / \mathrm{Ti}_{3} \mathrm{C}_{2} \mathrm{~T}_{\mathrm{x}}$ & Self-assembly & 2D heterostructures & Li-ion battery & $0.25 \mathrm{C}$ & $277 \mathrm{mAh} \mathrm{g}^{-1}$ & $\begin{array}{l}75.5 \% \text { after } 200 \\
\text { cycles }\end{array}$ & [186] \\
\hline $\mathrm{Nb}_{2} \mathrm{O}_{5} @ \mathrm{Nb}_{4} \mathrm{C}_{3} \mathrm{~T}_{\mathrm{x}}$ & Chemical exfoliation & Layered architecture & Li-ion battery & $0.25 \mathrm{C}$ & $208 \mathrm{mAh} \mathrm{g}^{-1}$ & $94 \%$ after 400 cycles & [187] \\
\hline $\mathrm{Fe}_{3} \mathrm{C} @ \mathrm{~N}-\mathrm{C}$ & Calcinate & $\begin{array}{l}\text { Frogspawn-like } \\
\text { architecture }\end{array}$ & Li-S battery & $0.5 \mathrm{C}$ & $586 \mathrm{mAh} \mathrm{g}^{-1}$ & $\begin{array}{l}99.92 \% \text { after } 400 \\
\text { cycles }\end{array}$ & [188] \\
\hline $\mathrm{W}_{2} \mathrm{C}$ NPs-CNFs & TPR & Nanoparticles & Li-S battery & $1 \mathrm{C}$ & $605 \mathrm{mAh} \mathrm{g}^{-1}$ & $\begin{array}{l}99.4 \% \text { after } 500 \\
\text { cycles }\end{array}$ & [189] \\
\hline $\mathrm{TiC}$ & Biotemplate method & Nanoflakes & Supercapacitor & $5 \mathrm{mV} \mathrm{s}^{-1}$ & $276.1 \mathrm{~F} \mathrm{~g}^{-1}$ & $\begin{array}{l}94 \% \text { after } 1000 \\
\text { cycles }\end{array}$ & [190] \\
\hline $\mathrm{Ti}_{3} \mathrm{C}_{2} \mathrm{~T}_{\mathrm{x}}$ & Directly annealing & Nanosheets & Supercapacitor & $0.5 \mathrm{~A} \mathrm{~g}^{-1}$ & $442 \mathrm{~F} \mathrm{~g}^{-1}$ & $\begin{array}{l}95.4 \% \text { after } 5000 \\
\text { cycles }\end{array}$ & [191] \\
\hline $\mathrm{TaC} / \mathrm{C}$ & Laser ablation & Nanospheres & Supercapacitor & $1 \mathrm{Ag}^{-1}$ & $223 \mathrm{~F} \mathrm{~g}^{-1}$ & $\begin{array}{l}94 \% \text { after } 5000 \\
\text { cycles }\end{array}$ & [192] \\
\hline $\mathrm{MoS}_{2} / \mathrm{Ti}_{3} \mathrm{C}_{2}$ & $\begin{array}{l}\text { Hydrothermal syn- } \\
\text { thesis }\end{array}$ & 2D heterostructures & Supercapacitor & $1 \mathrm{Ag}^{-1}$ & $386.7 \mathrm{~F} \mathrm{~g}^{-1}$ & $\begin{array}{l}91.1 \% \text { after } 20,000 \\
\text { cycles }\end{array}$ & [193] \\
\hline $\mathrm{MnO}_{2}-\mathrm{Mo}_{2} \mathrm{C} \mathrm{NFs}$ & Electrospinning & Nanoflakes & Supercapacitor & $0.1 \mathrm{~A} \mathrm{~g}^{-1}$ & $430 \mathrm{Fg}^{-1}$ & $\begin{array}{l}96.1 \% \text { after } 3000 \\
\text { cycles }\end{array}$ & [194] \\
\hline
\end{tabular}

and the area capacity under high sulfur load is as high as 3.6

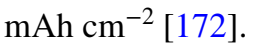

Compared with commercial lithium-ion batteries, rechargeable aluminum batteries have the advantages of safety, cheaper and higher energy density. Table 4 summarizes the recent TMCs-based energy storage development. However, due to the high charge density of $\mathrm{Al}^{3+}$ ions and their strong interaction with the host lattice, few $\mathrm{Al}^{3+}$ ions can reversibly intercalate these cathode materials. Vahid et al. reported a rechargeable Al-battery based on $2 \mathrm{D}$ vanadium carbide $\left(\mathrm{V}_{2} \mathrm{CT}_{\mathrm{x}}\right)$ cathode. The mechanism of charge storage is the reversible intercalation of $\mathrm{Al}^{3+}$ ions between $\mathrm{V}_{2} \mathrm{CT}_{\mathrm{x}}$ layers. The results show that the electrochemical performance can be significantly improved by converting $\mathrm{V}_{2} \mathrm{CT}_{\mathrm{x}}$ particles into multilayer films. The specific capacity of $\mathrm{V}_{2} \mathrm{CT}_{\mathrm{x}}$ electrode is more than $300 \mathrm{mAg}^{-1} \mathrm{Pt}$, and it has higher discharge rate and higher discharge potential, which is one of the best cathode materials for aluminum battery reported at present [173].

Like the $\mathrm{MnO}_{2}$, etc., metal oxides which have shown high electrochemical property resulting in high performance electrochemical capacitors [174, 175], the TMCs have also been used as electrode in supercapacitor, which has high power density [176-179]. Xin et al. predicted the application in supercapacitors through ab initio density functional theory considering its quantum capacitance and work function of $\mathrm{Nb}_{\mathrm{n}+1} \mathrm{C}_{\mathrm{n}} \mathrm{T}_{\mathrm{x}}$. It was found that the niobium carbide with free functional group is suitable for positive electrode, while niobium carbide with functional group has better performance as negative electrode in supercapacitor, showing its broad application prospects in the field of supercapacitor electrode materials. The theoretical quantum capacitances of the positive and negative electrodes are 1828.4 and 1091.1 $\mathrm{F} \mathrm{g}^{-1}$, respectively [75]. Guan et al. demonstrated that the 
specific capacitance of chemically exfoliated $\mathrm{V}_{2} \mathrm{CT}_{\mathrm{x}}$ MXene can reach up to $164 \mathrm{~F} \mathrm{~g}^{-1}$ and its specific capacitance retention rate can reach $90 \%$ after 10,000 cycles at $5 \mathrm{Ag}^{-1}$ [74]. Wang et al. prepared $\mathrm{V}_{2} \mathrm{C}$ layered by carbon nanotubes and studied its electrochemical performance as the electrode of $\mathrm{Zn}$ ion supercapacitor, which has a high capacity of $190.2 \mathrm{~F}$ $\mathrm{g}^{-1}$ at $0.5 \mathrm{Ag}^{-1}$ and excellent cycle stability [139]. Besides, the used electrolyte also significantly affects its supercapacitance; the maximum specific capacitances of $\mathrm{V}_{2} \mathrm{CT}_{\mathrm{x}}$ MXene in $1 \mathrm{M} \mathrm{H}_{2} \mathrm{SO}_{4}, 1 \mathrm{M} \mathrm{KOH}$ and $1 \mathrm{M} \mathrm{MgSO}_{4}$ solutions are 487,184 and $225 \mathrm{~F} \mathrm{~g}^{-1}$, respectively, which are the highest among similar micron TMCs electrodes reported [180]. Using seawater as the electrolyte, the supercapacitor based on $\mathrm{V}_{2} \mathrm{CT}_{\mathrm{x}}$ MXene has a volume specific capacitance of 317.8 $\mathrm{F} \mathrm{cm}^{-3}$ at $0.2 \mathrm{~A} \mathrm{~g}^{-1}$ and its capacitance retention rate is $8.1 \%$ after 5000 cycles [72]. The supercapacitance of bimetallic TMCs has also been studied. Through studying the influence of ratio of Mo and $\mathrm{V}$ in bimetallic MXene, it was found that $\mathrm{Mo}_{2.7} \mathrm{~V}_{1.3} \mathrm{C}_{3}$ has the highest volume capacitance $\left(860 \mathrm{~F} \mathrm{~cm}^{-3}\right)$ and high conductivity $\left(830 \mathrm{~S} \mathrm{~cm}^{-1}\right)$ at room temperature, suggesting that it was able to further optimize the performance by adjusting the element [78].

\subsection{Optoelectronic Devices}

The unique electronic structure and properties of TMCs, such as the high carrier concentration and high transmittance, would lead an enhanced interaction between phonon and matter, resulting in high photoresponse. Comparatively, the Ti-based MTCs photodetectors have got more investigated not only being employed as transparent electrode, but also being employed as reasonable materials in junctionbased photodetector. Significantly, due to the tunable work function by modulating its surface terminated group, the efficiency of junction-based photodetector could be easily improved. It was found that the MXene coated leaf vein network has a high transmittance (about 90\%) and low square resistance $\left(3 \Omega \mathrm{sq}^{-1}\right.$ ). The results show that the work function of the MXene electrode can be adjusted by changing the terminal atoms. The MXene electrode and electrospun $\mathrm{TiO}_{2}$ film were integrated to construct a translucent UV photodetector, which has high UV detection performance, excellent flexibility and stability, and can withstand 1000 bending cycles $[195,196]$. Yang et al. fabricated an InSe photodetector using $\mathrm{Ti}_{2} \mathrm{CT}_{\mathrm{x}}$ as the electrodes, as shown in
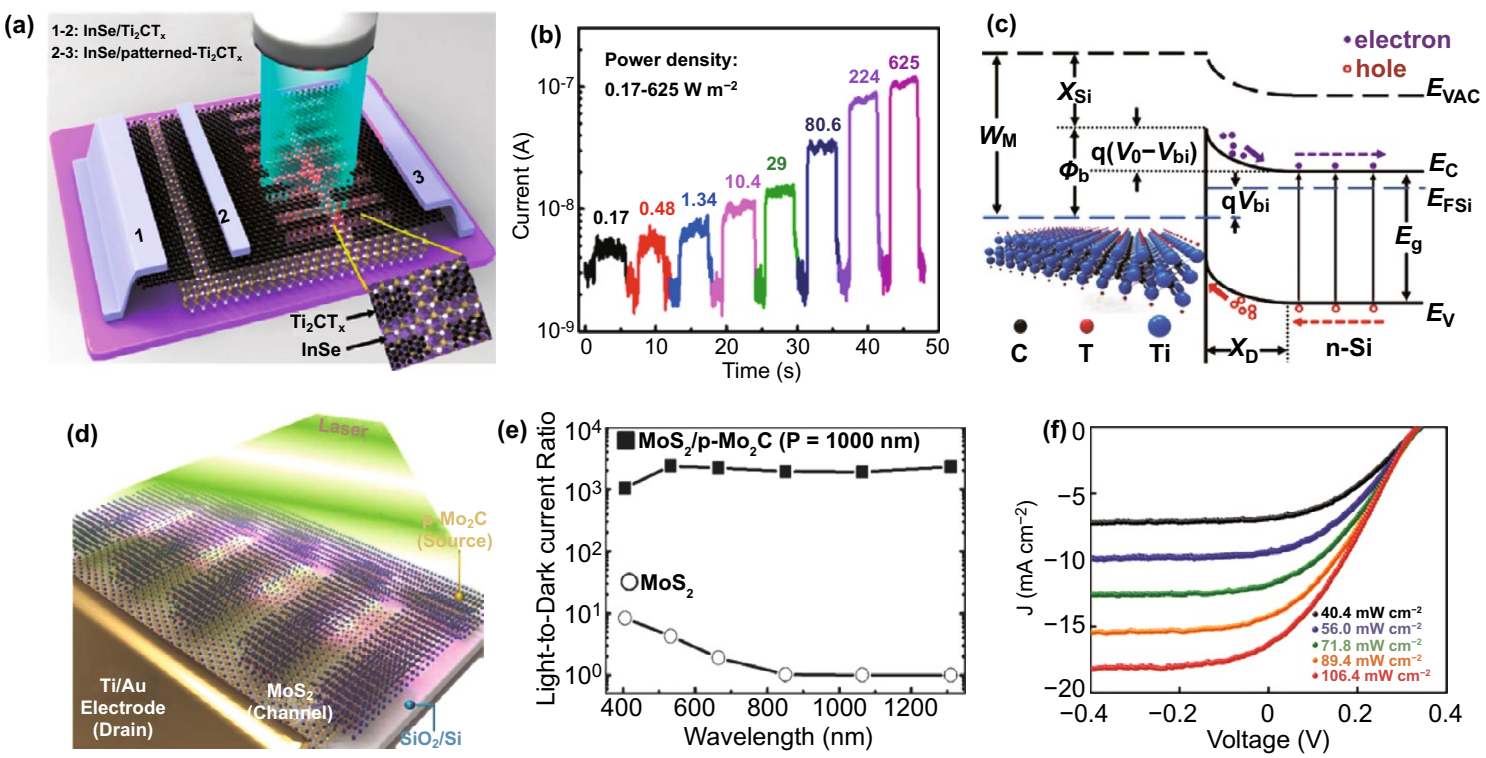

Fig. 11 Photoelectrical property of TMCs. a Schematic of unpatterned and patterned $\mathrm{InSe} / \mathrm{Ti}_{2} \mathrm{CT}_{\mathrm{x}}$ photodetectors. b Photoresponse curves of patterned InSe/ $\mathrm{Ti}_{2} \mathrm{CT}_{\mathrm{x}}$ avalanche photodetector under different illumination densities. Reproduced with permission from Ref. [197]. Copyright 2019, American Chemical Society. c Energy band diagram of $\mathrm{Ti}_{3} \mathrm{C}_{2} \mathrm{~T}_{\mathrm{x}} / \mathrm{n}$-Si Schottky junction upon illumination [199]. d Schematic figure of photodetector device with $\mathrm{MoS}_{2} / \mathrm{p}-\mathrm{Mo}_{2} \mathrm{C}$ hybrid structure under illumination. e $\mathrm{I}_{\mathrm{D}}-\mathrm{V}_{\mathrm{G}}$ curves of photodetector device with $\mathrm{MoS}_{2} / \mathrm{p}-\mathrm{Mo}_{2} \mathrm{C}$ hybrid structure under illumination with various wavelengths. Reproduced with permission from Ref. [201]. Copyright 2019, WILEY-VCH. f J-V curves of $\mathrm{Ti}_{3} \mathrm{C}_{2} \mathrm{~T}_{\mathrm{x}} / \mathrm{n}$-Si heterostructure device under various energy density illuminations. Reproduced with permission from Ref. [199]. Copyright 2017, WILEY-VCH 
Fig. 11a, b. Because the $\mathrm{Ti}_{2} \mathrm{CT}_{\mathrm{x}}$ electrode produces avalanche carrier multiplication effect, the photodetector has excellent photoelectric performance. In addition, the pattern of the $\mathrm{Ti}_{2} \mathrm{CT}_{\mathrm{x}}$ electrode into a plasmonic grating structure can further enhance the light absorption, achieving a dark current as low as $3 \mathrm{nA}$, a responsivity as high as $1 \times 10^{5} \mathrm{~A}$ $\mathrm{W}^{-1}$, a high detection rate $\left(7.3 \times 10^{12}\right.$ Jones $)$ and a shorter light response time $(0.5 \mathrm{~ms})$ [197].

Combining $2 \mathrm{D} \mathrm{Ti}_{3} \mathrm{C}_{2} \mathrm{~T}_{\mathrm{x}}$ with perovskite through top-down technology, it was able to design a large-scale image sensor array consisting of 25 groups of 50 pixels. Due to the good work function matching between the $\mathrm{Ti}_{3} \mathrm{C}_{2} \mathrm{~T}_{\mathrm{x}}$ layer and the perovskite active layer, it is helpful to form an effective interfacial charge transfer. The energy level alignment and resonance enhancement of the composite system can optimize the near-infrared absorption of the composite system. The results show that the device has excellent broadband spectral response, a response rate of $84.77 \mathrm{~A} \mathrm{~W}^{-1}$, a specific detection rate of $3.22 \times 10^{12}$ Jones, a linear dynamic range up to $82 \mathrm{~dB}$ and a near-infrared image capture capability [198]. Kang prepared the vertically $\mathrm{Ti}_{3} \mathrm{C}_{2} \mathrm{~T}_{\mathrm{x}} / \mathrm{n}$-Si Schottky heterojunction (as shown in Fig. 11c, f) and demonstrated that it has an open-circuit voltage of $0.34 \mathrm{~V}$ and a shortcircuit current density of $12.9 \mathrm{~mA} \mathrm{~cm}^{-2}$ under $100 \mathrm{~mW} \mathrm{~cm}^{-2}$ illumination, an $\mathrm{I}_{\mathrm{ph}} / \mathrm{I}_{\mathrm{dark}}$ ratio of about $10^{5}$, a responsivity of $26.95 \mathrm{~mA} \mathrm{~W}^{-1}$, a response time of $0.84 \mathrm{~ms}$ and a recovery time of $1.67 \mathrm{~ms}$ [199].

Other TMCs-based photoelectronic effects have also been studied. It is found that the relaxation time of $\mathrm{Nb}_{2} \mathrm{C}$ nanosheets can be tunable in the range from 37.43 fs to 0.57 ps by optimizing its size. The layered $\mathrm{Nb}_{2} \mathrm{C}$ nanosheets have promising potential applications in broadband ultrafast photonics and near-infrared photonic devices [200]. Jeon et al. demonstrated that the chemical vapor deposition grown $\mathrm{MoS}_{2}$ film can be chemical converted to $\mathrm{Mo}_{2} \mathrm{C}$ film, as shown in Fig. 11d, e. Using the interface characteristics of $\mathrm{MoS}_{2}$ and $\mathrm{Mo}_{2} \mathrm{C}$, that is, effective hot carrier injection from $\mathrm{Mo}_{2} \mathrm{C}$ to $\mathrm{MoS}_{2}$, the photodetector has high sensitivity and spectral response performance. By adjusting the grating period (400 1000 nm) of $\mathrm{Mo}_{2} \mathrm{C}$, a broad-spectrum response of light $(655 \sim 1200 \mathrm{~nm})$ can be achieved. The results show that the photodetector has high responsivity $\left(\mathrm{R}>10^{3} \mathrm{~A} \mathrm{~W}^{-1}\right)$ and bright-dark current ratio $\left(>10^{2}\right)$ in a wide spectral range $(405 \sim 1310 \mathrm{~nm})$, which is similar with that of transition metal dichalcogenides [201-203].

\subsection{Medical Treatment}

Due to the well photoelectronic and photothermal property, the TMCs have also been well used in medical treatment. Jastrzebska et al. proved for the first time that the highly negative surface charge of niobium carbide can be basically transformed into a high positive charge by surface modification with poly L-lysine (PLL). The conversion of surface charge will enable niobium carbide to obtain important biological effects, such as targeting tumors and inducing programmed cell death in G0/G1 phase, which are the most ideal effects for the design of tumor targeting drugs. Significantly, the biocompatibility of PLL modified niobium carbide $\left(\mathrm{Nb}_{2} \mathrm{C}\right.$ and $\left.\mathrm{Nb}_{4} \mathrm{C}_{3}\right)$ is better than that of unmodified niobium carbide [51]. Furthermore, $\mathrm{Nb}_{2} \mathrm{C}$ modified by PVP has been proofed effectively eliminate mouse tumor xenografts in NIR-I and NIR-II bio-windows, as shown in Fig. 12. Two-dimensional $\mathrm{Nb}_{2} \mathrm{C}$ nanosheets have excellent photothermal conversion efficiency (36.4\% for NIRI, $45.65 \%$ for NIR-II), and good photothermal stability. In addition, $\mathrm{Nb}_{2} \mathrm{C}$ nanosheets also have unique enzyme-responsive biodegradability to human myeloperoxidase [204]. 2D $\mathrm{Nb}_{2} \mathrm{C}$ nanosheets have been demonstrated with excellent antioxidant properties and can effectively scavenge hydrogen peroxide, hydroxyl radicals and superoxide radicals. The polyvinylpyrrolidone (PVP) modifying would significantly improve its biocompatibility, resulting in an effective protective effect on the hematopoietic system, testis, small intestine and lung of $\gamma$-ray irradiated mice, in particular, the hematopoietic system. Experiments show that $\mathrm{Nb}_{2} \mathrm{C}$-PVP can be effectively eliminated by the liver and kidneys in mice after 14 days [205].

$\mathrm{V}_{2} \mathrm{C}$, as a photothermal agent with excellent photothermal conversion efficiency, has a great application prospects in the field of photothermal therapy. Zada et al. reported a new exfoliation method, that is, the parent phase MAX is intercalated and delaminated by algae extract, and $\mathrm{V}_{2} \mathrm{C}$ nanowires with complete structure and high NIR absorption capacity are obtained. Through characterization, the photothermal conversion efficiency of the prepared $\mathrm{V}_{2} \mathrm{C}$ nanosheets is as high as $48 \%$ [50]. Lin et al. used $\mathrm{HF}$ as an etchant to synthesize two-dimensional $\mathrm{Ta}_{4} \mathrm{C}_{3}$ by chemical exfoliation, and explored its application in the photothermal ablation of tumors in vivo. It was proved that the soybean phospholipid-modified $\mathrm{Ta}_{4} \mathrm{C}_{3}$ has good biocompatibility, excellent 
(a)
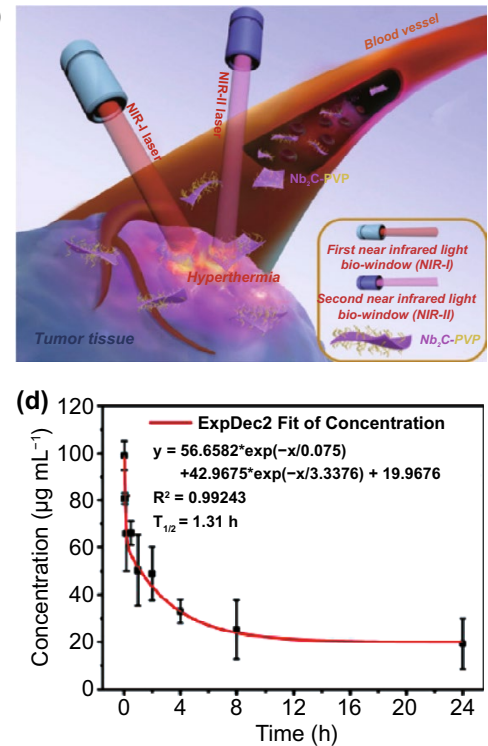
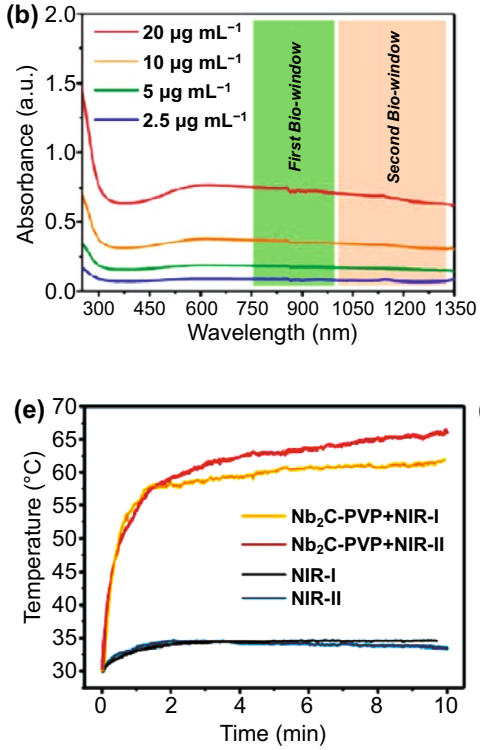
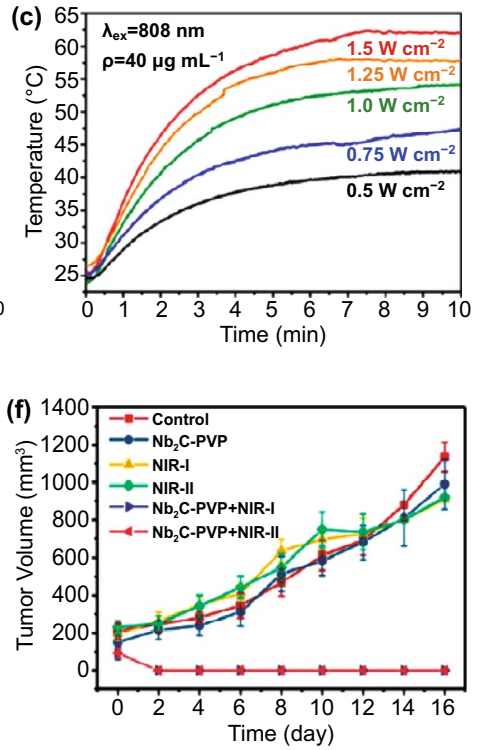

Fig. 12 Medical treatment based on $\mathrm{Nb}_{2} \mathrm{C}$. a Schematic diagram of two-dimensional $\mathrm{Nb}_{2} \mathrm{C}$ used in photothermal treatment of tumors. b S-NIR absorption spectra of different concentrations of $\mathrm{Nb}_{2} \mathrm{C} \mathrm{NSs}$ aqueous suspension. $\mathbf{c}$ Photothermal curve of $\mathrm{Nb}_{2} \mathrm{C}$ NSs aqueous suspension irradiated by $808 \mathrm{~nm}$ near-infrared light irradiation at different power densities. d Blood circulation lifetime of $\mathrm{Nb}_{2} \mathrm{C}-\mathrm{PVP}$ after intravenous injection into mice. e Temperature elevations at the tumor sites of 4T1-tumor-bearing mice in groups of NIR-I, NIR-II, Nb $2 \mathrm{C}-\mathrm{PVP}+\mathrm{NIR}-\mathrm{I}$ and $\mathrm{Nb}_{2} \mathrm{C}-\mathrm{PVP}+\mathrm{NIR}-\mathrm{II}$ during laser irradiation. f Time-dependent tumor growth curves after different treatments (control, Nb $2 \mathrm{C}-\mathrm{PVP}$ only, NIRI, NIR-II, $\mathrm{Nb}_{2} \mathrm{C}-\mathrm{PVP}+\mathrm{NIR}-\mathrm{I}$ and $\left.\mathrm{Nb}_{2} \mathrm{C}-\mathrm{PVP}+\mathrm{NIR}-\mathrm{II}\right)$. Reproduced with permission from Ref. [204]. Copyright 2017, American Chemical Society

performance of photothermal conversion (efficiency $\eta$ of $44.7 \%$ ) and in vitro/in vivo photothermal ablation of tumors [206]. The ionizing radiation generated by radiation accident will has a serious impact on exposed individuals. In addition, by functionalizing with $\mathrm{MnO}_{\mathrm{x}}$, the $\mathrm{Ta}_{4} \mathrm{C}_{3}$ is expected to be widely used in the field of tumor synergistic therapy based on its photothermal conversion performance, tumor microenvironment (TME)-responsive $\mathrm{T}_{1}$-weighted $\mathrm{MR}$ imaging capability and as the desirable contrast agents for PA imaging [35].

\subsection{Superconductor}

Due to the high carrier concentration and strong correlation system, the TMCs have been proved as a new superconductor member obtaining great attention. Using CVD-grown $\mathrm{Mo}_{2} \mathrm{C}$ as the model, $\mathrm{Xu}$ et al. demonstrated that the superconducting properties are consistent with the Berezinskii-Kosterlitz-Thouless behavior, and the superconducting properties depend on the crystal thickness, as shown in Fig. 13. Significantly, 2D $\mathrm{Mo}_{2} \mathrm{C}$ crystals also show strong magnetic anisotropy [90]. Furthermore, the graphene/2D $\alpha-\mathrm{Mo}_{2} \mathrm{C}$ structure has a superconducting transition phase diagram with multiple voltage steps in the transition zone, which is expected to be widely used in the field of highly transparent Josephson junction devices [95]. In addition, the influence of grain boundaries on the electron transport and superconductivity properties of $2 \mathrm{D}$ $\mathrm{Mo}_{2} \mathrm{C}$ were explored. In the normal state, with the increase in grain boundary inclination angle, the critical current decreases by 1 to 2 orders of magnitude during the transition from superconducting state to resistive state. In the superconducting state, crossing the grain boundary will lead to the critical current to decrease significantly [207]. Jin et al. prepared double-layer $\mathrm{Mo}_{2} \mathrm{Ga}_{2} \mathrm{C}$ by vacuum hot pressing. It was found that the $\mathrm{RT}$ thermal conductivity of $\mathrm{Mo}_{2} \mathrm{Ga}_{2} \mathrm{C}$ is $14.8 \pm 1.0 \mathrm{~W}(\mathrm{~m} \mathrm{~K})^{-1}$, the RT resistivity is $0.525 \pm 0.052 \mu \Omega \mathrm{m}$, and the Lorenz number is $2.22 \times 10^{-8}$ $\mathrm{W} \Omega \mathrm{K}^{-2}$. Importantly, $\mathrm{Mo}_{2} \mathrm{Ga}_{2} \mathrm{C}$ has superconductivity, and the superconducting transition temperature is $5.1 \mathrm{~K}$ [208]. Porrati used $\mathrm{Nb}\left(\mathrm{NMe}_{2}\right)_{3}(\mathrm{~N}-\mathrm{t}-\mathrm{Bu})$ as the precursor to prepare two-dimensional nanowires and self-supporting three-dimensional nanowires through focused electron beam-induced deposition (FEBID) and focused ion 

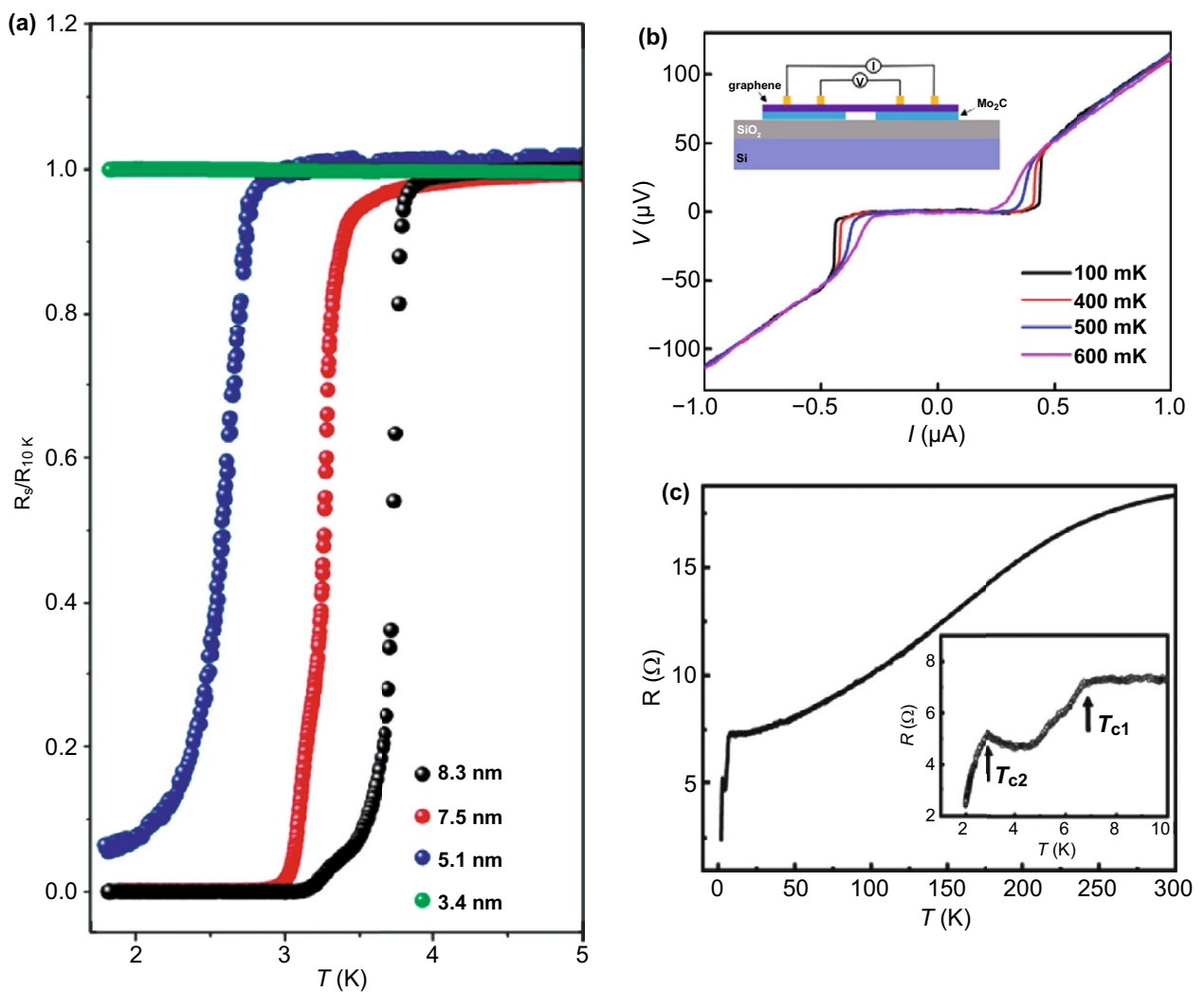

Fig. 13 Superconductivity characteristic of metal carbides. a Superconductivity characteristic of $\mathrm{Mo}_{2} \mathrm{C}$ flakes with different thickness. Reproduced with permission from Ref. [90]. Copyright 2015, Springer Nature. b Typical dc Josephson response of $\mathrm{Mo}_{2} \mathrm{C} / \mathrm{graphene} / \mathrm{Mo}_{2} \mathrm{C}$ junction taken at different temperatures. Reproduced with permission from Ref. [95]. Copyright 2017, American Chemical Society. c Superconductivity characteristic of NbC flakes. Reproduced with permission from Ref. [211]. Copyright 2020, American Physical Society

beam-induced deposition (FIBID). Electrical transmission measurements show that FEBID nanowires are insulated, FIBID two-dimensional nanowires have superconductivity at $\mathrm{T}_{\mathrm{c}} \approx 5 \mathrm{~K}$, and the critical superconducting temperature of self-supporting FIBID three-dimensional nanowires reaches $T_{c} \approx 11 \mathrm{~K}$. The results show that FIBID-NbC has broad application prospects in the preparation of superconducting nanowire single-photon detectors and quantum information processing, suggesting that the property is dependent on its dimensionality [209, 210].

\subsection{Other Potential Applications}

Similar with other 2D materials, such as graphene, phosphorene and transition metal dichalcogenides (e.g., $\mathrm{MoS}_{2}$ and $\mathrm{WS}_{2}$ ), which has shown great potential for thermal management and thermoelectric energy generation [212, 213], the thermal and thermoelectric properties of the TMCs, especially the MXene $\left(\mathrm{Ti}_{3} \mathrm{C}_{2} \mathrm{~T}_{\mathrm{x}}\right)$, have been studied. Due to its high electrical conductivity, TMCs have been usually composited in thermoelectric materials-based matrix. It was reported that compositing MXene $\left(\mathrm{Ti}_{3} \mathrm{C}_{2} \mathrm{~T}_{\mathrm{x}}\right)$ into $(\mathrm{Bi}, \mathrm{Sb})_{2} \mathrm{Te}_{3}$ matrix can simultaneously improve power factor and reduce thermal conductivity. Under a temperature gradient of $237 \mathrm{~K}$, the thermoelectric conversion efficiency reached a record of $7.8 \%$ [214]. Hong et al. reported the sub-nano ion channel based on 2D-TMCs, which can convert external temperature changes into electrical signals through the preferential diffusion of cations under a thermal gradient. Based on the photothermal conversion of MXenes, the $\mathrm{Ti}_{3} \mathrm{C}_{2} \mathrm{~T}_{\mathrm{x}}$ ion channel can capture the diffusion potential across the nanochannel under the axial temperature gradient of the light drive and exhibit the photothermoelectric ionic response of $1 \mathrm{mV} \mathrm{K}^{-1}$ [215].

Recently, TMCs have also been used to fabricate nanofiltration membranes due to its uniform nanopores. The TMCs-based nanofiltration membranes show extraordinary 
molecular separation performance. Kim et al. reported a slot-die coating method to prepare large-area $\mathrm{Ti}_{3} \mathrm{C}_{2} \mathrm{~T}_{\mathrm{x}}$ MXene. The $\mathrm{Ti}_{3} \mathrm{C}_{2} \mathrm{~T}_{\mathrm{x}}$ membrane exhibits excellent nanofiltration performance, which deliver a water permeability of $190 \mathrm{LMH} / \mathrm{bar}$ and a molecular weight cutoff rate of $269 \mathrm{Da}$ [216]. Stable interlayer space is the key factor to improve ion selectivity. Wang et al. proposed a strategy to stabilize $\mathrm{Ti}_{3} \mathrm{C}_{2} \mathrm{~T}_{\mathrm{x}}$ layered structure through alginate hydrogel pillars. The membrane has good permeation cutoff and screening performance for valence cations. Moreover, its excellent $\mathrm{H}^{+} / \mathrm{Fe}^{2+}$ selectivity makes this membrane promising as an ion-exchange membrane. Recently, the $\mathrm{Ti}_{3} \mathrm{C}_{2} \mathrm{~T}_{\mathrm{x}}$ stabilized by the alginate hydrogel pillars with the same d-spacing has $100 \% \mathrm{Na}_{2} \mathrm{SO}_{4}$ rejection and high water permeability [217]. Xu et al. developed a new way to use MXene nanosheets to overcome the trade-off limitation of membrane permeability and salt selectivity. The thin-film composite nanofiltration membranes have a permeability of $45.7 \mathrm{~L} \mathrm{~m}^{-2} \mathrm{~h}^{-1} \mathrm{bar}^{-1}$, and a $\mathrm{Na}_{2} \mathrm{SO}_{4}$ removal rate of $96 \%$ [218].

Due to its high electrical conductivity and high light adsorption, TMCs have also been used in electromagnetic shielding. Rajavel et al. prepared a flexible few-layer $\mathrm{Ti}_{3} \mathrm{C}_{2} \mathrm{~T}_{\mathrm{x}}$ film. At a thickness of $6 \mu \mathrm{m}$, the X-band conductivity is about $3669 \pm 33 \mathrm{~S} \mathrm{~m}^{-1}$, and the electromagnetic interference shielding efficiency is $31.97 \mathrm{~dB}$. It has also been demonstrated that through controlling the inherent defects, it was able to adjust the electromagnetic shielding performance of few-layer $\mathrm{Ti}_{3} \mathrm{C}_{2} \mathrm{~T}_{\mathrm{x}}$ [219]. Aïssa et al. prepared a twodimensional $\mathrm{Ti}_{3} \mathrm{C}_{2} \mathrm{~T}_{\mathrm{x}}$ MXene/GNPs composite film using electrohydrodynamic atomization deposition technique. The $\mathrm{Ti}_{3} \mathrm{C}_{2} \mathrm{~T}_{\mathrm{x}}$ MXene/GNP film with the thickness of $1.75 \mathrm{~mm}$ shows excellent electromagnetic shielding performance, with an electromagnetic interference absorbance of about $64 \mathrm{~dB}$ [220]. Further optimizing the fabrication of TMCs and designing the device could improve its performance.

Hydrogen energy is one of the most promising clean energy sources. However, the current hydrogen storage materials still not very well satisfy the industrial requirement. Due to the higher surface activity and larger surface area, recently, the hydrogen storage performance of the incomplete etched $\mathrm{Ti}_{2} \mathrm{CT}_{\mathrm{x}}$ MXene film has been investigated, and the hydrogen storage mechanism has been discussed [221]. It was found that the $\mathrm{Ti}_{2} \mathrm{CT}_{\mathrm{x}}$ film has excellent hydrogen storage efficiency, where $8.8 \mathrm{wt} \%$ hydrogen is completely absorbed at room temperature under the environment of
60 bar $\mathrm{H}_{2}$. The small interlayer distance of $\mathrm{Ti}_{2} \mathrm{CT}_{\mathrm{x}}$ MXene and the $\mathrm{F}$ functional group brought by etching are the key to its hydrogen storage, which will induce weak chemical adsorption assisted by nano-effects. Noh et al. used a twostep method to synthesize palladium nanoparticle-decorated multilayer $\mathrm{Ti}_{3} \mathrm{C}_{2} \mathrm{~T}_{\mathrm{x}}$ MXene $\left(\mathrm{Pd}-\mathrm{Ti}_{3} \mathrm{C}_{2} \mathrm{~T}_{\mathrm{x}}\right)$ [222]. It was found that $\mathrm{Pd}-\mathrm{Ti}_{3} \mathrm{C}_{2} \mathrm{~T}_{\mathrm{x}}$ exhibits typical hydrogen storage capacity at room temperature and $77 \mathrm{~K}$. Zhu et al. self-assembled $\mathrm{Ni}$ nanoparticles on $\mathrm{Ti}_{3} \mathrm{C}_{2}$ MXene obtained by etching and then composited with $\mathrm{MgH}_{2}$ by ball milling. The $\mathrm{MgH}_{2}+\mathrm{Ni} @$ Ti-MX composite material can absorb $5.4 \mathrm{wt} \% \mathrm{H}_{2}$ at $125^{\circ} \mathrm{C}$ for $25 \mathrm{~s}$, and release $5.2 \mathrm{wt} \% \mathrm{H}_{2}$ at $250{ }^{\circ} \mathrm{C}$ for $15 \mathrm{~min}$ [223]. Although the TMCs materials already exhibit the potential application in the hydrogen storage, further study including the correlation between the materials structure and its performance is still unclear and more efforts still need.

\section{Conclusions and Perspectives}

This article reviews the progress in the structure, properties, applications and synthesis methods of transition metal carbides represented by niobium carbide, vanadium carbide, molybdenum carbide and titanium carbide. Firstly, the different phase structures of four typical transition metal carbides are introduced. Different TMCs have the basic phase of NaCl-type cubic phase, and all group IV and $\mathrm{V}$ TCMs have $\mathrm{M}_{6} \mathrm{C}_{5}$ phase. Under different synthesis processes, carbon atoms and vacancies are rearranged to varying degrees, resulting in a variety of stable phase structures of transition metal carbides. Because the existence of different phase compositions gives transition metal carbides rich and diverse properties, they have been researched and developed in different fields. Based on their outstanding electronic, mechanical, magnetic, electrochemical, optical properties and atomic-level thickness, TMCs films have been applied in the fields of catalysis, energy storage, optoelectronics, biomedicine and superconductivity. The hydrogen adsorption on the surface of transition metal end carbides is significantly enhanced, which makes it good catalyst for electrocatalytic and photocatalytic hydrogen evolution. Due to the large specific surface area, good conductivity and excellent cation intercalation performance, TMCs have potential application in LIBs anode materials. Due to the rectifying electric shock with Schottky barrier height and internal electric field, 
and higher responsivity and quantum efficiency than $\mathrm{Au}$, $\mathrm{Ti}_{3} \mathrm{C}_{2} \mathrm{~T}_{\mathrm{x}}$ photodetector has better dynamic range and detection rate. The surface charge of $\mathrm{Nb}_{2} \mathrm{C}$ and $\mathrm{Nb}_{4} \mathrm{C}_{3}$ is transformed into high positive charge by surface modification, which has important biological effect on tumor targeting. TMC films such as $\alpha-\mathrm{Mo}_{2} \mathrm{C}$ and $\mathrm{NbC}$ have superconducting properties, and the critical superconducting temperature can be further increased by changing the synthesis process and adjusting the surface functional groups.

At present, the main ways to synthesize TMCs films include chemical exfoliation, chemical vapor deposition, temperatureprogrammed reduction and magnetic sputtering. In recent years, MXenes prepared by chemical exfoliation have been developed rapidly, and its layer structure similar to accordion has brought a wealth of applications. The TMCs synthesized by chemical vapor deposition have high purity and are easy to be uniformly doped. Temperature-programmed reduction provides a way for the synthesis of carbides with high synthesis temperature. Magnetic sputtering synthetic carbide film has the characteristics of high film formation rate, low substrate temperature and good film adhesion.

Although TMCs films have shown great potential in different fields, there are still some challenges in future applications. First of all, the current synthesis methods of TMC films still face some limitations. For example, it is difficult to synthesize the parent phase MAX of MXene, and many MXenes have not been successfully prepared by chemical exfoliation because of the inability to synthesize the stable MAX phase. Chemical vapor deposition has limitations in the preparation of large-size carbide films. Therefore, new methods for synthesizing TMCs have yet to be explored. Secondly, the theoretical mechanism of some characteristics of TMC films in the application field is still unclear. For example, in the field of energy storage, the ion dynamics and charge storage mechanism between carbide films are unclear. Thirdly, the improvement of electrochemical, mechanical and thermal stability of TMCs remains a topic of future research. It is worth mentioning that the research fields of TMCs films are full of opportunities and challenges, and there is still great application potential to be tapped in different fields. In the foreseeable future, transition metal carbide materials will play an increasingly important role in solving various global challenges.

Acknowledgements This research was supported by grants from by the National Natural Science Foundation of China (52002254),
Sichuan Science and Technology Program (2020YJ0262, 2021YFH0127), Chunhui plan of Ministry of Education of China, Fundamental Research Funds for the Central Universities, China (YJ201893), State Key Lab of Advanced Metals and Materials, China (Grant No. 2019-Z03), the Danish National Research Foundation and EU H2020RISE 2016-MNR4S Cell project.

Open Access This article is licensed under a Creative Commons Attribution 4.0 International License, which permits use, sharing, adaptation, distribution and reproduction in any medium or format, as long as you give appropriate credit to the original author(s) and the source, provide a link to the Creative Commons licence, and indicate if changes were made. The images or other third party material in this article are included in the article's Creative Commons licence, unless indicated otherwise in a credit line to the material. If material is not included in the article's Creative Commons licence and your intended use is not permitted by statutory regulation or exceeds the permitted use, you will need to obtain permission directly from the copyright holder. To view a copy of this licence, visit http://creativecommons.org/licenses/by/4.0/.

\section{References}

1. V. Nicolosi, M. Chhowalla, M.G. Kanatzidis, M.S. Strano, J.N. Coleman, Liquid exfoliation of layered materials. Science 340, 1226419 (2013). https://doi.org/10.1126/science. 1226419

2. A.K.G.K.S. Novoselov, S.V. Morozov, D. Jiang, Y. Zhang, S.V. Dubonos et al., Electric field effect in atomically thin carbon films. Science 306, 666-669 (2004). https://doi.org/ 10.1126/science. 1102896

3. L. Lin, B. Deng, J. Sun, H. Peng, Z. Liu, Bridging the gap between reality and ideal in chemical vapor deposition growth of graphene. Chem. Rev. 118, 9281-9343 (2018). https://doi.org/10.1021/acs.chemrev.8b00325

4. Z.-G. Wang, Y.-F. Chen, P.-J. Li, X. Hao, J.-B. Liu et al., Flexible graphene-based electroluminescent devices. ACS Nano 5, 7149-7154 (2011). https://doi.org/10.1021/nn201 8649

5. X. Wang, A. Jones, K. Seyler, V. Tran, Y. Jia et al., Highly anisotropic and robust excitons in monolayer black phosphorus. Nat. Nanotech. 10, 517-521 (2014). https://doi.org/10. 1038/nnano.2015.71

6. Z.W. Seh, K.D. Fredrickson, B. Anasori, J. Kibsgaard, A.L. Strickler et al., Two-dimensional molybdenum Carbide (MXene) as an efficient electrocatalyst for hydrogen evolution. ACS Energy Lett. 1, 589-594 (2016). https://doi.org/10. 1021/acsenergylett.6b00247

7. W. Yuan, L. Cheng, Y. An, H. Wu, N. Yao et al., MXene nanofibers as highly active catalysts for hydrogen evolution reaction. ACS Sustain. Chem. Eng. 6, 8976-8982 (2018). https://doi.org/10.1021/acssuschemeng.8b01348

8. P. Zhang, F. Wang, M. Yu, X. Zhuang, X. Feng, Two-dimensional materials for miniaturized energy storage devices: 
from individual devices to smart integrated systems. Chem. Soc. Rev. 47, 7426-7451 (2018). https://doi.org/10.1039/ C8CS00561C

9. P. Miró, M. Audiffred, T. Heine, An atlas of two-dimensional materials. Chem. Soc. Rev. 43, 6537-6554 (2014). https:// doi.org/10.1039/C4CS00102H

10. Z. Wang, J. Liu, X. Hao, Y. Wang, Y. Chen et al., Investigating the stability of molecule doped graphene field effect transistors. New J. Chem. 43, 15275-15279 (2019). https:// doi.org/10.1039/C9NJ03537K

11. Z. Wang, X. Xiong, J. Li, M. Dong, Screening fermi-level pinning effect through van der waals contacts to monolayer $\mathrm{MoS}_{2}$. Mater. Today Phys. 16, 100290 (2021). https://doi.org/ 10.1016/j.mtphys.2020.100290

12. A. Ayari, E. Cobas, O. Ogundadegbe, M.S. Fuhrer, Realization and electrical characterization of ultrathin crystals of layered transition-metal dichalcogenides. J. Appl. Phys. 101, 014507 (2007). https://doi.org/10.1063/1.2407388

13. L.H. Li, Y. Chen, G. Behan, H. Zhang, M. Petravic et al., Large-scale mechanical peeling of boron nitride nanosheets by low-energy ball milling. J. Mater. Chem. 21, 11862-11866 (2011). https://doi.org/10.1039/C1JM11192B

14. M. Özdemir, C. Çekil, Ö. Atasever, B. Ozdemir, Z. Yarar et al., Electron transport properties of silicene: Intrinsic and dirty cases with screening effects. J. Mol. Struct. 1199, 126878 (2019). https://doi.org/10.1016/j.molstruc.2019. 126878

15. Z. Wang, Q. Li, F. Besenbacher, M. Dong, Facile synthesis of single crystal $\mathrm{PtSe}_{2}$ nanosheets for nanoscale electronics. Adv. Mater. 28, 10224-10229 (2016). https://doi.org/10. 1002/adma.201602889

16. M. Naguib, M. Kurtoglu, V. Presser, J. Lu, J. Niu et al., Two-dimensional nanocrystals produced by exfoliation of $\mathrm{Ti}_{3} \mathrm{AlC}_{2}$. Adv. Mater. 23, 4248-4253 (2011). https://doi. org/10.1002/adma.201102306

17. R.B. Levy, M. Boudart, Platinum-like behavior of tungsten carbide in surface catalysis. Science 181, 547 (1973). https://doi.org/10.1126/science.181.4099.547

18. J. Claridge, A. York, A. Brungs, C. Márquez-Alvarez, J. Sloan et al., New catalysts for the conversion of methane to synthesis gas: molybdenum and tungsten carbide. J. Catal. 180, 85-100 (1998). https://doi.org/10.1006/jcat.1998.2260

19. J. Kitchin, J. Nørskov, M. Barteau, J. Chen, Trends in the chemical properties of early transition metal carbide surfaces: A density functional study. Catal. Today 105, 66-73 (2005). https://doi.org/10.1016/j.cattod.2005.04.008

20. N.C. Frey, A. Bandyopadhyay, H. Kumar, B. Anasori, Y. Gogotsi et al., Surface-engineered MXenes: Electric field control of magnetism and enhanced magnetic anisotropy. ACS Nano 13, 2831-2839 (2019). https://doi.org/10.1021/ acsnano.8b09201

21. M. Ashton, K. Mathew, R.G. Hennig, S.B. Sinnott, Predicted surface composition and thermodynamic stability of mxenes in solution. J. Phys. Chem. C 120, 3550-3556 (2016). https://doi.org/10.1021/acs.jpcc.5b11887
22. Z. Kan, M. Wen, Q. Meng, C. Hu, X. Li et al., Effects of substrate bias voltage on the microstructure, mechanical properties and tribological behavior of reactive sputtered niobium carbide films. Surf. Coat. Tech. 212, 185-191 (2012). https://doi.org/10.1016/j.surfcoat.2012.09.046

23. N. Nedfors, O. Tengstrand, E. Lewin, A. Furlan, P. Eklund et al., Structural, mechanical and electrical-contact properties of nanocrystalline-NbC/amorphous-C coatings deposited by magnetron sputtering. Surf. Coat. Tech. 206, 354-359 (2011). https://doi.org/10.1016/j.surfcoat.2011. 07.021

24. E.V. Pechen, S.I. Krasnosvobodtsev, N.P. Shabanova, E.V. Ekimov, A.V. Varlashkin et al., Tunneling and criticalmagnetic-field study of superconducting $\mathrm{NbC}$ thin films. Physica C 235-240, 2511-2512 (1994). https://doi.org/10. 1016/0921-4534(94)92476-7

25. M.G. Kostenko, A.V. Lukoyanov, A.A. Valeeva, Vacancy ordered structures in a nonstoichiometric niobium carbide $\mathrm{NbC}_{0.83}$. Mendeleev Commun. 29, 707-709 (2019). https:// doi.org/10.1016/j.mencom.2019.11.037

26. J. Smith, O. Carlson, R. de Avillez, ChemInform abstract: The niobium-carbon system. ChemInform (1987). https:// doi.org/10.1002/chin.198736371

27. M. Cuppari, S. Santos, Physical properties of the NbC carbide. Metals 6, 250 (2016). https://doi.org/10.3390/met61 00250

28. V. Lipatnikov, W. Lengauer, P. Ettmayer, E. Keil, G. Groboth et al., Effects of vacancy ordering on structure and properties of vanadium carbide. J. Alloys Compounds 261, 192-197 (1997). https://doi.org/10.1016/S0925-8388(97) 00224-7

29. L.W. Shacklette, W.S. Williams, Influence of order-disorder on the electrical resistivity of vanadium carbide. Phys. Rev. B (1973). https://doi.org/10.1103/PhysRevB.7.5041

30. X. Chong, Y. Jiang, R. Zhou, J. Feng, Electronic structure, mechanical and thermal properties of V-C binary compounds. RSC Adv. 4, 44959-44971 (2014). https://doi.org/ 10.1039/C4RA07543A

31. V.N. Lipatnikov, A.I. Gusev, P. Ettmayer, W. Lengauer, Phase transformations in non-stoichiometric vanadium carbide. J. Phys. Condensed Matter 11, 163-184 (1999). https://doi.org/10.1088/0953-8984/11/1/014

32. X.S. Fan, Z. Yang, Z. Yuduo, H. Che, Evaluation of vanadium carbide coatings on AISI H13 obtained by thermoreactive deposition/diffusion technique. Surf. Coat. Tech. 205, 641-646 (2010). https://doi.org/10.1016/j.surfcoat. 2010.07.065

33. Y. Zhong, X. Xia, F. Shi, J. Zhan, J. Tu et al., Transition metal carbides and nitrides in energy storage and conversion. Adv. Sci. 3, 1500286 (2016). https://doi.org/10.1002/advs.20150 0286

34. X. Zhao, W. Sun, D. Geng, W. Fu, J. Dan et al., Edge segregated polymorphism in 2D molybdenum carbide. Adv. Mater. 31, 1808343 (2019). https://doi.org/10.1002/adma.20180 8343 
35. C. Dai, Y. Chen, X. Jing, L. Xiang, D. Yang et al., Twodimensional tantalum carbide (MXenes) composite nanosheets for multiple imaging-guided photothermal tumor ablation. ACS Nano 11, 12696-12712 (2017). https://doi.org/ 10.1021/acsnano.7b07241

36. H. Liu, J. Zhu, Z. Lai, R. Zhao, D. He, A first-principles study on structural and electronic properties of $\mathrm{Mo}_{2} \mathrm{C}$. Scripta Mater. 60, 949-952 (2009). https://doi.org/10.1016/j.scrip tamat.2009.02.010

37. M. Tuo, C. Xu, H. Mu, X. Bao, Y. Wang et al., Ultrathin 2D Transition metal carbides for ultrafast pulsed fiber lasers. ACS Photonics 5, 1808-1816 (2018). https://doi.org/10.1021/ acsphotonics.7b01428

38. J. Jeon, H. Choi, S. Choi, J.-H. Park, B.H. Lee et al., Hybrid photodetectors: transition-metal-carbide $\left(\mathrm{Mo}_{2} \mathrm{C}\right)$ multiperiod gratings for realization of high-sensitivity and broad-spectrum photodetection. Adv. Funct. Mater. 29, 1970329 (2019). https://doi.org/10.1002/adfm.201970329

39. H.W. Hugosson, O. Eriksson, U. Jansson, B. Johansson, Phase stabilities and homogeneity ranges in 4d-transitionmetal carbides: A theoretical study. Phys. Rev. B 63, 134108 (2001). https://doi.org/10.1103/PhysRevB.63.134108

40. V.N. Lipatnikov, A.A. Rempel, A.I. Gusev, Atomic ordering and hardness of nonstoichiometric titanium carbide. Int. J. Refract. Met. Hard Mater. 15, 61-64 (1997). https://doi.org/ 10.1016/S0263-4368(96)00020-0

41. X.J. Li, L.L. He, Y.S. Li, Q. Yang, A. Hirose, Strain-induced ordered structure of titanium carbide during depositing diamond on Ti alloy substrate. Mater. Charact. 123, 227-232 (2017). https://doi.org/10.1016/j.matchar.2016.11.035

42. B. Yu, A. Huang, D. Chen, K. Srinivas, X. Zhang et al., In situ construction of $\mathrm{Mo}_{2} \mathrm{C}$ quantum dots-decorated cnt networks as a multifunctional electrocatalyst for advanced lithium-sulfur batteries. Small 17, 2100460 (2021). https:// doi.org/10.1002/smll.202100460

43. H. Goretzki, Neutron diffraction studies on titanium-carbon and zirconium-carbon alloys. Phys. Status Solidi B 20, K141K143 (1967). https://doi.org/10.1002/pssb.19670200260

44. B. Ji, S. Fan, X. Ma, K. Hu, L. Wang et al., Electromagnetic shielding behavior of heat-treated $\mathrm{Ti}_{3} \mathrm{C}_{2} \mathrm{TX}$ MXene accompanied by structural and phase changes. Carbon 165, 150-162 (2020). https://doi.org/10.1016/j.carbon.2020.04.041

45. N.V. Dzhalabadze, B.G. Éristavi, N.I. Maisuradze, K.K. Tskhovrebashvili, É.R. Kuteliya, Structural transformations in titanium carbide during diamond grinding. Powder Metall. Metal Ceram. 38, 292-296 (1999). https://doi.org/10.1007/ BF02675778

46. A.D. Dillon, M.J. Ghidiu, A.L. Krick, J. Griggs, S.J. May et al., Highly conductive optical quality solution-processed films of 2D titanium carbide. Adv. Funct. Mater. 26, 41624168 (2016). https://doi.org/10.1002/adfm.201600357

47. M. Khazaei, A. Ranjbar, M. Arai, T. Sasaki, S. Yunoki, Electronic properties and applications of MXenes: a theoretical review. J. Mater. Chem. C 5, 2488-2503 (2017). https://doi. org/10.1039/C7TC00140A
48. M. Kuang, W. Huang, C. Hegde, W. Fang, X. Tan et al., Interface engineering in transition metal carbides for electrocatalytic hydrogen generation and nitrogen fixation. Mater. Horizons 7, 32-53 (2020). https://doi.org/10.1039/C9MH0 1094G

49. G. Fiori, F. Bonaccorso, G. Iannaccone, T. Palacios, D. Neumaier et al., Electronics based on two-dimensional materials. Nat. Nanotechnol. 9, 768-779 (2014). https://doi.org/10. 1038/nnano.2014.207

50. S. Zada, W. Dai, Z. Kai, H. Lu, X. Meng et al., Algae extraction controllable delamination of vanadium carbide nanosheets with enhanced near-infrared photothermal performance. Angew. Chem. Int. Ed. 59, 6601-6606 (2020). https:// doi.org/10.1002/anie.201916748

51. A. Jastrzebska, A. Szuplewska, A. RozmysłowskaWojciechowska, J. Mitrzak, T. Wojciechowski et al., Juggling surface charges of 2D niobium carbide MXenes for a reactive oxygen species scavenging and effective targeting of the malignant melanoma cell cycle into programmed cell death. ACS Sustain. Chem. Eng. 8, 7942-7951 (2020). https://doi. org/10.1021/acssuschemeng.0c01609

52. J.A. Klug, T. Proslier, J.W. Elam, R.E. Cook, J.M. Hiller et al., Atomic layer deposition of amorphous niobium carbide-based thin film superconductors. J. Phys. Chem. C 115, 25063-25071 (2011). https://doi.org/10.1021/jp207612r

53. S. Pisana, P.M. Braganca, E.E. Marinero, B.A. Gurney, Tunable nanoscale graphene magnetometers. Nano Lett. 10, 341-346 (2010). https://doi.org/10.1021/n1903690y

54. A.P.M. Barboza, H. Chacham, C.K. Oliveira, T.F.D. Fernandes, E.H.M. Ferreira et al., Dynamic negative compressibility of few-layer graphene, h-BN, and $\mathrm{MoS}_{2}$. Nano Lett. 12, 2313-2317 (2012). https://doi.org/10.1021/nl300183e

55. J. Yang, M. Naguib, M. Ghidiu, L.-M. Pan, J. Gu et al., Twodimensional nb-based $\mathrm{M}_{4} \mathrm{C}_{3}$ solid solutions (MXenes). J. Am. Ceram. Soc. 99, 660-666 (2016). https://doi.org/10.1111/ jace. 13922

56. L. Verger, C. Xu, V. Natu, H.-M. Cheng, W. Ren et al., Overview of the synthesis of MXenes and other ultrathin 2D transition metal carbides and nitrides. Curr. Opin. Solid St. Mater. Sci. 23, 149-163 (2019). https://doi.org/ 10.1016/j.cossms.2019.02.001

57. M.R. Lukatskaya, O. Mashtalir, C.E. Ren, Y. Dall'Agnese, P. Rozier et al., Cation intercalation and high volumetric capacitance of two-dimensional titanium carbide. Science 341, 1502 (2013). https://doi.org/10.1126/science.1241488

58. A. Ren, J. Zou, H. Lai, Y. Huang, L. Yuan et al., Direct laser-patterned MXene-perovskite image sensor arrays for visible-near infrared photodetection. Mater. Horiz. 7, 1901-1911 (2020). https://doi.org/10.1039/D0MH00537A

59. C. Zhang, B. Anasori, A. Seral-Ascaso, S.-H. Park, N. McEvoy et al., Transparent, Flexible, and conductive 2d titanium carbide (MXene) films with high volumetric capacitance. Adv. Mater. 29, 1702678 (2017). https://doi. org/10.1002/adma.201702678 
60. M. Radovic, M. Barsoum, M.A.X. Phases, Bridging the gap between metals and ceramics. Am. Ceram. Soc. Bull. 92, 20-27 (2013)

61. S. Yang, P. Zhang, F. Wang, A.G. Ricciardulli, M.R. Lohe et al., Fluoride-free synthesis of two-dimensional titanium carbide (MXene) using a binary aqueous system. Angew. Chem. Inter. Ed. 57, 15491-15495 (2018). https://doi.org/ 10.1002/anie.201809662

62. J. Zhou, X. Zha, F.Y. Chen, Q. Ye, P. Eklund et al., A two-dimensional zirconium carbide by selective etching of $\mathrm{A} 13 \mathrm{C} 3$ from nanolaminated $\mathrm{Zr}_{3} \mathrm{Al}_{3} \mathrm{C}_{5}$. Angew. Chem. Inter. Ed. 55, 5008-5013 (2016). https://doi.org/10.1002/ anie. 201510432

63. M. Naguib, V.N. Mochalin, M.W. Barsoum, Y. Gogotsi, Twodimensional materials: 25th anniversary article: MXenes: a new family of two-dimensional materials. Adv. Mater. 26, 982-982 (2014). https://doi.org/10.1002/adma.201470041

64. M. Ghidiu, M. Lukatskaya, M.-Q. Zhao, Y. Gogotsi, M. Barsoum, Conductive two-dimensional titanium carbide 'clay' with high volumetric capacitance. Nature 516, 78-81 (2014). https://doi.org/10.1038/nature13970

65. F. Liu, A. Zhou, J. Chen, J. Jia, W. Zhou et al., Preparation of $\mathrm{Ti}_{3} \mathrm{C}_{2}$ and $\mathrm{Ti}_{2} \mathrm{C}$ MXenes by fluoride salts etching and methane adsorptive properties. Appl. Surf. Sci. 416, 781-789 (2017). https://doi.org/10.1016/j.apsusc.2017.04.239

66. F. Liu, J. Zhou, S. Wang, B. Wang, C. Shen et al., Preparation of high-purity $\mathrm{V}_{2} \mathrm{C}$ MXene and electrochemical properties as Li-Ion batteries. J. Electrochem. Soc. 164, A709-A713 (2017). https://doi.org/10.1149/2.0641704jes

67. J. Halim, M.R. Lukatskaya, K.M. Cook, J. Lu, C.R. Smith et al., Transparent conductive two-dimensional titanium carbide epitaxial thin films. Chem. Mater. 26, 2374-2381 (2014). https://doi.org/10.1021/cm500641a

68. M. Alhabeb, K. Maleski, B. Anasori, P. Lelyukh, L. Clark et al., Guidelines for synthesis and processing of two-dimensional titanium carbide $\left(\mathrm{Ti}_{3} \mathrm{C}_{2} \mathrm{~T}_{\mathrm{x}} \mathrm{MXene}\right)$. Chem. Mater. 29, 7633-7644 (2017). https://doi.org/10.1021/acs.chemmater. $7 \mathrm{~b} 02847$

69. A. Lipatov, M. Alhabeb, M.R. Lukatskaya, A. Boson, Y. Gogotsi et al., MXene materials: effect of synthesis on quality, electronic properties and environmental stability of individual monolayer $\mathrm{Ti}_{3} \mathrm{C}_{2}$ MXene flakes. Adv. Electron. Mater. 2, 1600255 (2016). https://doi.org/10.1002/aelm.201670068

70. J. Yi, J. Li, S. Huang, L. Hu, L. Miao et al., $\mathrm{Ti}_{2} \mathrm{CT}_{\mathrm{x}}$ MXenebased all-optical modulator. InfoMat 2, 601-609 (2020). https://doi.org/10.1002/inf2.12052

71. C. Zhang, L. Cui, S. Abdolhosseinzadeh, J. Heier, Twodimensional MXenes for lithium-sulfur batteries. InfoMat 2, 613-638 (2020). https://doi.org/10.1002/inf2.12080

72. Q.X. He, B. Wang, L. Wang, Q. Hu, A. Zhou, Two-dimensional vanadium carbide (V2CTx) MXene as supercapacitor electrode in seawater electrolyte. Chin. Chem. Lett. 31, 984-987 (2020). https://doi.org/10.1016/j.cclet.2019.08.025

73. E. Pomerantseva, Y. Gogotsi, Two-dimensional heterostructures for energy storage. Nat. Energy 2, 17089 (2017). https:// doi.org/10.1038/nenergy.2017.89
74. Y. Guan, S. Jiang, Y. Cong, J. Wang, Z. Dong et al., A hydrofluoric acid-free synthesis of $2 \mathrm{D}$ vanadium carbide $\left(\mathrm{V}_{2} \mathrm{C}\right)$ MXene for supercapacitor electrodes. 2D Mater. 7, 025010 (2020). https://doi.org/10.1088/2053-1583/ab6706

75. Y. Xin, Y.-X. Yu, Possibility of bare and functionalized niobium carbide MXenes for electrode materials of supercapacitors and field emitters. Mater. Design 130, 512-520 (2017). https://doi.org/10.1016/j.matdes.2017.05.052

76. Z. Wang, Q. Li, Y. Chen, B. Cui, Y. Li et al., The ambipolar transport behavior of $\mathrm{WSe}_{2}$ transistors and its analogue circuits. NPG Asia Mater. 10, 703-712 (2018). https://doi.org/ 10.1038/s41427-018-0062-1

77. S.-Y. Pang, W.-F. Io, L.-W. Wong, J. Zhao, J. Hao, Efficient energy conversion and storage based on robust fluoride-free self-assembled 1D niobium carbide in 3D nanowire network. Adv. Sci. 7, 1903680 (2020). https://doi.org/10.1002/advs. 201903680

78. D. Pinto, B. Anasori, H. Avireddy, C.E. Shuck, K. Hantanasirisakul et al., Synthesis and electrochemical properties of 2D molybdenum vanadium carbides - solid solution MXenes. J. Mater. Chem. A 8, 8957-8968 (2020). https://doi.org/10. 1039/D0TA01798A

79. D. Bloom, N. Grant, The system chromium-carbon. JOM 2, 41-46 (1950). https://doi.org/10.1007/BF03398977

80. M. Naguib, MXenes: A new family of two-dimensional materials and its application as electrodes for Li-ion batteries. Dissertations Theses Gradworks 45, 787-799 (2015)

81. C. Wan, Y.N. Regmi, B.M. Leonard, Multiple phases of molybdenum carbide as electrocatalysts for the hydrogen evolution reaction. Angew. Chem. Int. Ed. 53, 6407-6410 (2014). https://doi.org/10.1002/anie.201402998

82. J. Luo, E. Matios, H. Wang, X. Tao, W. Li, Interfacial structure design of MXene-based nanomaterials for electrochemical energy storage and conversion. InfoMat 2, 1057-1076 (2020). https://doi.org/10.1002/inf2.12118

83. O. Mashtalir, M. Naguib, V. Mochalin, Y. Dall'Agnese, M. Heon et al., Intercalation and delamination of layered carbides and carbonitrides. Nat. Commun. 4, 1716 (2013). https://doi.org/10.1038/ncomms2664

84. B. Anasori, Y. Xie, M. Beidaghi, J. Lu, B.C. Hosler et al., Two-dimensional, ordered, double transition metals carbides (MXenes). ACS Nano 9, 9507-9516 (2015). https:// doi.org/10.1021/acsnano.5b03591

85. Y. Omomo, T. Sasaki, L. Wang, M. Watanabe, Redoxable nanosheet crystallites of $\mathrm{MnO}_{2}$ derived via delamination of a layered manganese oxide. ChemInform (2003). https:// doi.org/10.1002/chin.200324215

86. M. Naguib, R. Unocic, B. Armstrong, J. Nanda, Large-scale delamination of multi-layers transition metal carbides and carbonitrides “MXenes.” Dalton Trans. 44, 9353 (2015). https://doi.org/10.1039/C5DT01247C

87. O. Mashtalir, M.R. Lukatskaya, M.-Q. Zhao, M.W. Barsoum, Y. Gogotsi, Amine-assisted delamination of $\mathrm{Nb}_{2} \mathrm{C}$ MXene for Li-Ion energy storage devices. Adv. Mater. 27, 3501-3506 (2015). https://doi.org/10.1002/adma.20150 0604 
88. A. Reina, X. Jia, J. Ho, D. Nezich, H. Son et al., Few-Layer graphene films on arbitrary substrates by chemical vapor deposition. Nano Lett. 9, 30-35 (2009). https://doi.org/10. 1021/n1901829a

89. X. Wang, H. Feng, Y. Wu, L. Jiao, Controlled synthesis of highly crystalline $\mathrm{MoS}_{2}$ flakes by chemical vapor deposition. J. Am. Chem. Soc. 135, 5304-5307 (2013). https://doi.org/ 10.1021/ja4013485

90. C. Xu, L. Wang, Z. Liu, L. Chen, J. Guo et al., Large-area high-quality $2 \mathrm{D}$ ultrathin $\mathrm{Mo}_{2} \mathrm{C}$ superconducting crystals. Nat. Mater. 14, 1135-1141 (2015). https://doi.org/10.1038/ nmat 4374

91. C. Xu, L. Chen, Z. Liu, H.-M. Cheng, W. Ren, Bottom-Up synthesis of 2D transition metal carbides and nitrides. 2D Metal Carbides and Nitrides (MXenes) (2019), pp. 89-109

92. D. Geng, X. Zhao, Z. Chen, W. Sun, W. Fu et al., Direct synthesis of large-area $2 \mathrm{D} \mathrm{Mo}_{2} \mathrm{C}$ on In situ grown graphene. Adv. Mater. 29, 1700072 (2017). https://doi.org/10.1002/ adma.201700072

93. D. Geng, X. Zhao, L. Li, P. Song, B. Tian et al., Controlled growth of ultrathin $\mathrm{Mo}_{2} \mathrm{C}$ superconducting crystals on liquid Cu surface. 2D Mater. 4, 011012 (2016). https://doi.org/10. 1088/2053-1583/aa51b7

94. C. Zhang, Z. Wang, R. Tu, M. Dong, J. Li et al., Growth of self-aligned single-crystal vanadium carbide nanosheets with a controllable thickness on a unique staked metal substrate. Appl. Surf. Sci. 499, 143998 (2019). https://doi.org/ 10.1016/j.apsusc. 2019.143998

95. C. Xu, S. Song, Z. Liu, L. Chen, L. Wang et al., Strongly coupled high-quality graphene/2D superconducting $\mathrm{Mo}_{2} \mathrm{C}$ vertical heterostructures with aligned orientation. ACS Nano 11, 5906-5914 (2017). https://doi.org/10.1021/acsnano.7b01638

96. C. Zhang, Z. Wang, R. Tu, M. Dong, J. Li et al., Growth of self-aligned single-crystal vanadium carbide nanosheets with a controllable thickness on a unique staked metal substrate. Appl. Surf. Sci. 499, 143998 (2020). https://doi.org/ 10.1016/j.apsusc.2019.143998

97. T. Ikenoue, T. Yoshida, M. Miyake, R. Kasada, T. Hirato, Fabrication and mechanical properties of tungsten carbide thin films via mist chemical vapor deposition. J. Alloys Compounds 829, 154567 (2020). https://doi.org/10.1016/j.jallc om.2020.154567

98. H.E. Rebenne, D.G. Bhat, Review of CVD TiN coatings for wear-resistant applications: deposition processes, properties and performance. Surf. Coat. Tech. 63, 1-13 (1994). https:// doi.org/10.1016/S0257-8972(05)80002-7

99. L. Volpe, M. Boudart, Compounds of molybdenum and tungsten with high specific surface area: I. Nitrides. J. Solid State Chem. 59, 332-347 (1985). https://doi.org/10.1016/00224596(85)90301-9

100. J.B. Claridge, A.P.E. York, A.J. Brungs, M.L.H. Green, Study of the temperature-programmed reaction synthesis of early transition metal carbide and nitride catalyst materials from oxide precursors. Chem. Mater. 12, 132-142 (2000). https:// doi.org/10.1021/cm9911060
101. A.T. Peters, Ullmann's encyclopedia of industrial chemistry: vols A5-A7. VCH Verlagsgesellschaft, Weinheim, FRG, 1986. vols A5 (ISBN 3-527-20105-X; xv + 556 pp). Dyes Pigm. 9, 165-166 (1988). https://doi.org/10.1016/01437208(88)80015-9

102. V.L.S. Teixeira da Silva, E.I. Ko, M. Schmal, S.T. Oyama, Synthesis of niobium carbide from niobium oxide aerogels. Chem. Mater. 7, 179-184 (1995). https://doi.org/10.1021/ cm00049a027

103. V.L.S. Teixeira da Silva, M. Schmal, S.T. Oyama, Niobium carbide synthesis from niobium oxide: study of the synthesis conditions, kinetics, and solid-state transformation mechanism. J. Solid State Chem. 123, 168-182 (1996). https://doi. org/10.1006/jssc.1996.0165

104. R. Kapoor, S.T. Oyama, Synthesis of high surface area vanadium nitride. J. Solid State Chem. 99, 303-312 (1992). https://doi.org/10.1016/0022-4596(92)90318-P

105. J.G. Choi, H.G. Oh, Y.S. Baek, Tantalum carbide hydrodenitrogenation catalysts. J. Ind. Eng. Chem. 4, 94-98 (1998)

106. L. Fei, X. Gan, S.M. Ng, H. Wang, M. Xu et al., Observable two-step nucleation mechanism in solid-state formation of tungsten carbide. ACS Nano 13, 681-688 (2019). https://doi. org/10.1021/acsnano.8b07864

107. S. Biira, T. Thabethe, H. Bissett, T. Ntsoane, J.B. Malherbe, Investigating the thermal stability of the chemical vapour deposited zirconium carbide layers. J. Alloys Compounds 834, 155003 (2020). https://doi.org/10.1016/j.jallcom.2020. 155003

108. W. Sun, X. Kuang, H. Liang, X. Xia, Z. Zhang et al., Mechanical properties of tantalum carbide from high-pressure/hightemperature synthesis and first-principles calculations. Phys. Chem. Chem. Phys. 22, 5018-5023 (2020). https://doi.org/ 10.1039/C9CP06819H

109. G. Zou, H. Wang, N. Mara, H. Luo, N. Li et al., Chemical solution deposition of epitaxial carbide films. J. Am. Chem. Soc. 132, 2516-2517 (2010). https://doi.org/10.1021/ja910 2315

110. R.E. Jilek, E. Bauer, A.K. Burrell, T.M. McCleskey, Q. Jia et al., Preparation of epitaxial uranium dicarbide thin films by polymer-assisted deposition. Chem. Mater. 25, 4373-4377 (2013). https://doi.org/10.1021/cm402655p

111. M. Backhaus-Ricoult, Oxidation behavior of SiC-whiskerreinforced alumina-zirconia composites. J. Am. Ceram. Soc. 74, 1793-1802 (1991). https://doi.org/10.1111/j.1151-2916. 1991.tb07790.x

112. E. Lewin, M. Råsander, M. Klintenberg, A. Bergman, O. Eriksson et al., Design of the lattice parameter of embedded nanoparticles. Chem. Phys. Lett. 496, 95-99 (2010). https:// doi.org/10.1016/j.cplett.2010.07.013

113. D.V. Shtansky, E.A. Levashov, A.N. Sheveiko, J.J. Moore, Synthesis and characterization of Ti-Si-C-N films. Metall. Mater. Trans. A 30, 2439-2447 (1999). https://doi.org/10. 1007/s11661-999-0252-0

114. Z. Kan, M. Wena, G. Chengb, X. Lia, Q. Meng et al., Reactive magnetron sputtering deposition and characterization of 
niobium carbide films. Vacuum 99, 233-241 (2014). https:// doi.org/10.1016/j.vacuum.2013.06.012

115. S.A. Shiryaev, M. Atamanov, M. Guseva, Y. Martynenko, A. Mitin et al., Production and properties of metal-carbon composite coatings with a nanocrystalline structure. Tech. Phys. 47, 238-243 (2002). https://doi.org/10.1134/1.14519 74

116. D. Yang, Z. Su, Y. Chen, K. Srinivas, J. Gao et al., Electronic modulation of hierarchical spongy nanosheets toward efficient and stable water electrolysis. Small 17, 2006881 (2021). https://doi.org/10.1002/smll.202006881

117. J. Wang, S. Liu, Y. Wang, T. Wang, S. Shang et al., Magnetron-sputtering deposited molybdenum carbide MXene thin films as a saturable absorber for passively Q-switched lasers. J. Mater. Chem. C 8, 1608-1613 (2020). https://doi.org/10. 1039/C9TC06117G

118. R.W. Chorley, P.W. Lednor, Synthetic routes to high surface area non-oxide materials. Adv. Mater. 3, 474-485 (1991). https://doi.org/10.1002/adma.19910031004

119. T.P. Nguyen, D.M. Tuan Nguyen, D.L. Tran, H.K. Le, D.V.N. Vo et al., MXenes: Applications in electrocatalytic, photocatalytic hydrogen evolution reaction and $\mathrm{CO}_{2}$ reduction. Mol. Catal. 486, 110850 (2020). https://doi.org/10.1016/j. mcat.2020.110850

120. Z. Wang, H.-H. Wu, Q. Li, F. Besenbacher, Y. Li et al., Reversing interfacial catalysis of ambipolar $\mathrm{WSe}_{2}$ single crystal. Adv. Sci. 7, 1901382 (2020). https://doi.org/10.1002/ advs.201901382

121. Z. Wang, Q. Li, H. Xu, C. Dahl-Petersen, Q. Yang et al., Controllable etching of MoS2 basal planes for enhanced hydrogen evolution through the formation of active edge sites. Nano Energy 49, 634-643 (2018). https://doi.org/10.1016/j.nanoen. 2018.04.067

122. G. Gao, A.P. O’Mullane, A. Du, 2D MXenes: A new family of promising catalysts for the hydrogen evolution reaction. ACS Catal. 7, 494-500 (2017). https://doi.org/10.1021/acsca tal.6b02754

123. J. Wan, C. Wang, T. Qian, X. Gu, M. He, First-principles study of vanadium carbides as electrocatalysts for hydrogen and oxygen evolution reactions. RSC Adv. 9, 37467-37473 (2019). https://doi.org/10.1039/c9ra06539c

124. L. Tian, S. Min, F. Wang, Z. Zhang, Enhanced photocatalytic hydrogen evolution on $\mathrm{TiO} 2$ employing vanadium carbide as an efficient and stable cocatalyst. Int. J. Hydrogen Energy 45, 1878-1889 (2020). https://doi.org/10.1016/j.ijhydene.2019. 11.094

125. Z. Hu, C. Chen, H. Meng, R. Wang, P. Shen et al., Oxygen reduction electrocatalysis enhanced by nanosized cubic vanadium carbide. Electrochem. Commun. 13, 763-765 (2011). https://doi.org/10.1016/j.elecom.2011.03.004

126. L. Guo, Y. Liu, X. Teng, Y. Niu, S. Gong et al., Self-supported vanadium carbide by an electropolymerizationassisted method for efficient hydrogen production. Chemsuschem 13, 3671-3678 (2020). https://doi.org/10.1002/cssc. 202000769
127. Y. Yoon, A.P. Tiwari, M. Choi, T.G. Novak, W. Song et al., Precious-metal-free electrocatalysts for activation of hydrogen evolution with nonmetallic electron donor: chemical composition controllable phosphorous doped vanadium carbide MXene. Adv. Funct. Mater. 29, 1903443 (2019). https:// doi.org/10.1002/adfm.201903443

128. C.-F. Du, X. Sun, H. Yu, W. Fang, Y. Jing et al., $V_{4} C_{3} T_{x}$ MXene: A promising active substrate for reactive surface modification and the enhanced electrocatalytic oxygen evolution activity. InfoMat 2, 950-959 (2020). https://doi.org/10. 1002/inf2.12078

129. U. Jansson, E. Lewin, Sputter deposition of transition-metal carbide films - a critical review from a chemical perspective. Thin Solid Films 536, 1-24 (2013). https://doi.org/10. 1016/j.tsf.2013.02.019

130. W.-F. Chen, C.-H. Wang, K. Sasaki, N. Marinkovic, W. Xu et al., Highly active, durable, and nanostructured molybdenum carbide electrocatalysts for hydrogen production. Energy Environ. Sci. 6, 943 (2013). https://doi.org/10.1039/C2EE2 $3891 \mathrm{H}$

131. Z. Chen, T. Guo, Z. Wu, D. Wang, Boron triggers the phase transformation of MoxC $\left(\alpha-\mathrm{MoC}_{1-\mathrm{x}} / \beta-\mathrm{Mo}_{2} \mathrm{C}\right)$ for enhanced hydrogen production. Nanotechnology. (2019). https://doi. org/10.1088/1361-6528/ab5a25

132. N. Han, K.R. Yang, Z. Lu, Y. Li, W. Xu et al., Nitrogen-doped tungsten carbide nanoarray as an efficient bifunctional electrocatalyst for water splitting in acid. Nat. Commun. 9, 924 (2018). https://doi.org/10.1038/s41467-018-03429-z

133. L. Lin, M. Chen, L. Wu, Synthesis of molybdenum-tungsten bimetallic carbide hollow spheres as $\mathrm{pH}$-Universal electrocatalysts for efficient hydrogen evolution reaction. Adv. Mater. Interfaces 5, 1801302 (2018). https://doi.org/10.1002/admi. 201801302

134. J. Chen, B. Ren, H. Cui, C. Wang, Constructing pure phase tungsten-based bimetallic carbide nanosheet as an efficient bifunctional electrocatalyst for overall water splitting. Small 16, 1907556 (2020). https://doi.org/10.1002/smll.201907556

135. L. Wang, Z. Liu, S. Zhu, M. Shao, B. Yang et al., Tungsten carbide and cobalt modified nickel nanoparticles supported on multiwall carbon nanotubes as highly efficient electrocatalysts for urea oxidation in alkaline electrolyte. ACS Appl. Mater. Interfaces 10, 41338-41343 (2018). https://doi.org/ 10.1021/acsami.8b14397

136. K. Kui, K. Xi, Z. Pu, S. Mu, Constructing carbon-cohered high-index (222) faceted tantalum carbide nanocrystals as a robust hydrogen evolution catalyst. Nano Energy 36, 374-380 (2017). https://doi.org/10.1016/j.nanoen.2017.04.057

137. W. Huang, H. Meng, Y. Gao, J. Wang, C. Yang et al., Metallic tungsten carbide nanoparticles as a near-infrared-driven photocatalyst. J. Mater. Chem. A 7, 18538-18546 (2019). https://doi.org/10.1039/C9TA03151K

138. S. Li, P. Tuo, J. Xie, X. Zhang, J. Xu et al., Ultrathin MXene nanosheets with rich fluorine termination groups realizing efficient electrocatalytic hydrogen evolution. Nano Energy 
47, 512-518 (2018). https://doi.org/10.1016/j.nanoen.2018. 03.022

139. C. Wang, S. Wei, S. Chen, D. Cao, L. Song, Delaminating vanadium carbides for Zinc-ion storage: hydrate precipitation and $\mathrm{H}^{+} / \mathrm{Zn}^{2+}$ Co-action mechanism. Small Methods 3, 1900495 (2019). https://doi.org/10.1002/smtd.201900495

140. L. Liao, S. Wang, J. Xiao, X. Bian, Y. Zhang et al., A nanoporous molybdenum carbide nanowire as an electrocatalyst for hydrogen evolution reaction. Energy Environ. Sci. 7, 387-392 (2014). https://doi.org/10.1039/C3EE42441C

141. L. Ma, L.R.L. Ting, V. Molinari, C. Giordano, B.S. Yeo, Efficient hydrogen evolution reaction catalyzed by molybdenum carbide and molybdenum nitride nanocatalysts synthesized via the urea glass route. J. Mater. Chem. A 3, 8361-8368 (2015). https://doi.org/10.1039/C5TA00139K

142. A.D. Handoko, K.D. Fredrickson, B. Anasori, K.W. Convey, L.R. Johnson et al., Tuning the basal plane functionalization of two-dimensional metal carbides (MXenes) to control hydrogen evolution activity. ACS Appl. Energy Mater. 1, 173-180 (2018). https://doi.org/10.1021/acsaem.7b00054

143. Z. Kou, K. Xi, Z. Pu, S. Mu, Constructing carbon-cohered high-index (222) faceted tantalum carbide nanocrystals as a robust hydrogen evolution catalyst. Nano Energy 36, 374-380 (2017). https://doi.org/10.1016/j.nanoen.2017.04.057

144. D.P. Valencia, L. Yate, W. Aperador, Y. Li, E. Coy, High electrocatalytic response of ultra-refractory ternary alloys of Ta-Hf-C carbide toward hydrogen evolution reaction in acidic media. J. Phys. Chem. C 122, 25433-25440 (2018). https:// doi.org/10.1021/acs.jpcc.8b08123

145. L. Qiao, A. Zhu, W. Zeng, R. Dong, P. Tan et al., Achieving electronic structure reconfiguration in metallic carbides for robust electrochemical water splitting. J. Mater. Chem. A 8, 2453-2462 (2020). https://doi.org/10.1039/C9TA10682K

146. C.-F. Du, K.N. Dinh, Q. Liang, Y. Zheng, Y. Luo et al., Selfassemble and in situ formation of Ni1-xFexPS3 nanomosaicdecorated MXene hybrids for overall water splitting. Adv. Energy Mater. 8, 1801127 (2018). https://doi.org/10.1002/ aenm. 201801127

147. D. Das, S. Santra, K.K. Nanda, In situ fabrication of a Nickel/Molybdenum carbide-anchored N-doped graphene/ CNT hybrid: an efficient (pre)catalyst for OER and HER. ACS Appl. Mater. Interf. 10, 35025-35038 (2018). https:// doi.org/10.1021/acsami.8b09941

148. H. Fan, H. Yu, Y. Zhang, Y. Zheng, Y. Luo et al., Fe-doped $\mathrm{Ni}_{3} \mathrm{C}$ nanodots in $\mathrm{N}$-doped carbon nanosheets for efficient hydrogen-evolution and oxygen-evolution electrocatalysis. Angew. Chem. Int. Ed. 56, 12566-12570 (2017). https:// doi.org/10.1002/anie.201706610

149. L. Zhao, B. Dong, S. Li, L. Zhou, L. Lai et al., Interdiffusion reaction-assisted hybridization of two-dimensional metal-organic frameworks and $\mathrm{Ti}_{3} \mathrm{C}_{2} \mathrm{~T}_{\mathrm{x}}$ nanosheets for electrocatalytic oxygen evolution. ACS Nano 11, 58005807 (2017). https://doi.org/10.1021/acsnano.7b01409

150. S. Gao, H. Chen, Y. Liu, G.-D. Li, R. Gao et al., Surfaceclean, phase-pure multi-metallic carbides for efficient electrocatalytic hydrogen evolution reaction. Inorg. Chem.
Front. 6, 940-947 (2019). https://doi.org/10.1039/C8QI0 $1360 \mathrm{H}$

151. Y. Yoon, A.P. Tiwari, M. Lee, M. Choi, W. Song et al., Enhanced electrocatalytic activity by chemical nitridation of two-dimensional titanium carbide MXene for hydrogen evolution. J. Mater. Chem. A 6, 20869-20877 (2018). https:// doi.org/10.1039/C8TA08197B

152. X. Zang, W. Chen, X. Zou, J.N. Hohman, L. Yang et al., Self-assembly of large-area 2D polycrystalline transition metal carbides for hydrogen electrocatalysis. Adv. Mater. 30, 1805188 (2018). https://doi.org/10.1002/adma.201805188

153. A. Mondal, K. Sinha, A. Paul, D.N. Srivastava, A.B. Panda, Large scale synthesis of $\mathrm{Mo}_{2} \mathrm{C}$ nanoparticle incorporated carbon nanosheet $\left(\mathrm{Mo}_{2} \mathrm{C}-\mathrm{C}\right)$ for enhanced hydrogen evolution reaction. Int. J. Hydrogen Energy 45, 18623-18634 (2020). https://doi.org/10.1016/j.ijhydene.2019.09.051

154. Y. Jiang, T. Sun, X. Xie, W. Jiang, J. Li et al., Oxygen-functionalized ultrathin $\mathrm{Ti}_{3} \mathrm{C}_{2} \mathrm{~T}_{\mathrm{x}}$ MXene for enhanced electrocatalytic hydrogen evolution. Chemsuschem 12, 1368-1373 (2019). https://doi.org/10.1002/cssc.201803032

155. Y. Zhou, R. Ma, P. Li, Y. Chen, Q. Liu et al., Ditungsten carbide nanoparticles encapsulated by ultrathin graphitic layers with excellent hydrogen-evolution electrocatalytic properties. J. Mater. Chem. A 4, 8204-8210 (2016). https://doi.org/10. 1039/C6TA01601D

156. L. Wang, Z. Li, K. Wang, Q. Dai, C. Lei et al., Tuning d-band center of tungsten carbide via Mo doping for efficient hydrogen evolution and $\mathrm{Zn}-\mathrm{H}_{2} \mathrm{O}$ cell over a wide $\mathrm{pH}$ range. Nano Energy 74, 104850 (2020). https://doi.org/10.1016/j.nanoen. 2020.104850

157. D.B. Burueva, A.A. Smirnov, O.A. Bulavchenko, I.P. Prosvirin, E.Y. Gerasimov et al., Pairwise parahydrogen addition over molybdenum carbide catalysts. Top. Catal. 63, 2-11 (2020). https://doi.org/10.1007/s11244-019-01211-Z

158. T. Xiao, A. York, V. Williams, H. Almegren, A. Hanif et al., Preparation of molybdenum carbides using butane and their catalytic performance. Chem. Mater. (2000). https://doi.org/ $10.1021 / \mathrm{cm} 001157 \mathrm{t}$

159. E.B. Deeva, A. Kurlov, P.M. Abdala, D. Lebedev, S.M. Kim et al., In Situ XANES/XRD study of the structural stability of two-dimensional molybdenum carbide $\mathrm{Mo}_{2} \mathrm{CT}_{\mathrm{x}}$ : implications for the catalytic activity in the water-gas shift reaction. Chem. Mater. 31, 4505-4513 (2019). https://doi.org/10.1021/ acs.chemmater.9b01105

160. A. Pajares, H. Prats, A. Romero, F. Viñes, P.R. de la Piscina et al., Critical effect of carbon vacancies on the reverse water gas shift reaction over vanadium carbide catalysts. App. Catal. B-Environ. 267, 118719 (2020). https://doi.org/ 10.1016/j.apcatb.2020.118719

161. E. Lee, A. VahidMohammadi, Y.S. Yoon, M. Beidaghi, D.-J. Kim, Two-dimensional vanadium carbide MXene for gas sensors with ultrahigh sensitivity toward nonpolar gases. ACS Sensors 4, 1603-1611 (2019). https://doi.org/10.1021/acsse nsors.9b00303

162. L. Zhao, K. Wang, W. Wei, L. Wang, W. Han, High-performance flexible sensing devices based on polyaniline/MXene 
nanocomposites. InfoMat 1, 407-416 (2019). https://doi.org/ 10.1002/inf 2.12032

163. S. Sun, M. Wang, X. Chang, Y. Jiang, D. Zhang et al., W18O49/Ti3C2Tx Mxene nanocomposites for highly sensitive acetone gas sensor with low detection limit. Sens. Actuators B Chem. 304, 127274 (2020). https://doi.org/10.1016/j. snb.2019.127274

164. W. Li, Y. Yang, G. Zhang, Y.-W. Zhang, Ultrafast and directional diffusion of lithium in phosphorene for high-performance lithium-ion battery. Nano Lett. 15, 1691-1697 (2015). https://doi.org/10.1021/n1504336h

165. H. Jin, S. Xin, C. Chuang, W. Li, H. Wang et al., Black phosphorus composites with engineered interfaces for high-rate high-capacity lithium storage. Science 370, 192 (2020). https://doi.org/10.1126/science.aav5842

166. P. Ma, D. Fang, Y. Liu, Y. Shang, Y. Shi et al., MXene-Based materials for electrochemical sodium-ion storage. Adv. Sci. (2021). https://doi.org/10.1002/advs.202003185

167. M. Naguib, J. Halim, J. Lu, K.M. Cook, L. Hultman et al., New two-dimensional niobium and vanadium carbides as promising materials for Li-Ion batteries. J. Am. Chem. Soc. 135, 15966-15969 (2013). https://doi.org/10.1021/ja405735d

168. Z. Lin, P. Rozier, B. Duployer, P.-L. Taberna, B. Anasori et al., Electrochemical and In-situ X-ray diffraction Studies of $\mathrm{Ti}_{3} \mathrm{C}_{2} \mathrm{~T}_{\mathrm{x}}$ MXene in Ionic liquid Electrolyte. Electrochem. Commun. (2016). https://doi.org/10.1016/j.elecom.2016.08. 023

169. J. Zhou, S. Lin, Y. Huang, P. Tong, B. Zhao et al., Synthesis and lithium ion storage performance of two-dimensional $\mathrm{V}_{4} \mathrm{C}_{3}$ MXene. Chem. Eng. J. 373, 203-212 (2019). https:// doi.org/10.1016/j.cej.2019.05.037

170. J. Zhao, J. Wen, L. Bai, J. Xiao, R. Zheng et al., One-step synthesis of few-layer niobium carbide MXene as a promising anode material for high-rate lithium ion batteries. Dalton Trans. 48, 14433-14439 (2019). https://doi.org/10.1039/ C9DT03260F

171. S. Shen, X. Xia, Y. Zhong, S. Deng, D. Xie et al., Implanting niobium carbide into trichoderma spore carbon: a new advanced host for sulfur cathodes. Adv. Mater. 31, 1900009 (2019). https://doi.org/10.1002/adma.201900009

172. C. Wenlong, G. Li, K. Zhang, G. Xiao, C. Wang et al., Conductive nanocrystalline niobium carbide as high-efficiency polysulfides tamer for lithium-sulfur batteries. Adv. Funct. Mater. 28, 1704865 (2017). https://doi.org/10.1002/adfm. 201704865

173. A. VahidMohammadi, A. Hadjikhani, S. Shahbazmohamadi, M. Beidaghi, Two-dimensional vanadium carbide (MXene) as a high-capacity cathode material for rechargeable aluminum batteries. ACS Nano 11, 11135-11144 (2017). https:// doi.org/10.1021/acsnano.7b05350

174. J. Yu, M. Li, X. Wang, Z. Yang, Promising high-performance supercapacitor electrode materials from $\mathrm{MnO}_{2}$ Nanosheets@ Bamboo leaf carbon. ACS Omega 5, 16299-16306 (2020). https://doi.org/10.1021/acsomega.0c02169

175. Y. Zhao, Q. Fang, X. Zhu, L. Xue, M. Ni et al., Structure reinforced birnessite with an extended potential window for supercapacitors. J. Mater. Chem. A 8, 8969-8978 (2020). https://doi.org/10.1039/D0TA01480J

176. Z. Wang, J. Liu, X. Hao, Y. Wang, Y. Chen et al., Enhanced power density of a supercapacitor by introducing 3D-interfacial graphene. New J. Chem. 44, 13377-13381 (2020). https://doi.org/10.1039/D0NJ02105A

177. J. Xiao, H. Zhan, X. Wang, Z.-Q. Xu, Z. Xiong et al., Electrolyte gating in graphene-based supercapacitors and its use for probing nanoconfined charging dynamics. Nat. Nanotech. 15, 683-689 (2020). https://doi.org/10.1038/s41565-020-0704-7

178. H. Dong, P. Xiao, N. Jin, B. Wang, Y. Liu et al., Molten salt derived $\mathrm{Nb}_{2} \mathrm{CT}_{\mathrm{x}}$ MXene anode for Li-ion batteries. ChemElectroChem 8, 957-962 (2021). https://doi.org/10.1002/celc. 202100142

179. Y. Li, H. Shao, Z. Lin, J. Lu, L. Liu et al., A general Lewis acidic etching route for preparing MXenes with enhanced electrochemical performance in non-aqueous electrolyte. Nat. Mater. 19, 894-899 (2020). https://doi.org/10.1038/ s41563-020-0657-0

180. Q. Shan, X. Mu, M. Alhabeb, C.E. Shuck, D. Pang et al., Two-dimensional vanadium carbide $\left(\mathrm{V}_{2} \mathrm{C}\right)$ MXene as electrode for supercapacitors with aqueous electrolytes. Electrochem. Commun. 96, 103-107 (2018). https://doi.org/10. 1016/j.elecom.2018.10.012

181. G. Lv, J. Wang, Z. Shi, L. Fan, Intercalation and delamination of two-dimensional MXene $\left(\mathrm{Ti}_{3} \mathrm{C}_{2} \mathrm{~T}_{\mathrm{x}}\right)$ and application in sodium-ion batteries. Mater. Lett. 219, 45-50 (2018). https:// doi.org/10.1016/j.matlet.2018.02.016

182. S. Nam, S. Umrao, S. Oh, K.H. Shin, H.S. Park et al., Sonochemical self-growth of functionalized titanium carbide nanorods on $\mathrm{Ti}_{3} \mathrm{C}_{2}$ nanosheets for high capacity anode for lithium-ion batteries. Compos. Part B-Eng. 181, 107583 (2020). https://doi.org/10.1016/j.compositesb.2019.107583

183. C.E. Ren, M.-Q. Zhao, T. Makaryan, J. Halim, M. Boota et al., Porous two-dimensional transition metal carbide (MXene) flakes for high-performance Li-Ion storage. ChemElectroChem 3, 689-693 (2016). https://doi.org/10.1002/celc. 201600059

184. S. Zhao, X. Meng, K. Zhu, F. Du, G. Chen et al., Li-ion uptake and increase in interlayer spacing of $\mathrm{Nb}_{4} \mathrm{C}_{3}$ MXene. Energy Storage Mater. 8, 42-48 (2017). https://doi.org/10. 1016/j.ensm.2017.03.012

185. L. Ma, T. Chen, G. Zhu, Y. Hu, H. Lu et al., Pitaya-like microspheres derived from Prussian blue analogues as ultralong-life anodes for lithium storage. J. Mater. Chem. A 4, 15041-15048 (2016). https://doi.org/10.1039/C6TA06692E

186. Y.-T. Liu, P. Zhang, N. Sun, B. Anasori, Q.-Z. Zhu et al., Self-Assembly of Transition metal oxide nanostructures on MXene nanosheets for fast and stable lithium storage. Adv. Mater. 30, 1707334 (2018). https://doi.org/10.1002/adma. 201707334

187. C. Zhang, S.J. Kim, M. Ghidiu, M.-Q. Zhao, M.W. Barsoum et al., Layered orthorhombic $\mathrm{Nb}_{2} \mathrm{O}_{5} @ \mathrm{Nb}_{4} \mathrm{C}_{3} \mathrm{~T}_{\mathrm{x}}$ and $\mathrm{TiO}_{2} @$ $\mathrm{Ti}_{3} \mathrm{C}_{2} \mathrm{~T}_{\mathrm{x}}$ hierarchical composites for high performance $\mathrm{Li}$-ion batteries. Adv. Funct. Mater. 26, 4143-4151 (2016). https:// doi.org/10.1002/adfm.201600682 
188. H. Zhang, H. Cui, J. Li, Y. Liu, Y. Yang et al., Frogspawn inspired hollow $\mathrm{Fe}_{3} \mathrm{C} @ \mathrm{~N}-\mathrm{C}$ as an efficient sulfur host for high-rate lithium-sulfur batteries. Nanoscale 11, 2153221541 (2019). https://doi.org/10.1039/C9NR07388D

189. F. Zhou, Z. Li, X. Luo, T. Wu, B. Jiang et al., Low cost metal carbide nanocrystals as binding and electrocatalytic sites for high performance Li-S batteries. Nano Lett. 18, 1035-1043 (2018). https://doi.org/10.1021/acs.nanolett.7b04505

190. T. Chen, M. Li, S. Song, P. Kim, J. Bae, Biotemplate preparation of multilayered $\mathrm{TiC}$ nanoflakes for high performance symmetric supercapacitor. Nano Energy 71, 104549 (2020). https://doi.org/10.1016/j.nanoen.2020.104549

191. X. Zhao, Z. Wang, J. Dong, T. Huang, Q. Zhang et al., Annealing modification of MXene films with mechanically strong structures and high electrochemical performance for supercapacitor applications. J. Power Sources 470, 228356 (2020). https://doi.org/10.1016/j.jpowsour.2020.228356

192. H. Zhang, J. Liu, Z. Tian, Y. Ye, Y. Cai et al., A general strategy toward transition metal carbide/carbon core/shell nanospheres and their application for supercapacitor electrode. Carbon 100, 590-599 (2016). https://doi.org/10.1016/j. carbon.2016.01.047

193. X. Wang, H. Li, H. Li, S. Lin, W. Ding et al., 2D/2D $1 \mathrm{~T}-\mathrm{MoS}_{2} / \mathrm{Ti}_{3} \mathrm{C}_{2}$ MXene heterostructure with excellent supercapacitor performance. Adv. Funct. Mater. 30, 0190302 (2020). https://doi.org/10.1002/adfm.201910302

194. M. Shi, L. Zhao, X. Song, J. Liu, P. Zhang et al., Highly conductive $\mathrm{Mo} 2 \mathrm{C}$ nanofibers encapsulated in ultrathin $\mathrm{MnO}_{2}$ nanosheets as a self-supported electrode for high-performance capacitive energy storage. ACS Appl. Mater. Interf. 8, 32460-32467 (2016). https://doi.org/10.1021/acsami.6b106 37

195. J. Chen, Z. Li, F. Ni, W. Ouyang, X. Fang, Bio-inspired transparent MXene electrodes for flexible UV photodetectors. Mater. Horizons 7, 1828-1833 (2020). https://doi.org/ 10.1039/D0MH00394H

196. K. Montazeri, M. Currie, L. Verger, P. Dianat, M.W. Barsoum et al., Beyond gold: Spin-Coated $\mathrm{Ti}_{3} \mathrm{C}_{2}$-based MXene photodetectors. Adv. Mater. 31, 1903271 (2019). https:// doi.org/10.1002/adma.201903271

197. Y. Yang, J. Jeon, J.-H. Park, M.S. Jeong, B.H. Lee et al., Plasmonic transition metal carbide electrodes for high-performance inse photodetectors. ACS Nano 13, 8804-8810 (2019). https://doi.org/10.1021/acsnano.9b01941

198. A. Ren, J. Zou, H. Lai, Y. Huang, L. Yuan et al., Direct laser-patterned MXene-perovskite image sensor arrays for visible-near infrared photodetection. Mater. Horizons 7, 1901-1911 (2020). https://doi.org/10.1039/D0MH00537A

199. Z. Kang, Y. Ma, X. Tan, M. Zhu, Z. Zheng et al., MXeneSilicon van der waals heterostructures for high-speed selfdriven photodetectors. Adv. Electron. Mater. 3, 1700165 (2017). https://doi.org/10.1002/aelm.201700165

200. L. Gao, H. Chen, F. Zhang, S. Mei, Y. Zhang et al., Ultrafast relaxation dynamics and nonlinear response of fewlayer niobium carbide MXene. Small Methods (2020). https://doi.org/10.1002/smtd.202000250
201. J. Jeon, H. Choi, S. Choi, J.-H. Park, B.H. Lee et al., Transition-metal-carbide $\left(\mathrm{Mo}_{2} \mathrm{C}\right)$ multiperiod gratings for realization of high-sensitivity and broad-spectrum photodetection. Adv. Electron. Mater. 29, 1905384 (2019). https://doi.org/ 10.1002/adfm.201905384

202. L. Hao, Y. Du, Z. Wang, Y. Wu, H. Xu et al., Wafer-size growth of 2D layered SnSe films for UV-Visible-NIR photodetector arrays with high responsitivity. Nanoscale 12, 7358-7365 (2020). https://doi.org/10.1039/D0NR00319K

203. H. Xu, L. Hao, H. Liu, S. Dong, Y. Wu et al., Flexible SnSe Photodetectors with ultrabroad spectral response up to $10.6 \mu \mathrm{m}$ enabled by photobolometric effect. ACS Appl. Mater. Interfaces 12, 35250-35258 (2020). https://doi.org/ 10.1021/acsami.0c09561

204. H. Lin, S. Gao, C. Dai, Y. Chen, J. Shi, A two-dimensional biodegradable niobium carbide (MXene) for photothermal tumor eradication in NIR-I and NIR-II biowindows. J. Am. Chem. Soc. 139, 16235-16247 (2017). https://doi.org/10. 1021/jacs.7b07818

205. X. Ren, M. Huo, M. Wang, H. Lin, X. Zhang et al., Highly catalytic niobium carbide (MXene) promotes hematopoietic recovery after radiation by free radical scavenging. ACS Nano 13, 6438-6454 (2019). https://doi.org/10.1021/acsna no. 8 b09327

206. H. Lin, Y. Wang, S. Gao, Y. Chen, J. Shi, Theranostic 2D tantalum carbide (MXene). Adv. Mater. 30, 1703284 (2018). https://doi.org/10.1002/adma.201703284

207. W. Ren, Z. Liu, C. Xu, C. Wang, S. Song et al., Grain boundaries and tilt angle-dependent transport properties of 2D $\mathrm{Mo}_{2} \mathrm{C}$ superconductor. Nano Lett. 19, 857-865 (2019). https://doi.org/10.1021/acs.nanolett.8b04065

208. S. Jin, T. Su, Q. Hu, A. Zhou, Thermal conductivity and electrical transport properties of double-A-layer MAX phase $\mathrm{Mo}_{2} \mathrm{Ga}_{2} \mathrm{C}$. Mater. Res. Lett. 8, 158-164 (2020). https://doi.org/10.1080/21663831.2020.1724204

209. F. Porrati, S. Barth, R. Sachser, O.V. Dobrovolskiy, A. Seybert et al., Crystalline niobium carbide superconducting nanowires prepared by focused ion beam direct writing. ACS Nano 13, 6287-6296 (2019). https://doi.org/10.1021/ acsnano.9b00059

210. Z. Wang, H.-H. Wu, Q. Li, F. Besenbacher, X.C. Zeng et al., Self-scrolling $\mathrm{MoS}_{2}$ metallic wires. Nanoscale 10, 18178-18185 (2018). https://doi.org/10.1039/C8NR0 $4611 \mathrm{E}$

211. M. Hao, C. Xu, Z. Liu, C. Wang, Z. Liu et al., Transport through a network of two-dimensional NbC superconducting crystals connected via weak links. Phys. Rev. B 101, 115422 (2020). https://doi.org/10.1103/PhysRevB.101. 115422

212. Y. Cheng, X. Wu, Z. Zhang, Y. Sun, Y. Zhao et al., Thermomechanical correlation in two-dimensional materials. Nanoscale 13, 1425-1442 (2021). https://doi.org/10.1039/ D0NR06824A

213. G. Zhang, Y.-W. Zhang, Thermal properties of two-dimensional materials. Chin. Phys. B 26, 034401 (2017). https:// doi.org/10.1088/1674-1056/26/3/034401 
214. X. Lu, Q. Zhang, J. Liao, H. Chen, Y. Fan et al., High-efficiency thermoelectric power generation enabled by homogeneous incorporation of MXene in $\left(\mathrm{Bi}, \mathrm{Sb}_{2} 2 \mathrm{~T}_{\mathrm{e}} 3\right.$ Matrix. Adv. Energy Mater. 10, 1902986 (2020). https://doi.org/10. 1002/aenm.201902986

215. S. Hong, G. Zou, H. Kim, D. Huang, P. Wang et al., Photothermoelectric response of $\mathrm{Ti}_{3} \mathrm{C}_{2} \mathrm{~T}_{\mathrm{x}}$ MXene confined ion channels. ACS Nano 14, 9042-9049 (2020). https://doi.org/ 10.1021/acsnano.0c04099

216. J.H. Kim, G.S. Park, Y.-J. Kim, E. Choi, J. Kang et al., Large-area $\mathrm{Ti}_{3} \mathrm{C}_{2} \mathrm{~T}_{\mathrm{x}} \mathrm{MXene}$ coating: toward industrialscale fabrication and molecular separation. ACS Nano 15, 8860-8869 (2021). https://doi.org/10.1021/acsnano.1c014 48

217. J. Wang, Z. Zhang, J. Zhu, M. Tian, S. Zheng et al., Ion sieving by a two-dimensional $\mathrm{Ti}_{3} \mathrm{C}_{2} \mathrm{~T}_{\mathrm{x}}$ alginate lamellar membrane with stable interlayer spacing. Nat. Commun. 11, 3540 (2020). https://doi.org/10.1038/s41467-020-17373-4

218. D. Xu, X. Zhu, X. Luo, Y. Guo, Y. Liu et al., MXene nanosheet templated nanofiltration membranes toward ultrahigh water transport. Environ. Sci. Technol. 55, 12701278 (2021). https://doi.org/10.1021/acs.est.0c06835

219. K. Rajavel, X. Yu, P. Zhu, Y. Hu, R. Sun et al., Exfoliation and defect control of two-dimensional few-layer MXene
$\mathrm{Ti}_{3} \mathrm{C}_{2} \mathrm{~T}_{\mathrm{x}}$ for electromagnetic interference shielding coatings. ACS Appl. Mater. Interfaces 12, 49737-49747 (2020). https://doi.org/10.1021/acsami.0c12835

220. B. Aïssa, A. Sinopoli, A. Ali, Y. Zakaria, A. Zekri et al., Nanoelectromagnetic of a highly conductive 2D transition metal carbide (MXene)/Graphene nanoplatelets composite in the EHF M-band frequency. Carbon 173, 528-539 (2021). https://doi.org/10.1016/j.carbon.2020.11.024

221. S. Liu, J. Liu, X. Liu, J. Shang, L. Xu et al., Hydrogen storage in incompletely etched multilayer $\mathrm{Ti}_{2} \mathrm{CT}_{\mathrm{x}}$ at room temperature. Nat. Nanotechnol. 16, 331-336 (2021). https:// doi.org/10.1038/s41565-020-00818-8

222. T.H. Phuong Doan, W.G. Hong, J.-S. Noh, Palladium nanoparticle-decorated multi-layer $\mathrm{Ti}_{3} \mathrm{C}_{2} \mathrm{~T}_{\mathrm{x}}$ dual-functioning as a highly sensitive hydrogen gas sensor and hydrogen storage. RSC Adv. 11, 7492-7501 (2021). https://doi.org/ 10.1039/D0RA10879K

223. W. Zhu, S. Panda, C. Lu, Z. Ma, D. Khan et al., Using a selfassembled two-dimensional MXene-based catalyst (2D-Ni@ $\mathrm{Ti}_{3} \mathrm{C}_{2}$ ) to enhance hydrogen storage properties of $\mathrm{MgH}_{2}$. ACS Appl. Mater. Interfaces 12, 50333-50343 (2020). https://doi. org/10.1021/acsami.0c12767 